\title{
CAMA
}

Centre for Applied Macroeconomic Analysis

\section{The Shale Oil Boom and the US Economy: Spillovers and Time-Varying Effects}

\section{CAMA Working Paper 59/2019 August 2019}

Hilde C. Bjørnland

Centre for Applied Macroeconomics and Commodity Prices (CAMP), BI Norwegian Business School

Centre for Applied Macroeconomic Analysis, ANU

\section{Julia Zhulanova}

Centre for Applied Macroeconomics and Commodity Prices (CAMP), BI Norwegian Business School

\section{Abstract}

We analyze if the transmission of oil price shocks on the U.S. economy has changed with the shale oil boom. To do so, we put forward a framework that allows for spillovers between industries and learning by doing (LBD) over time. We identify these spillovers using a time-varying parameter factor-augmented vector autoregressive (VAR) model with both state level and country level data. In contrast to previous results, we find considerable changes in the way oil price shocks are transmitted to the U.S economy: there are now positive spillovers to non-oil investment, employment and production from an increase in the oil price - effects that were not present before the shale oil boom. 


\section{Keywords}

Shale oil boom, Oil Prices, Time-varying factor-augmented VAR model, Spillovers, Geographical Dispersion

\section{JEL Classification}

C11, C55, E32, E42, Q43

\section{Address for correspondence:}

(E) cama.admin@anu.edu.au

\section{ISSN 2206-0332}

The Centre for Applied Macroeconomic Analysis in the Crawford School of Public Policy has been established to build strong links between professional macroeconomists. It provides a forum for quality macroeconomic research and discussion of policy issues between academia, government and the private sector.

The Crawford School of Public Policy is the Australian National University's public policy school, serving and influencing Australia, Asia and the Pacific through advanced policy research, graduate and executive education, and policy impact. 


\title{
The Shale Oil Boom and the U.S. Economy: Spillovers and Time-Varying Effects*
}

\author{
Hilde C. Bjørnland ${ }^{\dagger} \quad$ Julia Zhulanova ${ }^{\ddagger}$
}

August 7, 2019

\begin{abstract}
We analyze if the transmission of oil price shocks on the U.S. economy has changed with the shale oil boom. To do so, we put forward a framework that allows for spillovers between industries and learning by doing (LBD) over time. We identify these spillovers using a time-varying parameter factor-augmented vector autoregressive (VAR) model with both state level and country level data. In contrast to previous results, we find considerable changes in the way oil price shocks are transmitted to the U.S economy: there are now positive spillovers to non-oil investment, employment and production from an increase in the oil price - effects that were not present before the shale oil boom.
\end{abstract}

JEL-codes: C11, C55, E32, E42, Q43

Keywords: Shale oil boom, Oil Prices, Time-varying factor-augmented VAR model, Spillovers, Geographical dispersion

*The authors would like to thank Fabio Canova, Francesco Ravazzolo, Leif Anders Thorsrud, Ragnar Torvik, Rob Vigfusson, Jing Cynhia Wu and participants at the 4th CAMA-CAMP workshop in Canberra, the 'Economics of Oil' conference in Rio de Janeiro, the 26th SNDE Symposium in Tokyo, the 2019 IJCB Annual Conference in Oslo and the 2019 North American Meeting in Econometrics in Seattle for valuable comments. This paper is part of the research activities at the Centre for Applied Macro and commodity Prices (CAMP) at the BI Norwegian Business School. The views expressed are those of the authors and do not necessarily reflect those of Norges Bank. The usual disclaimers apply.

${ }^{\dagger}$ Centre for Applied Macroeconomics and commodity Prices (CAMP), BI Norwegian Business School; Centre for Applied Macroeconomic Analysis (CAMA), ANU; and Norges Bank. Email: hilde.c.bjornland@bi.no

$\ddagger$ Centre for Applied Macroeconomics and commodity Prices (CAMP), BI Norwegian Business School. Email: julia.zhulanova@bi.no 


\section{Introduction}

In view of the volatile oil prices experienced over the past decades, understanding the impact of oil price fluctuations on economic activity has been important. When oil prices fell by more than $70 \%$ between 2014 and 2016, a natural question therefore quickly rose as to what extent this massive oil price decline would stimulate U.S. economic growth. After all, such a decline in oil prices should be good news to both consumers and producers in an oil importing country: the cost of producing domestic output should decrease, while demand for other goods and services should pick up as consumers have more money to spend, all else equal. ${ }^{1}$ Little evidence, however, has been found to back up such claims. In fact, according to an IMF Survey (March 2016), cheap oil doesn't seem to have given the expected boost to U.S. real economic activity.

Why didn't growth in the U.S. pick up following the decline in oil prices? One hypothesis is that the U.S. has dramatically reduced its dependence on petroleum imports as its own production of oil has surged. Throughout the 2000s, horizontal drilling and hydraulic fracturing led to a massive boost in the production of oil from shale rock deep underground. Thus, when oil prices declined in 2014, U.S. oil producers were instead hurt, affecting the overall economy negatively.

Yet, recent studies analyzing whether the shale boom has fundamentally changed the way oil price shocks are being transmitted to the U.S. economy, have not found evidence of such effects. In particular, Baumeister and Kilian (2016) analyze the effects of the recent oil price decrease on the U.S. economy using simple regressions, and conclude that while real investments in the oil sector did decline, private real consumption and non-oil related business investments were positively stimulated by the oil price decline, offsetting the negative drawback from the oil sector. Thus, according to Baumeister and Kilian (2016), nothing has really changed: the U.S. still responds to the oil price shocks as a typical net oil importer: when oil prices rise, U.S. activity falls, and vice versa when oil prices fall.

We challenge this claim on two grounds. First, we believe that the transition U.S. is experiencing, i.e., gradually changing from being a net oil importer to being the world's largest oil producer, ${ }^{2}$ does not happen by itself. Such a transition requires capital, technology, labor, skills, and, most importantly, learning by doing (LBD) over a prolonged period

\footnotetext{
${ }^{1}$ See for instance Hamilton (1983) for a seminal paper and e.g. Hamilton (2009), Kilian (2009), Kilian and Vigfusson (2011), Lippi and Nobili (2012), Peersman and Robays (2012), Cashin et al. (2014), Aastveit (2014), Aastveit et al. (2015) and Stock and Watson (2016) for some recent studies emphasising different sources of shocks and identification methods when analysing the effects of oil price changes.

${ }^{2}$ While the United States is still a net oil importer, it is expected that by 2020 the U.S. will export more petroleum and other liquids than it is importing, see EIA's Annual Energy Outlook (AEO) from 2018.
} 


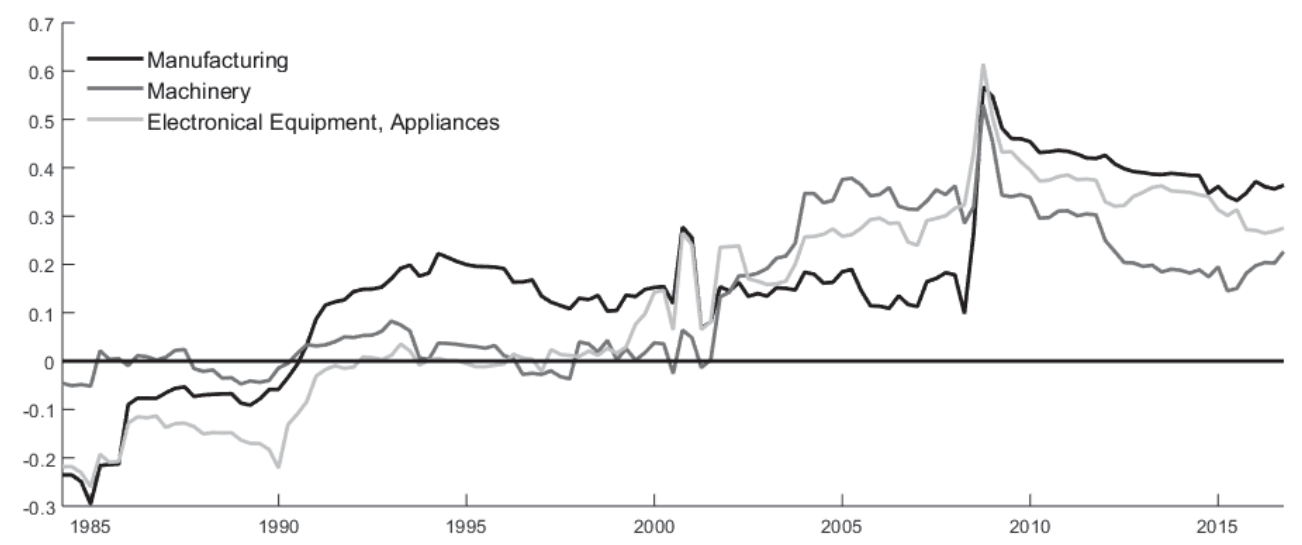

Figure 1. Rolling correlation between the real price of oil and manufacturing industries, sample period 1974:Q2-2016:Q4, Moving Window 40 quarters. The correlation coefficient from each rolling sample is plotted in the end of each sample. Hence, the last observation is the rolling sample from 2006Q4-2016Q4.

of time. In fact, the seed of the shale gas boom was planted already in the 1970s when the U.S. government decided to fund R\&D programs and provide tax credits to enterprises interested in developing unconventional natural gas. Still, it was not before the private entrepreneurship of Mitchell Energy, who experimented with new techniques for drilling shale in the early 2000s, i.e., combining horizontal drilling with hydraulic fracturing, that the process escalated and the natural gas boom spread to oil. ${ }^{3}$ Hence, when analyzing the effects of the recent oil price drop on the U.S. economy, allowing for changing dynamics related to the development of the shale oil boom seems imperative. And indeed, Figure 1 motivates such a a claim. It displays rolling correlation coefficients between the real price of oil and production in some key U.S. industries such as, manufacturing, electrical equipment and machinery. The figure clearly shows that the correlations have changed, from being negative in the 1970s and 1980s, to being positive after 2000. We hypothesize that these changes signal more than just correlations: they signal a structural change in how the U.S. economy is affected by oil price shocks following the shale oil boom.

Second, during such a transition process, there may be productivity spillovers between the oil-related and non-oil related industries. To the extent that these spillovers are important, it could imply wider benefits for the economy, cf. Bjørnland and Thorsrud (2016) and Bjørnland et al. (2019) for theoretical arguments and empirical applications to resource rich countries such as Australia and Norway. In particular, Bjørnland et al. (2019) have shown that by developing a dynamic three sector model that incorporates

\footnotetext{
3 Natural gas from shale could now be economically produced, which led to dramatic increase in natural gas production, and consequently lower prices of natural gas in the U.S. In 2009, when oil prices were relatively high, firms began to experiment with shale technology to extract oil. Several firms were successful in adopting shale technology in oil basins and production of shale oil increased significantly (see Wang and Krupnick (2013) for the review of history of shale gas development in the United States).
} 
the productivity dynamics from the spending as well as the resource movement effect, the growth effects of natural resources are likely to be positive and affect many industries outside oil. Hence, we may expect both direct and indirect spillovers of oil on the wider economy. Allowing for these spillovers seems therefore important when analyzing the effect of a resource boom on the U.S. economy. In fact, claims for local spillovers are already being backed up by a recent branch of literature using primarily cross-section or panel data, see, e.g., Weber (2012), Allcott and Keniston (2018), Feyrer et al. (2017), and Gilje et al. (2016) among others. Applied to regional data in resource abundant U.S. states, these studies consistently find that energy booms benefit local non-oil employment, wages and production.

Common to these recent (panel) data studies, however, is the fact that they focus on activity at the local level in resource abundant U.S. states. Hence, while accounting for instantaneous spillovers in certain geographical areas, little is known about the dynamic effects on the aggregate economy outside the resource rich areas. Our hypothesis is that the oil boom has had positive spillovers to many different industries across the U.S., and that these spillovers have changed over time, consistent with the pattern seen in Figure 1. For this purpose, we need a time-series framework that also allows for geographical dispersion. Previous times series studies addressing this issue have typically been aggregate and focus on only a few macroeconomic variables. Furthermore, most often they rely on time-invariant regressions. Thus, their maintaining assumption is that the effect of an oil price shock has not changed over time, and that the role of the oil sector is of little importance when analysing the dynamic effects of oil prices on the U.S. economy.

We address all of these shortcomings. In particular, we analyse the effects of oil price shocks on the U.S. economy taking into account spillovers from oil to various industries and employment across the U.S. states, while also allowing these dynamics to vary over time. In so doing, we investigate whether the effects of an oil price shock has changed during the last two decades. For this purpose we specify and estimate a time-varying parameter (TVP) factor-augmented VAR (FAVAR) model with stochastic volatility, see e.g. Korobilis (2013), Bernanke et al. (2005), Primiceri (2005) for seminal contributions.

Doing so, we find substantial changes in the way an oil price shock is transmitted to the U.S. economy. In contrast to previous studies, our analysis suggests that an increase in the oil price has now positive spillovers to the aggregate U.S. economy, effects that were not present before the shale oil boom. In particular, we find non-oil nonresidential business investments, as well as non-oil employment in both oil-producing and many manufacturing-intensive producing states to increase following an oil price rise. What's more, there are positive spillovers to real personal income, and, to some extent, to personal consumption. Hence, the U.S. responses to an oil price shock now more resemble those 
of an oil exporter rather than those of an oil importer. Assuming symmetric effects (c.f., Kilian and Vigfusson (2011)), our results imply that an oil price decline will have negative effects on the U.S. economy. This explains the puzzle that has preoccupied IMF recently: namely why did the U.S. not experience a boom following the steep decline in oil prices between 2014 and 2016? The answer is simply that the U.S. has increased its reliance of oil, not as a consumer, but by becoming the world's largest oil producer. Going forward, policymakers needs to take into account that the transmission of an oil price shock has changed with the shale oil boom. An oil price increase may now actually be good news for many industries and states in the U.S. economy. This should have far reaching implications for both fiscal and monetary policy.

Our paper relates and combines several approaches already developed in the literature, but in a separate manner. First, although different in methodology and focus, our paper relates to a recent literature showing that shocks to certain sectors can have a large impact on aggregate macroeconomic fluctuations. In particular, using network theories, Acemoglu et al. (2012) show that sectors with a small factor share that are highly complementary to other inputs can have a large impact on aggregate macroeconomic fluctuations. Gabaix (2011) shows similar results when the firm size distribution is sufficiently heavy-tailed and the largest firms contribute disproportionally to output.

Second, we relate to a large literature that analyses the effect of oil price shocks on the U.S. economy, see e.g. Hamilton (2009), Kilian (2009), Edelstein and Kilian (2009), Lippi and Nobili (2012) and Aastveit (2014) among many others. However, in contrast to these papers which analyze the effect of oil price shocks on the U.S. economy using linear models, we allow for changing dynamics. Furthermore, while these studies typically focus on aggregate macroeconomic variables, we explicitly include the oil sector and disaggregate state level data into the analysis to account for the potential new spillovers due to the shale oil boom. For this purpose, we use a FAVAR model with a large data set and time varying parameters.

Third, our TVP framework builds on a growing literature allowing for stochastic volatility when analysing the effect of oil price shocks (i) on the U.S. macroeconomy (e.g. Baumeister and Peersman (2013b) and Bjørnland et al. (2018)), (ii) on the inflation passthrough (e.g. Clark and Terry (2010)), (iii) on the U.S. stock market (e.g. Kanga et al. (2015) and Foronia et al. (2017)) and (iv) on the oil market (e.g. Baumeister and Peersman (2013a)). While we also control for stochastic volatility, our main focus is to examine if the dynamic effects have changed over time following the shale oil boom.

Fourth, we relate to a branch of the literature that has documented important heterogeneous effects in the transmission channels of oil price shocks to disaggregate industries, see e.g. Bresnahan and Ramey (1993), Davis and Haltiwanger (2001), Lee and Ni (2002) 
and Herrera (2018). However, while these papers have primarily studied how the negative effects of an oil price shock are transmitted to industries when the U.S was an oil importer, our focus is to unravel potential heterogeneous effects due to the shale oil boom, at both the industry level and across U.S. states. For this reason, the oil sector is explicitly included into the model, as well as employment at the state level.

Finally, and as discussed above, we relate to the recent literature using panel data studies that have consistently found that energy booms benefit non-oil employment at the local level in many resource abundant U.S. states, c.f. Weber (2012), Allcott and Keniston (2018), Feyrer et al. (2017), and Gilje et al. (2016) among others. In contrast to these papers, however, we focus on the geographical dispersion of the oil price shocks across all U.S. states, allowing also for time varying changes.

The TVP-FAVAR model is particularly useful when it comes to answering our research questions. First, it allows us to distinguish between different types of shocks affecting the oil market. Second, we are able to simultaneously estimate direct and indirect spillovers between the different sectors of the economy. Third, we can estimate responses to a large number of variables that is not possible with standard multivariate time series techniques due to the curse of dimensionality. Lastly, we are able to take into account the time variation and investigate how the effects of shocks have changed over time. To the best of our knowledge, this is the first paper that models the interaction between the oil market and the U.S. economy in a large data environment, allowing also for time-varying changes during the fracking revolution.

The remainder of the paper is structured as follows. Section 2 describes a framework for analysing spillovers of oil and learning by doing in an resource rich economy while Section 3 describes the TVP-FAVAR model and the dataset. Empirical results are discussed in Section 4, focusing on, among others, the effects of an oil price shock on various industries, the general macroeconomy and geographical dispersion of shocks to state level employment. In Section 5 we analyse extensive robustness while Section 6 concludes.

\section{Theoretical framework: Oil booms - a blessing or a curse?}

The history of the petroleum industry in the United States goes back to the early 19th century. Petroleum became a major industry following the discovery of oil at Oil Creek, Pennsylvania in 1859, and for much of the 19th and 20th centuries, the U.S. was the largest oil producing country in the world. However, after production peaked in 1970, the U.S. has experienced decades of production decline. Over time, the country has become increasingly dependent on imports of oil, and in 1973, the U.S. government banned firms 


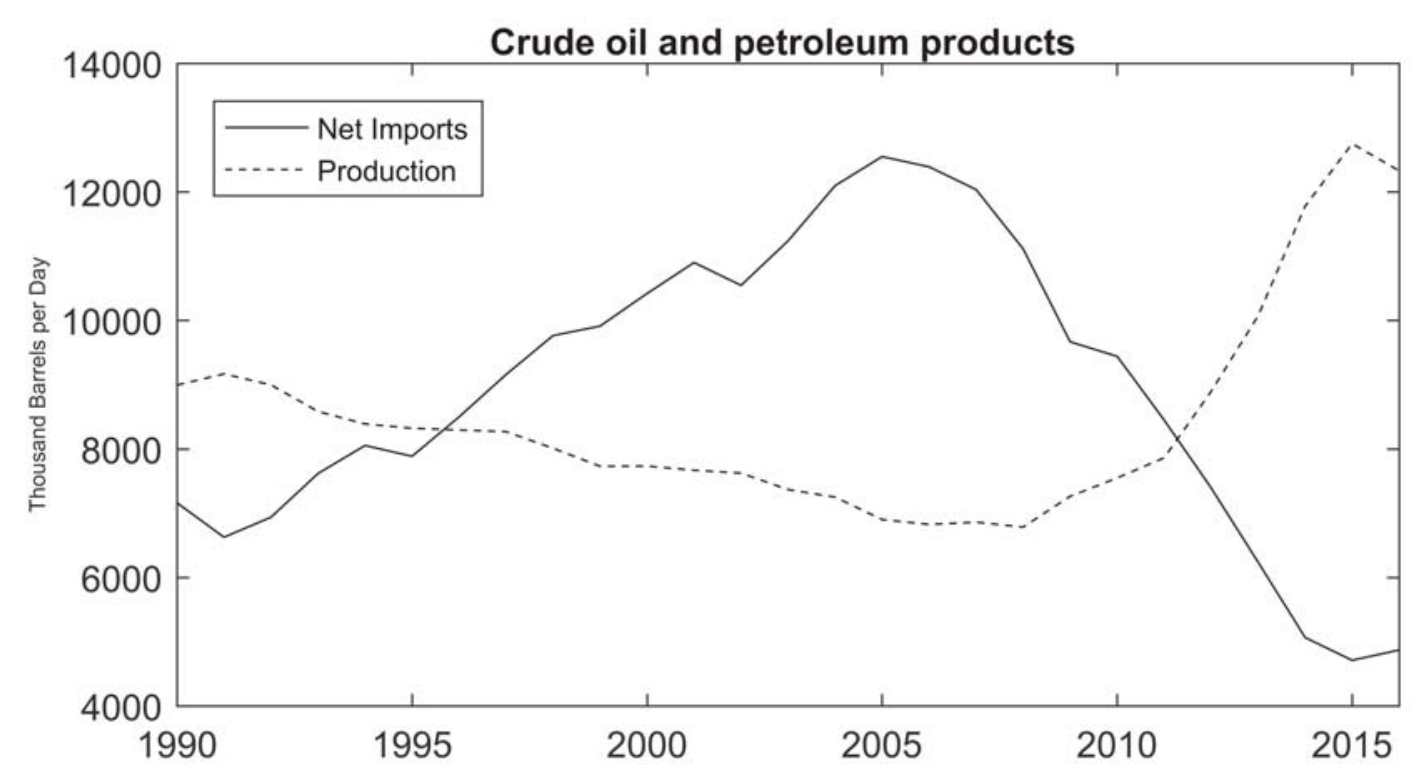

Figure 2. US: Net import of petroleum and crude oil vs. crude oil production

from exporting oil.

The empirical oil-macroeconomic literature, which took off after the seminal contribution of Hamilton (1983), has typically analyzed the effect of oil price shocks on the U.S. economy focusing on the period when the U.S. was a net oil importer. In line with this, scholars have also found that the U.S. economy responds negatively to an oil price shock that increases oil prices, as both consumers and producers have to pay more for the imported energy products and for the complementary products to energy; again, see, for instance, Hamilton (2009) and Kilian (2009) among many others.

The shale oil boom may have changed this relationship. By 2015 the U.S. oil production had surpassed Russia and Saudi Arabia to become the worlds biggest producer of oil and gas. By the end of that year, the export ban was lifted, and the U.S. is on its way to become a net oil exporter. Figure 2 illustrates the transition. It shows how net import of crude oil has plummeted from 2005/06 as the shale oil boom sparked a strong recovery in the production of crude oil.

In line with this increased production, the oil-producing industry has also grown, with potential spillovers to other industries. The spillovers can, of course, be of any form, crowding in or crowding out other industries. In particular, traditional theories suggest that energy booms often lead to a 'crowding out' of other tradable industries, such as manufacturing. The idea is that gains from the boom largely accrue to the profitable sectors servicing the resource industry, while the rest of the country, including traditional manufacturing, suffers adverse effects from increased wage costs, an appreciated exchange rate, and a lack of competitiveness as a result of the boom. In the literature, such a phenomenon is commonly referred to as Dutch disease, based on similar experiences in 
the Netherlands in the 1960s, see e.g. Corden and Neary (1982) and Corden (1984) for influential early contributions.

Traditional theories of Dutch disease, however, do not account for productivity spillovers and learning by doing (LBD) between the booming resource sector and other non-resource sectors. Instead, they emphasise that labour would be transferred from strong (tradeable) to weak (non-tradeable) LBD sectors, and therefore reduce overall growth, see e.g. van Wijnbergen (1984), Krugman (1987), Sachs and Warner (1995), Gylfason et al. (1999) and Torvik (2001) among others. However, more recently, some studies have shown that oil endowment may not necessary be a curse, but can instead be an engine for growth. For instance, Bjørnland et al. (2019) have shown that by developing a dynamic three sector model (non-traded, traded, and oil service sector) that incorporates the productivity dynamics from the spending as well as the resource movement effect of oil, the conclusions proffered by earlier models of LBD and the Dutch disease are altered dramatically. In particular, the resource movement effect implies that the growth effects of natural resources are likely to be positive, reversing previous growth results in the literature. The wider benefits for the economy are particularly evident when taking account of productivity 'spillovers' and 'learning-by-doing' from the oil-related (service) industry to other traded and non-traded industries, as has also been shown empirically for the resource rich countries Australia and Norway, see Bjørnland and Thorsrud (2016) and Bjørnland et al. (2019). In particular, learning-by-doing may strengthen the spillovers between the sectors, thus enforcing growth in the overall economy.

That the shale oil boom has had implications for economic growth at the local level in the oil producing U.S. states, was pointed out in the introduction above. In particular, Allcott and Keniston (2018) examine county-level data to investigate the local spillover effects of boom-bust cycles in natural resource production, Weber (2012) examines county level direct effect of drilling, Maniloff and Mastromonaco (2015) study the effect of the number of wells on local economies, Fetzer (2014) estimates the effect of any drilling activity after 2007 on economic outcomes at the local level, while Feyrer et al. (2017) measure the effect of new oil and gas production on income and employment at the county and regional level. Despite different methods, measures of oil and gas activity, areas of study, and time frames, these studies consistently find that energy booms benefit local or regional employment in the resource rich states in the U.S. ${ }^{4}$

However, little, if anything, is known about the spillovers of the shale boom to employment outside the oil rich states, and ultimately, to the aggregate U.S. economy. In

${ }^{4}$ In addition, Gilje et al. (2016) analyze in a recent study the effect of shale oil development on asset prices. Using the shale oil discovery announcement as their measure of technology innovation the authors find that in the period from 2012 to 2014 these technology shocks explain a significant component of cross-sectional and time series variation in both asset prices and employment growth. 
particular, to what extent will a resource boom stimulate investment, production, employment, and wages beyond those at the local level in the energy rich states? If there is LBD between industries, one should expect some positive spillovers for the wider economy. However, are these positive spillovers sufficiently strong so as to offset any negative effects for consumption and investment when oil prices increase? According to Baumeister and Kilian (2016), the answer to this question is no. They find no spillovers from oil-related investment to non-oil related investment. In fact, they argue that the recent U.S. economy's response to oil price changes has not been fundamentally different from that observed after the oil price decline in 1986.

Based on this, we re-address the question of whether the shale boom has changed the transmission of oil price shocks, focusing in particular on the potential spillovers from the oil industry to other industries, and the extent to which these spillovers have changed the transmission of oil price shocks to the U.S. economy over time. To do so, we specify a model that can account for (i) heterogeneous responses in employment to the oil price shocks across U.S. states; (ii) spillovers between industries; and (iii) time-varying responses. We now turn to describe the econometric model in detail.

\section{Empirical Modeling Framework}

Many recent papers, including those cited above, have used SVAR models to study the effects of oil price shocks on the aggregate U.S. economy. As we want to consider the role of the oil industry for the dispersion of oil price shocks to economic activity, we augment the standard VAR model with estimated factors that reflect information from both oil and non-oil variables. To that end, we specify a factor-augmented vector autoregressive (FAVAR) model that includes four factors. The factors will be driven by shocks that have the potential to affect all sectors of the U.S. economy. First, we include a measure of global activity and the real price of oil as two separate factors in the model. These are included to capture, respectively, international business cycle conditions and developments in the oil market that are relevant for the U.S. economy. This allows us in turn to identify two foreign shocks: a global activity shock and an oil price shock, both of which can affect the real oil price, though with potentially very different macroeconomic implications.

Second, to take into account the fact that there may be heterogeneous responses to the oil price across U.S. industries, we estimate two separate latent factors for the U.S. economy. The inclusion of latent factors also enables us to simultaneously estimate direct and indirect spillovers between different industries and states in the U.S. The simultaneous spillovers between different sectors at different geographical levels can not be captured by including only observable variables in a small panel of data and have therefore not 
been taken into account in previous studies. ${ }^{5}$ While we do not impose any identifying restrictions on these factors, we find that the factors capture different aspects of the U.S. economy related to oil and non-oil, see Section 3.4.

Finally, the factors are used in a time-varying parameter (TVP) Vector Autoregressive model with both time-varying coefficients and time-varying variance covariance matrix of innovations. By allowing coefficients in the VAR augmented with factors to vary over time we account for possible non-linearities or time variations between the oil price and the U.S. economy. To account for possible heteroscedasticity of the structural shocks and nonlinearities in the simultaneous relations among the variables we allow for multivariate stochastic volatility. ${ }^{6}$ All together, this framework allows us to investigate if the transmissions of oil price shocks have changed over time.

On a final note, we have chosen to use a TVP approach to capture smooth changes in the transmission of shocks. This is important, as we believe the transmission from a net oil importer to a major oil producer takes time and is therefore well approximated with the TVP approach, rather than a framework that allows for discrete breaks.

\subsection{Data}

We use a large panel of domestic and international quarterly series, covering the sample period from 1990Q1 to 2016Q4. ${ }^{7}$ In particular, to accommodate the effects of oil price shocks on the U.S. economy, we include a broad range of domestic macroeconomic indicators as observable variables (reported in Appendix A - Table 2). Among others, we include consumer and producer prices, investment series, stock prices, personal income, various IP series, consumption, and the short term interest rates. To account for local effects we also include employment series in 50 states of the U.S, and distinguish between oil-related and non-oil employment series. These disaggregate employment series are only available since 1990, hence the choice of starting date for the sample.

We include two observable 'foreign' factors; global activity and the real oil price. For the global activity factor, we use an estimate of industrial production for the OECD plus other major countries (Brazil, China, India, Indonesia, Russia, and South Africa) published by OECD Main Economic Indicators, and extended from November 2011 by Baumeister and Hamilton (2019), see also Hamilton (2018) for justification. However, we also analyze extensive robustness to our choice of variable in Section 5 by, among others,

\footnotetext{
${ }_{5}$ As was shown by Aastveit (2014), the response of macroeconomic variables to different oil price shocks can be considerably different when one jointly models the interaction among endogenous variables.

${ }^{6}$ As was documented by Baumeister and Peersman (2013a) and Baumeister and Peersman (2013b), there have been changes in elasticities in the oil market in recent decades.

${ }^{7}$ The first 10 years of the sample are used as a training period to estimate priors, see Appendix B for details.
} 
using a factor that captures global demand proposed by Chiaie et al. (2017) instead of the index suggested by Baumeister and Hamilton (2019). For the real oil price, we follow Lee and Ni (2002) and Herrera (2018), among many others, and use the U.S. Refineries Acquisition Cost deflated by CPI.

In sum, this gives us a panel of 107 domestic and international quarterly series. All the series were initially transformed to induce stationarity and demeaned, while the series used to extract factors were also standardized.

\subsection{The time-varying FAVAR Model}

Our framework builds on the FAVAR model, first proposed by Stock and Watson (2005) and Bernanke et al. (2005). Technically, the developed and employed model is most closely related to the set-up used in Korobilis (2013). In particular, we use a two-step estimator and replace the factors by the first principal components obtained from the singular value decomposition of the data matrix, and consequently treat them as observables. These factors are then used in a time-varying VAR model with both time-varying coefficients and time-varying variance covariance matrix of innovations, see Primiceri (2005).

Still, we deviate from Korobilis (2013) in several important ways. First, while Korobilis (2013) uses a framework based on Bernanke et al. (2005) and Belviso and Milani (2006) to identify the factors, we follow Boivin and Giannoni (2007) since it is well suited to use with quarterly data. ${ }^{8}$ Second, to keep our model as parsimonious as possible, we do not allow for stochastic volatility in the factor analysis regression. Finally, we stick to the standard convention in the literature and model the random walk evolution of the VAR parameters as in Primiceri (2005).

Now, let $F_{t}$ be a $m \times 1$ vector of common factors assumed to drive the dynamics of the economy. In our application, $F_{t}$ contains both observable factors $y_{t}$ of dimension $l \times 1$ and unobservable latent factors, $f_{t}$ of dimension $k \times 1$, such that $F_{t}=\left(\begin{array}{c}y_{t} \\ f_{t}\end{array}\right)$ and $l+k=m$. The latent factors are extracted from a larger dataset $X_{t}$ of dimension $n \times 1$, and assumed to summarize additional information not captured by the observable factors. We assume that $X_{t}$ can be described by an approximate dynamic factor model given by

$$
X_{t}=\Lambda F_{t}+e_{t}
$$

where $\Lambda$ is $n \times m$ matrix of factor loadings and $e_{t} \sim \mathcal{N}(0, R)$, is $n \times 1$ vector of errors assumed to be uncorrelated with the factors $F_{t}$ and mutually uncorrelated. The joint

\footnotetext{
${ }^{8}$ While Bernanke et al. (2005) and Belviso and Milani (2006) perform a transformation of the principal components exploiting the different behavior of "slow moving" and "fast moving" variables, the same identification scheme would be not be suitable for quarterly data series as most of these series would respond as "fast moving" to oil price shocks within a quarter.
} 
dynamics of the factors $F_{t}$ are given by the following transition equation:

$$
F_{t}=c_{t}+b_{1 t} F_{t-1}+\ldots+b_{p t} F_{t-p}+u_{t},
$$

where $c_{t}$ is an $m \times 1$ vector of time-varying intercepts; $b_{j t}$ are $m \times m$ matrices for $j=1, . ., p$ of time-varying coefficients; $u_{t}$ is an unconditionally heteroskedastic disturbance term that is normally distributed with zero mean and time-varying covariance matrix $\Omega_{t}$. According to the literature on efficiently parametrizing large covariance matrices, Primiceri (2005), we decompose $\Omega_{t}$ in the following way:

$$
\Omega_{t}=A_{t}^{-1} \Sigma_{t} \Sigma_{t}^{\prime}\left(A_{t}^{-1}\right)
$$

where $\Sigma_{t}$ is a diagonal matrix that contains the stochastic volatilities and $A_{t}$ is a unit lower triangular matrix with ones on the main diagonal that models the contemporaneous interactions among the variables in (2):

$$
A_{t}=\left[\begin{array}{cccc}
1 & 0 & \cdots & 0 \\
a_{21, t} & 1 & \ddots & \vdots \\
\vdots & \ddots & \ddots & 0 \\
a_{m 1, t} & \cdots & a_{m(m-1), t} & 1
\end{array}\right], \Sigma_{t}=\left[\begin{array}{cccc}
\sigma_{1, t} & 0 & \cdots & 0 \\
0 & \sigma_{2, t} & \ddots & 0 \\
\vdots & \ddots & \ddots & 0 \\
0 & \cdots & 0 & \sigma_{m, t}
\end{array}\right]
$$

It follows that

$$
F_{t}=b_{1 t} F_{t-1}+\ldots+b_{p t} F_{t-p}+A_{t}^{-1} \Sigma_{t} \varepsilon_{t} .
$$

We follow the standard convention and assume that model's time-varying parameters and stochastic volatilities follow random walk processes. Let $B_{t}=\left(\operatorname{vec}\left(c_{t}\right)^{\prime}, \operatorname{vec}\left(b_{1 t}\right)^{\prime}, \ldots, v e c\left(b_{p t}\right)^{\prime}\right)^{\prime}$ be the vector of all R.H.S. coefficients in (5), $\alpha_{t}=\left(a_{j 1, t}^{\prime}, \ldots, a_{j(j-1), t}^{\prime}\right)^{\prime}$ for $j=1, \ldots, m$ be the vector of nonzero and nonone elements of the matrix $A_{t}$, and $\sigma_{t}=\left(\sigma_{1, t}^{\prime}, \ldots, \sigma_{m, t}^{\prime}\right)^{\prime}$ be the vector containing the diagonal elements of $\Sigma_{t}$. The dynamics of the three processes are specified as follows:

$$
\begin{aligned}
B_{t} & =B_{t-1}+\eta_{t}^{B} \\
\alpha_{t} & =\alpha_{t-1}+\eta_{t}^{\alpha} \\
\log \sigma_{t} & =\log \sigma_{t-1}+\eta_{t}^{\sigma}
\end{aligned}
$$

We assume that innovations in the model are jointly normally distributed with the following assumptions on the variance covariance matrices:

$$
\operatorname{Var}\left(\left[\begin{array}{c}
e_{t} \\
\varepsilon_{t} \\
\eta_{t}^{B} \\
\eta_{t}^{\alpha} \\
\eta_{t}^{\sigma}
\end{array}\right]\right)=\left[\begin{array}{ccccc}
R & 0 & 0 & 0 & 0 \\
0 & I_{m} & 0 & 0 & 0 \\
0 & 0 & Q & 0 & 0 \\
0 & 0 & 0 & S & 0 \\
0 & 0 & 0 & 0 & W
\end{array}\right]
$$


where $I_{m}$ is an $m$-dimensional identity matrix.

Following Primiceri (2005), we postulate a block-diagonal structure for $S$, with blocks corresponding to parameters belonging to separate equations. Thus, the shocks to the coefficients of the contemporaneous relations among variables in (5) are assumed to be correlated within equations, but uncorrelated across equations.

\subsection{Identification}

As motivated above, we estimate a model with four factors, $m=4$, and with associated shocks that have the potential to affect all sectors of the U.S. economy. The first two 'foreign' factors represent global activity and the real price of oil, and are treated as observables. The two latent factors capture different parts og the domestic activity in the U.S. and are inferred from data.

Starting with the two observable factors, we identify two structural shocks: a global activity (demand) shock and an oil price shock. Specifically, we identify a global activity shock and an oil price shock in a recursive manner, ordering oil prices after global activity in the VAR. Thus we follow the usual assumption from the models of oil markets, and restrict global activity to respond to oil price shocks with a lag (one quarter), see e.g., Hamilton (2009). In turn, any unexpected news regarding global activity is assumed to affect oil price contemporaneously, see e.g., Kilian (2009) and Aastveit et al. (2015). ${ }^{9}$

Turning to the domestic economy, we assume domestic structural shocks can have no contemporaneous effects on foreign variables (i.e., within the quarter), including the oil price. Hence, the oil price is predetermined with respect to the domestic U.S. variables, in line with findings of Kilian and Vega (2011). Still, one could argue that as the U.S. has gained in importance as an oil producer, news about the U.S. oil activity may have an immediate impact on oil prices. However, we believe our assumption is reasonable, as during most of the period we are analysing, the U.S. oil producers have not been able to export their crude oil. Still, as the U.S. is a part of the global activity measure (being a large open economy), a shock that originates in the U.S. can still affect the real price of oil contemporaneously via the global activity measure.

Finally, note that all observable variables in the vector $X_{t}$ may respond to all shocks on impact inasmuch as they are contemporaneously related to the factors through the loading matrix, $\Lambda$.

\footnotetext{
${ }^{9} \overline{\text { In contrast to these papers, and to keep }}$ our empirical model as parsimonious as possible, we do not explicitly identify a global oil supply shock, but assume the oil price shock captures all supply side developments. We believe this is reasonable. As shown in Kilian (2009) and a range of subsequent papers, supply shocks explain a trivial fraction of the total variance in the price of oil, and do not account for a large fraction of the variation in real activity either (at least in the sample used here).
} 


\subsection{Estimation and interpretations of the factors}

Our model is estimated using a computationally simple two-step estimation method, see Korobilis (2013) and Stock and Watson (2005). In the first step, we estimate the space spanned by the factors using the approach advocated by Boivin and Giannoni (2007), to ensure that the estimated latent factors, $f_{t}$, will recover dimensions of the common dynamics not already captured by the observable variables, $y_{t}$. Once we have estimated the factors, we treat them as observables, before moving to the second step in which we estimate the time-varying parameters in (5).

In the estimation, we use 4 lags $(p=4)$ for the VAR. ${ }^{10} \mathrm{~A}$ more detailed description of the estimation strategy and prior specification is provided in Appendix B. In Appendix C we provide justification of convergence of the Markov Chain Monte Carlo Algorithm. The system is estimated using two observable and two latent factors in the vector $F_{t}(l=2$, $k=2$ ). These four factors explain roughly 60 percent of the variation in $X_{t}$. Adding one additional factor increases the variance explained by a modest 5 percent. Even using 8 factors, the variance has only increased to 70 percent.

Before going into the details of the empirical results, we interpret the factors somewhat. As discussed above, the four factors are included to capture different aspects of relevance to the U.S. economy. While the two observable factors are easily interpretable insofar as they capture global activity and the oil price, the two latent factors are unobservable, estimated using the whole dataset for the U.S. Tables 3 and 4 in Appendix A shed some light on the latent factors by displaying correlations between each factor and some of the series. We focus here on the series that display a correlation coefficient above 0.5 with either of the factors. We note from Table 3 that the first factor turns out to be a good proxy for real non-oil activity in the U.S, as it captures most of the movements in non-farm employment in non-oil states and some key macroeconomic aggregates. Still, the factor has also a small positive correlation with some oil related series. Turning to the second factor, this can be interpreted as an oil activity factor as it follows very closely the movements in oil-related employment and oil investments, and has a small negative correlation with employment in non-oil states, see Table 4. Finally, as we can see from Figure 11 in Appendix A, the factors seem to fit data quite well, even though all the series in our dataset load on these factors.

\footnotetext{
${ }^{10}$ Hamilton and Herrera (2004) show that a too restrictive lag length can produce misleading results regarding the effects of oil market shocks on the macro economy, while increasing the lag length to over one year has negligible effects.
} 


\section{Empirical Results}

The aim of this paper is to analyze if the transmission of oil price shocks on the U.S. economy has changed as a result of the shale oil boom. To that end, we focus on the effects of an oil price shock that is normalized to increase oil prices, using impulse responses and variance decompositions. As we will allow for time-varying changes, we report two types of impulse responses. We report median impulse responses at different dates: 2001:Q1, 2004:Q1, 2007:Q1, 2011:Q1, 2013:Q1, 2014:Q1, and 2015:Q1. These dates are chosen arbitrarily and are not crucial for our conclusion. In addition, we also report the impulse responses after 4 quarters over all periods. In so doing we emphasize the maximum effect of an oil price shock, which typically occurs after about three to four quarters according to Hamilton (2008), Herrera and Pesavento (2009), Clark and Terry (2010), Peersman and Robays (2012) and Herrera (2018), at various points in time. However, our conclusions are robust for alternative horizons. Note that all estimated responses have been accumulated and are shown in levels. To ensure that we compare an equal sized shock over time, we normalize the dynamic effects of exogenous oil price shock to a 1 percent increase in the oil price on impact (for all the calculated responses). ${ }^{11}$

\subsection{Oil prices and resource booms}

We start by examining the impact of the oil price shock on investment and production in the oil-producing sector, see Figure 3. The figure reports impulse responses of oil investment and mining to an oil price shock. In the left column, we focus on median responses at different time intervals (c.f. the explanation above), while the right column displays responses after four quarters. To the extent that higher oil prices also generate a resource boom ${ }^{12}$ in the U.S. economy, we should expect to see investment and production in the oil sector increase. And we do, cf. Figure 3. Both oil investment and mining activity are increasing gradually. These effects are in line with our expectations: a higher oil price makes it more profitable for firms operating in the oil sector to produce, and stimulates their investments and activity. We also note that the (maximum) effect has drifted slightly up over time. That is, for an equally sized increase in oil prices, oil investment and mining activity increase slightly more now than before. Interestingly, these results are consistent with Bjørnland et al. (2017) and Bornstein et al. (2018), that find, using micro data, that shale (unconventional) oil producers are more price responsive than conventional oil

\footnotetext{
${ }^{11} \mathrm{~A}$ common way to report impulse responses is to examine one standard deviation shock. However, in the models where volatility changes over time, one standard deviation shock corresponds to a different-sized shock at each point in time. Therefore, we normalize the impact effects of the shock over time.

${ }^{12} \mathrm{~A}$ resource boom takes the form of either a new oil discovery, a more productive oil field or higher real oil prices, see Corden (1984).
} 


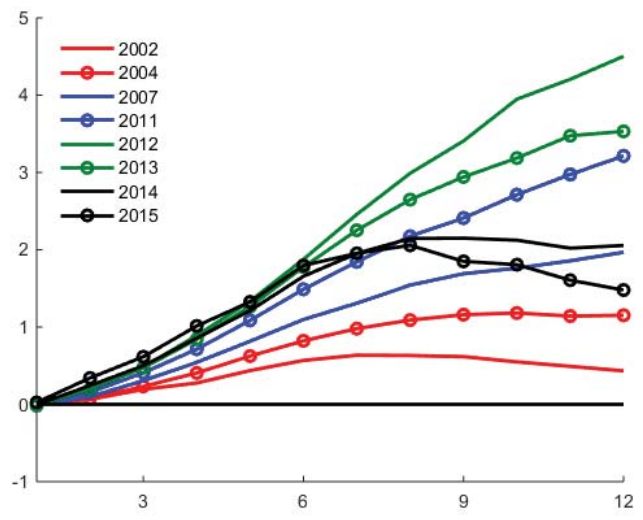

(a) Oil Investment (median)

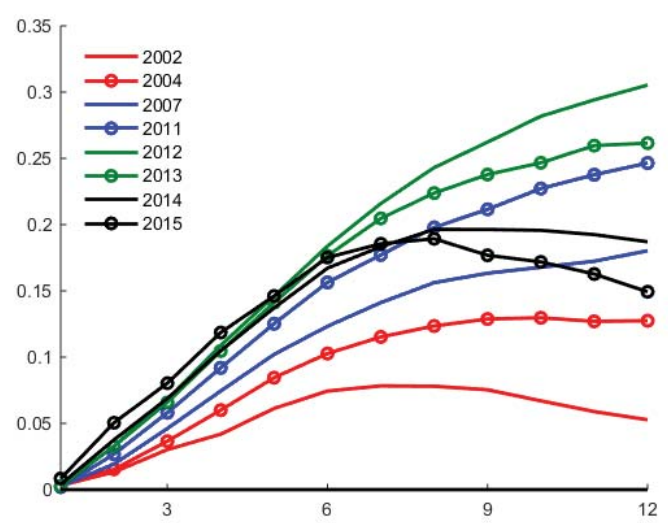

(c) Mining (median)

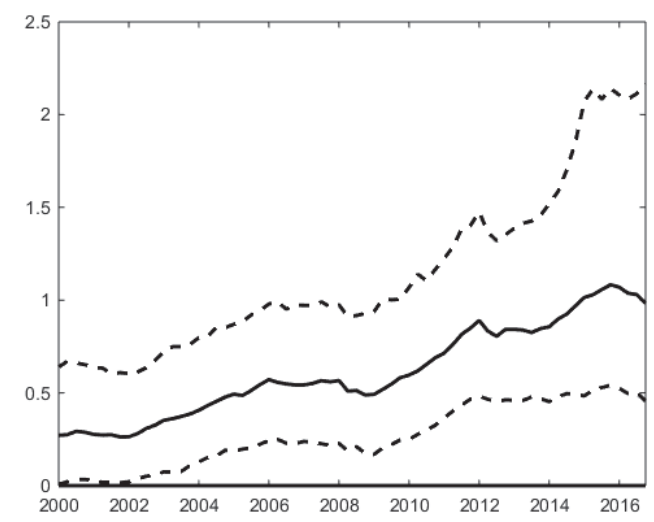

(b) Oil investment (4 quarters)

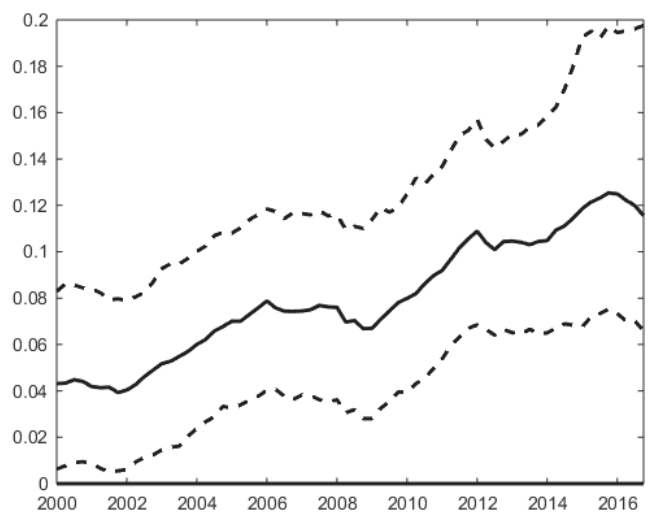

(d) Mining (4 quarters)

Figure 3. The effect of an oil price shock: Impulse responses for the resource sector: oil-investment and mining. Left column: Posterior median of impulse responses. Right column: Impulse responses after 4 quarters with 16-th and 84-th percentiles

producers.

Hence, we conclude that higher oil prices generate an oil boom in the U.S. economy, and even more so now than prior to the shale oil boom. This emphasizes that activity in the oil industry is procyclical with the changes in oil price. The question is, to what extent does the increased activity in the oil sector following the higher oil prices generate spillovers to other industries and states? We turn to examine this now.

\subsection{Aggregate macro effects}

Having established that an oil price shock leads to a resource boom, we next examine the impact on the aggregate macroeconomy. In particular, Figure 4 presents the responses of an oil price shock after four quarters to some key nominal macro variables: CPI, interest rates, dollar exchange rates, and SP500, while in Figure 5 we examine the responses in 


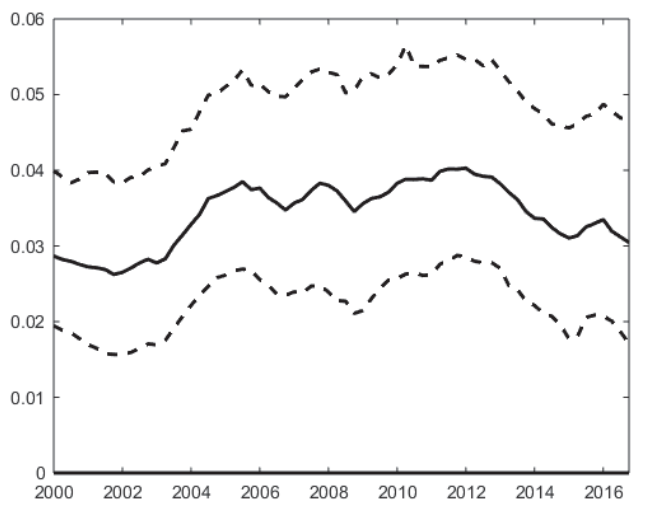

(a) CPI

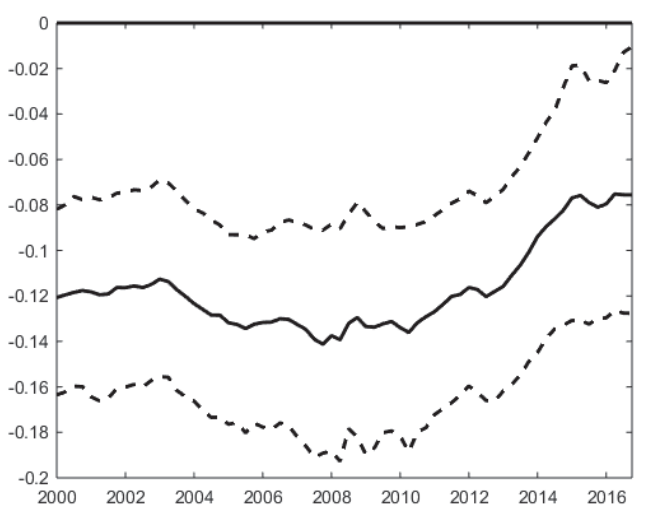

(c) Exchange rate

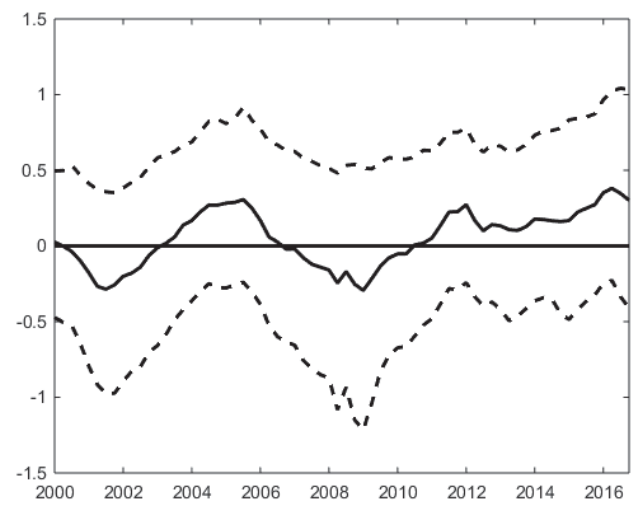

(b) Interest rate

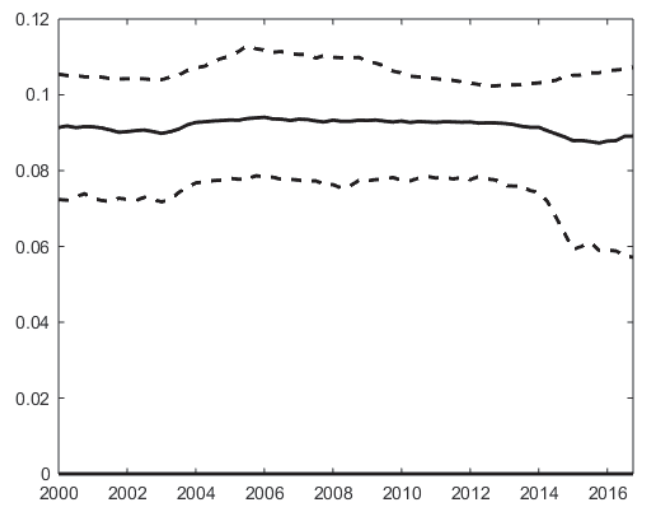

(d) Stock prices (S\&P 500)

Figure 4. The effect of an oil price shock: Impulse responses for selected nominal variables in the U.S. economy with 16-th and 84-th percentiles. All responses are reported after 4 quarters, except the response in the stock price that is displayed after 1 quarter

some key real variables; investment, income, and consumption. After this we turn to examine various disaggregate industry effects in Section 4.3.

We first note from Figure 4 that an oil price increase is strongly associated with an increase in consumer prices (CPI). This effect is significant during the whole sample and is in line with our expectations and previous findings in the literature (c.f., Hamilton and Herrera (2004)): higher oil prices lead to higher cost for firms, hence prices rise. We also note that the effect on consumer prices shows little time variation. Second, the central bank does not seem to respond strongly to changes in oil prices, as the response of the interest rate is insignificant during the whole sample. This could explain some of the passthrough of oil price shocks into consumer prices. Third, the exchange rate depreciates following an oil price shock. This is consistent with many previous studies where it is noted that, since 2000, there has been a negative relationship between the oil price and U.S. dollar, see e.g. Fratzscher et al. (2014). Still, we find that the negative relationship 


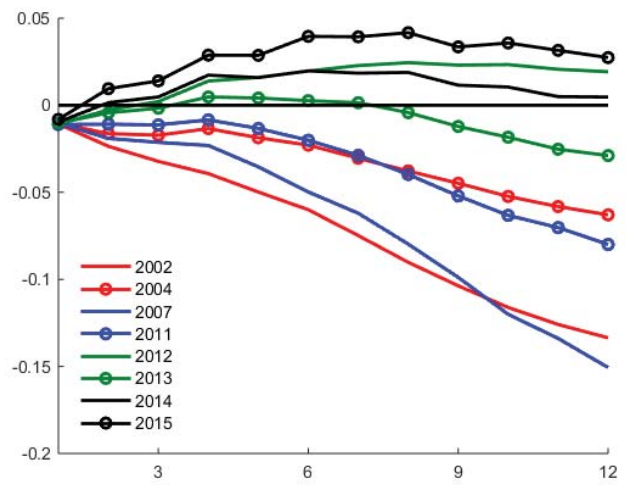

(a) Investment (median)

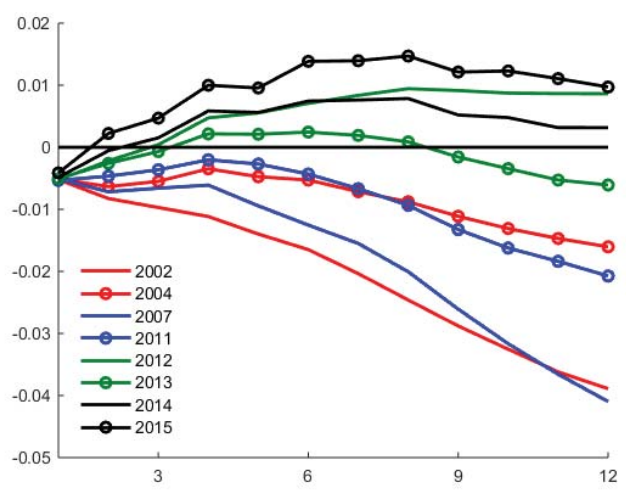

(c) Income (median)

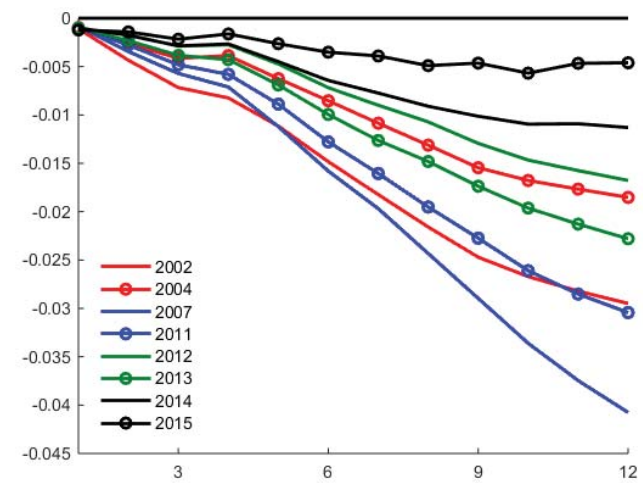

(e) Consumption (median)

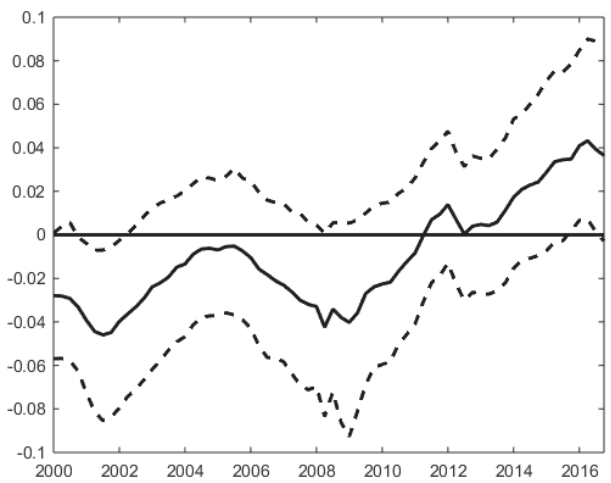

(b) Investment (4 quarters)

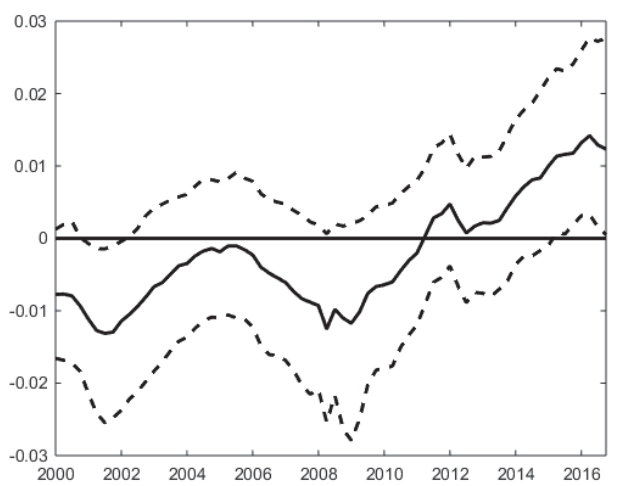

(d) Income (4 quarters)

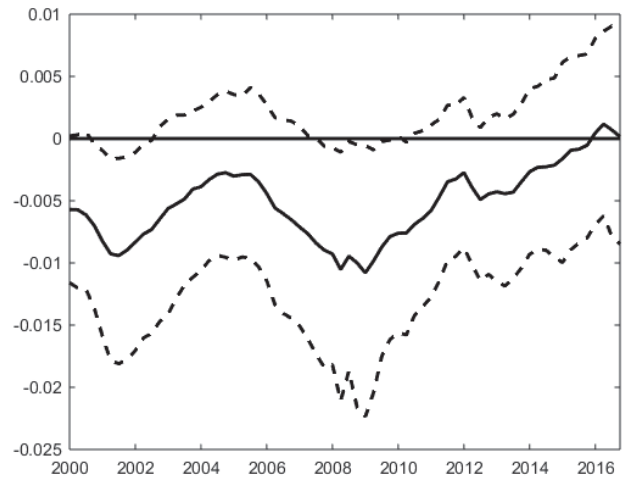

(f) Consumption (4 quarters)

Figure 5. The effect of an oil price shock: Impulse responses for selected real variables of the U.S. economy. Left column: posterior median of impulse responses. Right column: impulse responses after 4 quarters with 16 -th and 84 -th percentiles

has declined somewhat over time. Finally, we find that stock prices increase on impact ${ }^{13}$ following an oil price shock. This is very different from the findings in Kilian and Park (2000) using a sample ending in 2006, but well in line with more recent studies such as

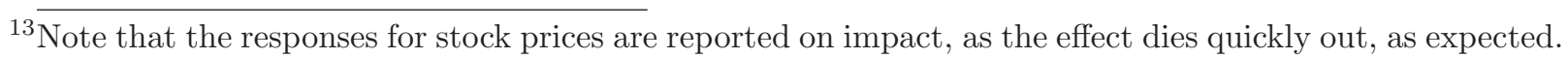


Fratzscher et al. (2014) and Mohaddes and Pesaran (2017).

Hence, oil price shocks may act as cost push shocks, in the sense that they increase prices. Yet, the response is quite muted. Furthermore, there is little time variation in the way oil price shocks are transmitted to nominal prices, consistent with what has previously been found in the literature, c.f. Clark and Terry (2010). ${ }^{14}$ The next question is therefore, does an adverse oil price shock also depress real activity?

Figure 5 addresses this, by presenting the median impulse responses (left column) and the responses after four quarters (right column) to non-residential investment, real personal income, and real private consumption of a higher oil price. In contrast to the nominal variables that did not show much evidence of time-variation, we now observe important time-variation in how the real variables are responding. First, we find that non-residential (non-oil related) investment has responded systematically more positively to an oil price shock throughout the 2000s, and the effect is significant and positive from 2013/2014, cf. Figure 5. Hence, while non-oil investment in the U.S. economy previously fell when oil prices rose, it is now picking up. This is a new finding in the literature.

Second, for an oil importing country, a higher oil price typically means lower purchasing power and potentially also lower demand for goods and services, as prices increase, c.f. Figure 4. This is manifested in lower income and consumption throughout the first part of the sample, see Figure 5. However, from 2012 and onward, real personal income starts to drift upward following an oil price shock. Consistent with this, the response in consumption has also gradually changed, and consumption is no longer responding significantly negatively following an oil price shock.

Taken together, these results are consistent with U.S. becoming a major oil producer. Following an oil price increase, investment and production in the oil sector increase, with subsequent spillovers to non-oil aggregate investment and income, which also now increase slightly with the U.S. resource boom. While these results may be consistent with what has been documented at the local level in oil rich states recently, c.f., Feyrer et al. (2017) and Allcott and Keniston (2018), these are new results for the aggregate U.S. economy. Importantly, this suggests that higher oil prices are no longer bad news for the U.S. economy. Hence, and oil price decline such as that experienced between 2014 and 2016, may not be beneficial either. The main question remains, though: which industries and states, are driving these results? Clearly, not all industries will benefit equally from the direct and indirect spillovers of oil. Some may even still be negatively affected as before, in particular if they are energy intensive in production. We turn to examine this next.

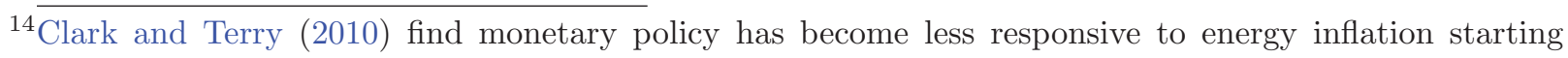
around 1985, but stable since then.
} 


\subsection{Disaggregate industry effects}

Having seen that there are now some positive effects on the aggregate U.S. economy arising from an oil price shock that increases oil prices (via the oil boom), Figure 6 examines in more detail the response in various industry groups. Not surprisingly, we find that the effect of higher oil prices on energy materials is significantly positive, and shows little time variation over the sample. Hence, production of energy materials increases with the oil boom. More interestingly, however, we observe a strong upward drift in the impulse responses for business equipment and manufacturing, which respond positively to an oil price shock by the end of the sample. Hence, there are now some positive spillovers from the resource boom to production of manufacturing and business equipment, effects that were not present before the shale oil boom.

We could think of three possible mechanisms through which the fracking boom could positively affect manufacturing sector in the U.S. The first mechanism is by creating energy independence and costs savings, as contraction of local energy prices (due to increased supply) enhances competitiveness for U.S. manufacturing companies that operate in energy-intensive sectors, c.f. Fetzer (2014). The second mechanism is through direct purchases of manufactured inputs, as there are many manufacturing industries from which the oil and gas sector makes input purchases. The third potential mechanism is productivity and LBD spillovers between oil and other industries. That is an indirect effect, which assumes that other industries benefits from new knowledge and technologies created under the development of oil sector, c.f. Bjørnland et al. (2019).

To investigate this further, we analyse responses to subgroups of manufacturing production in Figure 7. Doing so, we find heterogeneous responses among different industries. For energy-intensive industries, i.e., food, beverage and tobacco products, motor vehicles, and chemical products, responses are negative as expected, and for food, beverage and tobacco, even significantly so. Higher oil prices increase the cost of producing and leads a decline in demand, all else equal. ${ }^{15}$ This is as expected, and in line with what Baumeister and Kilian (2016) found for these industries. Furthermore, we do not find much variation over time, suggesting that the cost savings mechanism is of little importance on aggregate level. Instead, we find support for the two other mechanisms: first, we find a systematically more positive response for industries that benefit directly from the booming resource sector, i.e. machinery (machinery is used as input in production in the shale oil sector), suggesting direct spillovers through inputs. Second, industries like fabricated metal prod-

\footnotetext{
${ }^{15}$ We also find that petroleum and coal production declines temporarily with the oil boom, which could relate to the fact that downstream oil and gas industries, such as refining and petrochemicals, typically benefit from falling energy prices, not vice versa, see e.g. Herrera (2018) and Brown and Yücel (2013) for further discussions.
} 


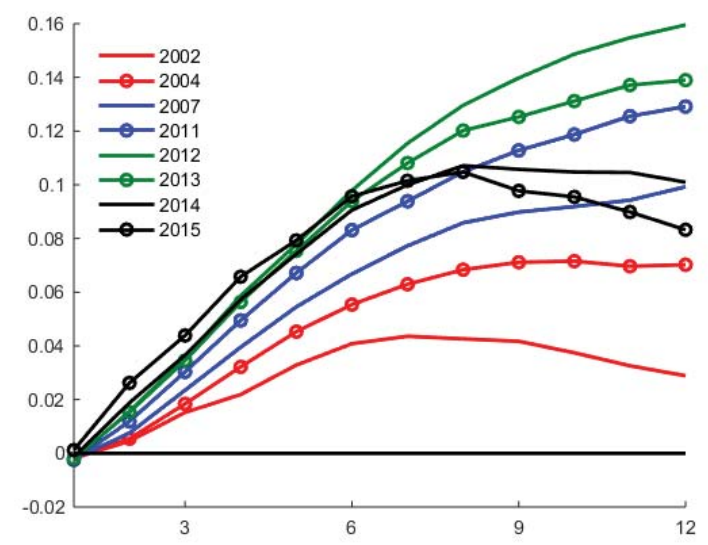

(a) Energy materials (Median)

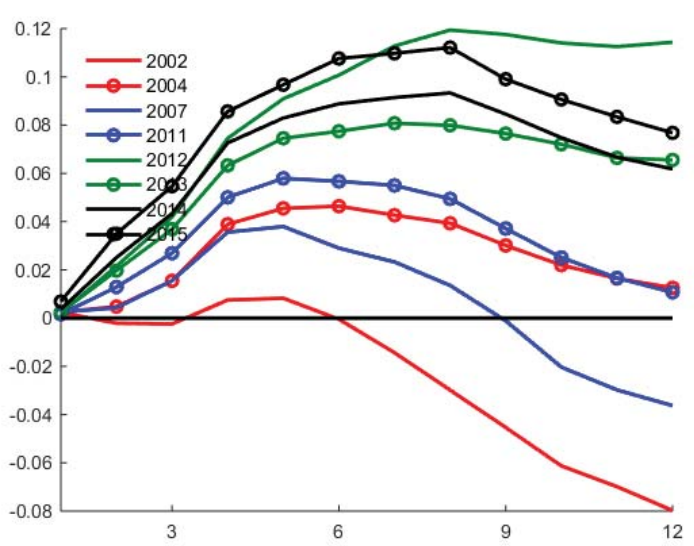

(c) Business equipment (Median)

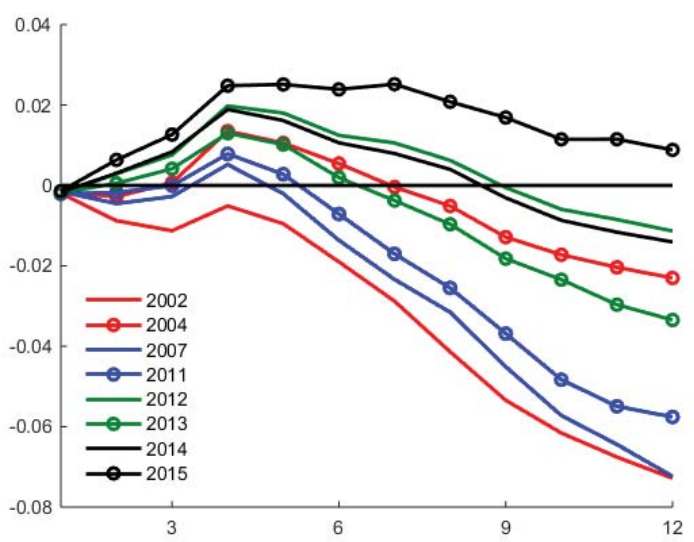

(e) Manufacturing (Median)

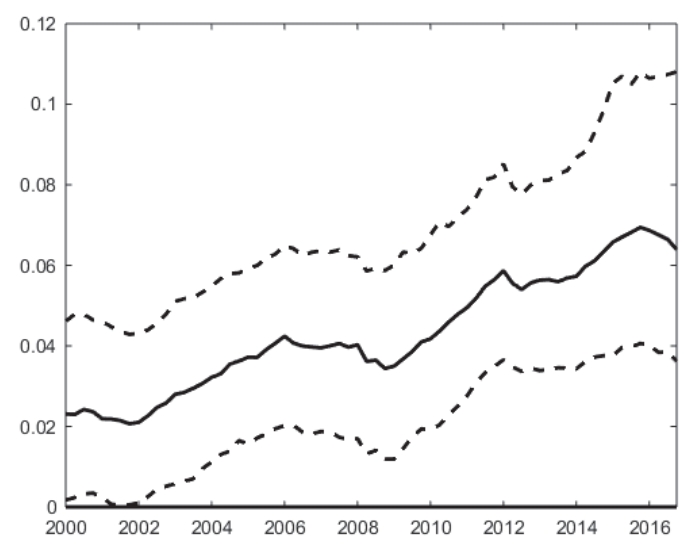

(b) Energy materials (4 quarters)

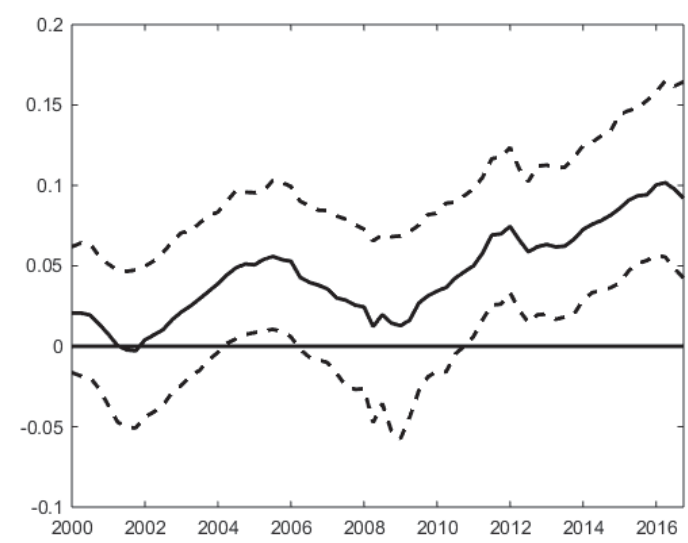

(d) Business equipment (4 quarters)

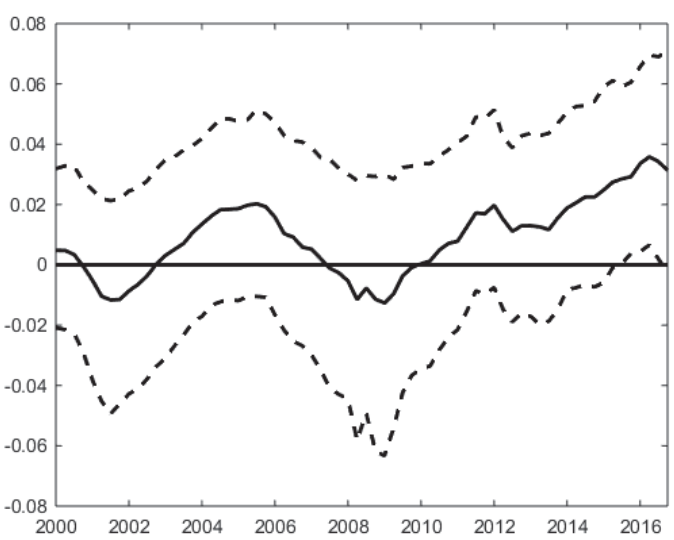

(f) Manufacturing (4 quarters)

Figure 6. The effect of an oil price shock: Impulse responses for Industrial Production series divided according to Market Groups. Responses are reported after 4 quarters with 16-th and 84-th percentiles

ucts and computer and electronic products, again see Figure 7, that are technological advances industries, could have benefited from indirect productivity spillovers from the resource boom, responding gradually more positively throughout the period. 


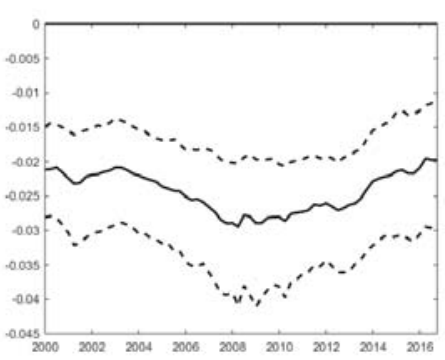

(a) Food and beverage

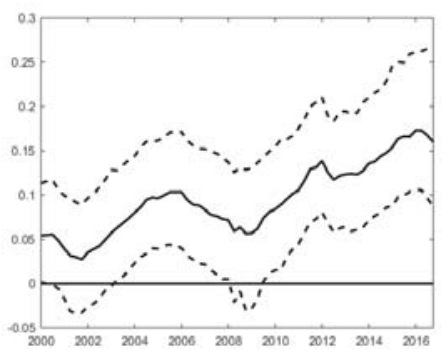

(d) Machinery

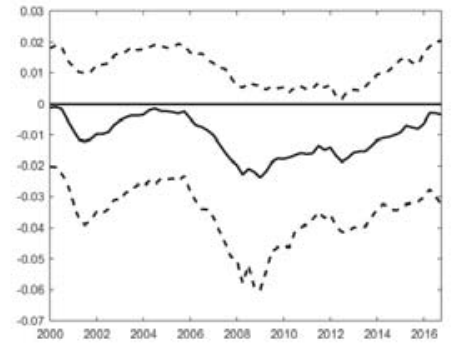

(b) Chemical

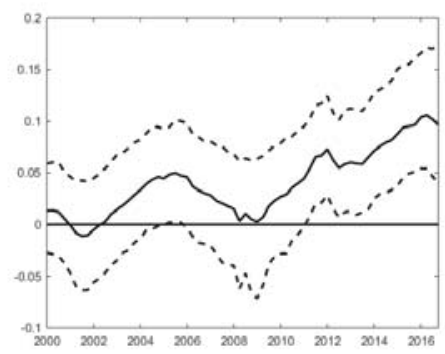

(e) Fabricated metal

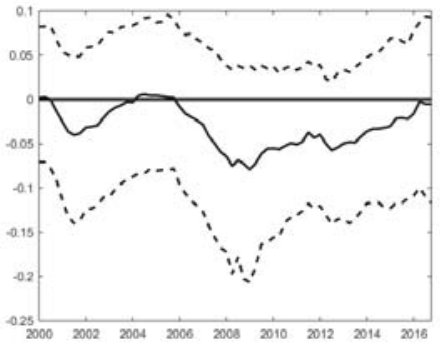

(c) Motor vehicles

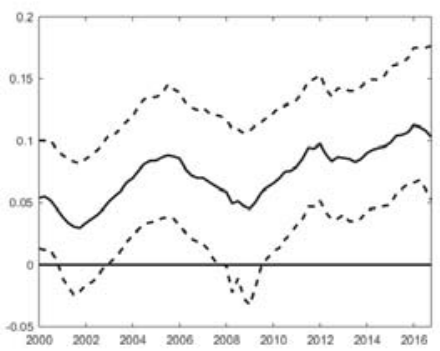

(f) Computer and electronics

Figure 7. The effect of an oil price shock: Impulse responses for Manufacturing series at a disaggregate level. Responses are reported after 4 quarters with 16-th and 84-th percentiles

Thus, we suggest that a gradual shift has taken place for several important industries in manufacturing sector. In line with Baumeister and Kilian (2016) we find that most of the energy intensive industries respond (insignificantly) negative, supporting the view that the cost channel is of less importance. However, the industries that have direct and indirect relationship to oil sector, have benefited from higher oil activity and are now responding by increasing investment and activity when oil prices increase. This suggests why, on average, manufacturing has benefited from higher oil prices during the shale boom, cf. Figure 6. That is, allowing for spillovers between industries, we have found that the oil industry can be an engine for growth. These is a new finding in the literature.

\subsection{Geographical dispersion: State level effects - employment}

So far we have focused on aggregate macroeconomic responses or disaggregate industry responses for the U.S. taken as a whole. We now turn to investigate the response in employment at the state level. We focus on employment as an important part of a oil boom is the resource movement of labour into the energy producing sector, see Corden (1984) for theory. Furthermore, there is recent empirical evidence of local spillovers to non-oil employment in the oil rich states, see Allcott and Keniston (2018) and Feyrer et al. (2017). Our focus is to investigate spillovers also outside the oil states. To do so, we focus on both oil-rich and non-oil states. That is, we investigate the responses to an increase in oil prices for both oil related employment and non-farm (non-oil) employment 
in oil rich states in Figure 8, and for non-farm employment in non-oil states in Figure 9. We display results for a few of the states in these figures, emphasising the dispersion of results. Detailed responses for all states can be found in Appendix D. Finally, Figure 10 displays the geographical dispersion of the oil price shocks for the whole of U.S.

Starting with the left column in Figure 8, we see that for all the oil-producing states, oil-related employment responds significantly positive during the whole period, and there is little evidence of time variation, see also Figure 12 in Appendix D. Hence, as expected, employment in mining and oil-related industries rise with higher oil prices, and has done so over the whole sample. Again, this indicates that the identified oil shock generate a broad oil boom across the oil producing states in the U.S. More interestingly, there is now clear evidence of time variation in employment outside mining in the oil-rich states, see the right column in Figure 8. In particular, for some oil rich states, non-oil employment is now increasing with the higher oil prices, see for instance Texas and Oklahoma. In fact, we find significant positive effects on non-oil employment for the 9 biggest oil-producing states. For California, however, the response is not significant positive, c.f. Figure 13 in Appendix D. These results are consistent with the literature using cross-section data that find positive spillovers from oil activity on local employment in oil rich states related to the shale oil boom, see e.g., Feyrer et al. (2017). The findings are also consistent with the results we have seen at the aggregate level, indicating a geographical dispersion of oil related shocks to non-oil sectors within resource abundant states.

Turning to the non-oil states, we find evidence that non-farm employment has gradually responded more positively to an oil shock. Still, responses are heterogeneous, with some states responding significantly positive, while others do not, see Figure 9 for some examples and Figure 13 in Appendix D for results for all states. For instance, three states where employment responds significantly positive are: Iowa, Vermont and Connecticut. As it turns out, these have all important manufacturing industries. In Iowa, the biggest manufacturing industry is machinery, in Vermont it is computer and electronic products, while in Connecticut it is aerospace and other transportation equipment. This is consistent with what we have seen in Figure 7, where production in these industries respond positively to the oil boom. On the other hand, states such as District of Columbia, where there is almost no manufacturing production (manufacturing employs $0.2 \%$ of the workforce in D.C), or in Missouri and New Jersey, where production of chemical products is the biggest manufacturing industry, do not find positive effects.

Thus, there responses are heterogeneous across U.S. states, depending on industry structure. How does this tally with the location of the various industries? To discuss this issue we illustrate geographical dispersion of oil price shocks in Figure 10. To this end, we let dark gray refer to the oil-rich states where employment responds now significantly 


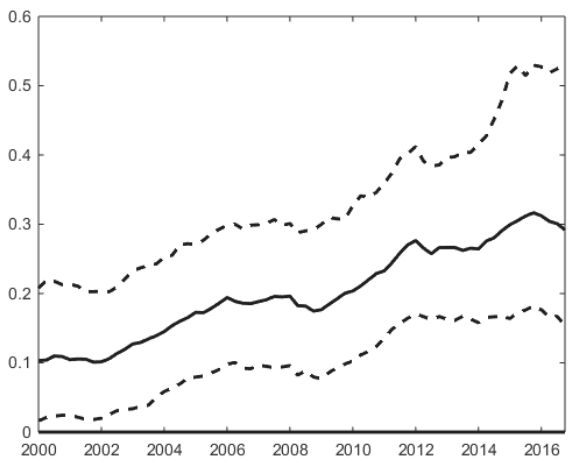

(a) Texas: Oil employment

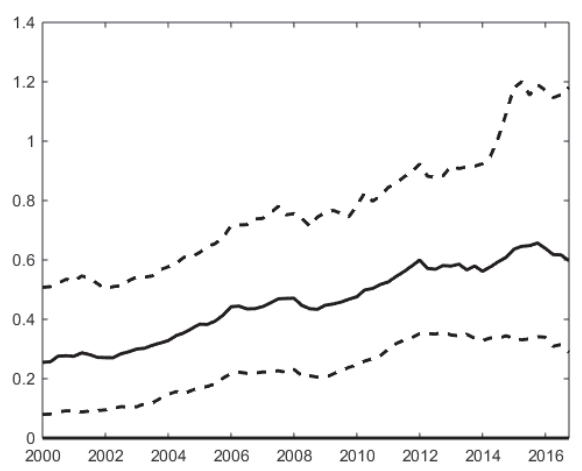

(c) North Dakota: Oil employment

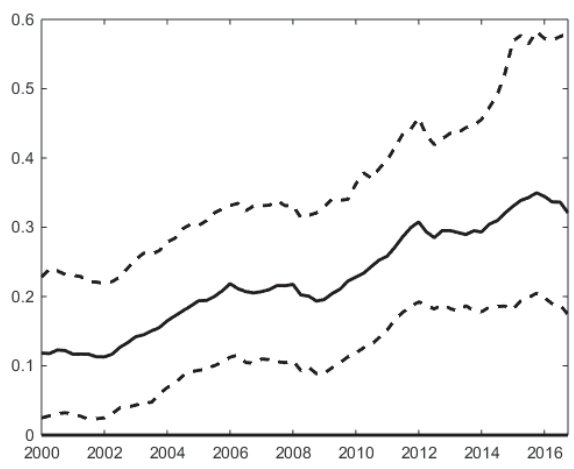

(e) Oklahoma: Oil employment

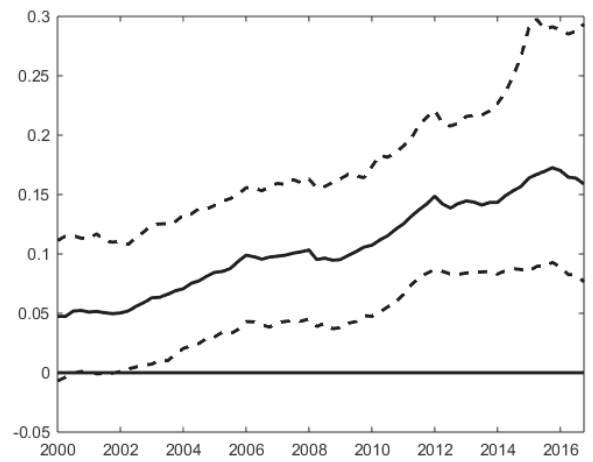

(g) Alaska: Oil employment

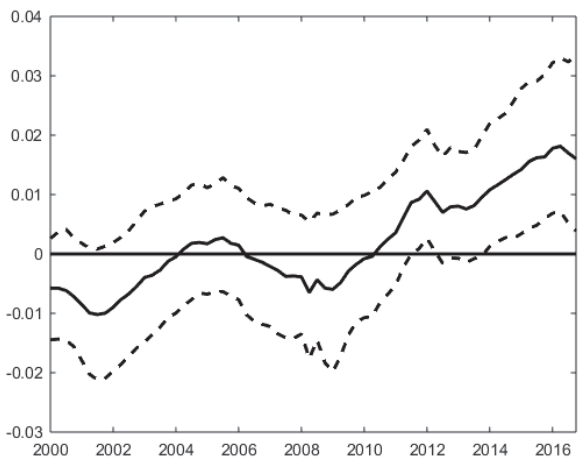

(b) Texas: Non-oil employment

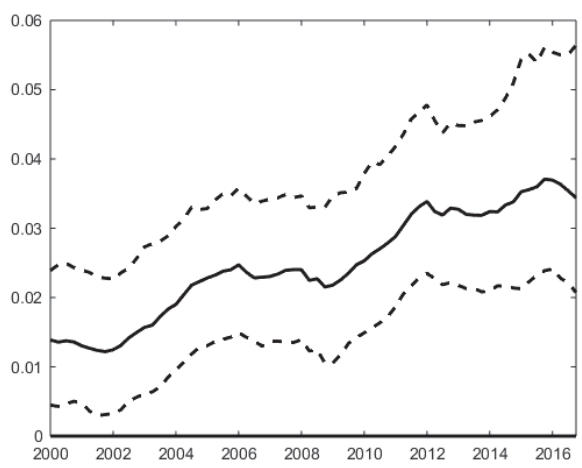

(d) North Dakota: Non-oil employment

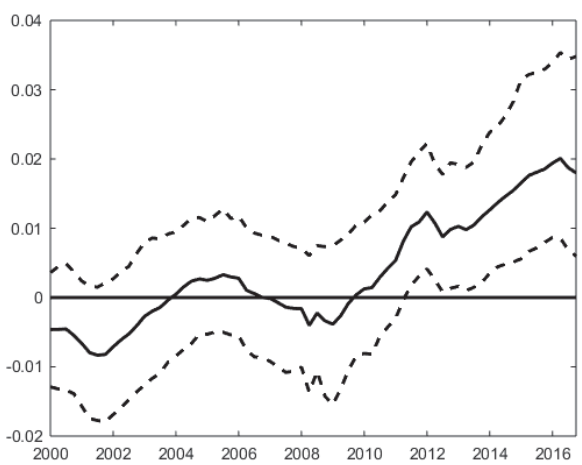

(f) Oklahoma: Non-oil employment

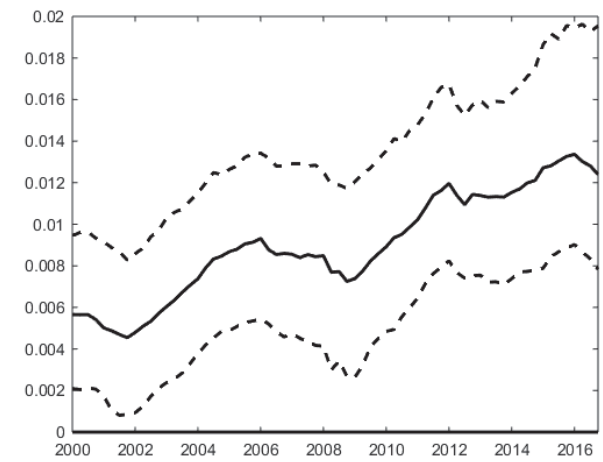

(h) Alaska: Non-oil employment

Figure 8. The effect of an oil price shock: Posterior median of impulse responses for employment series in oil-producing states 


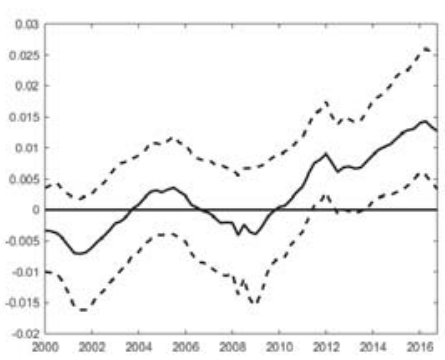

(a) Iowa

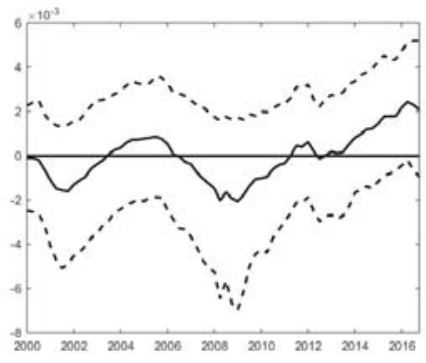

(d) District of Columbia

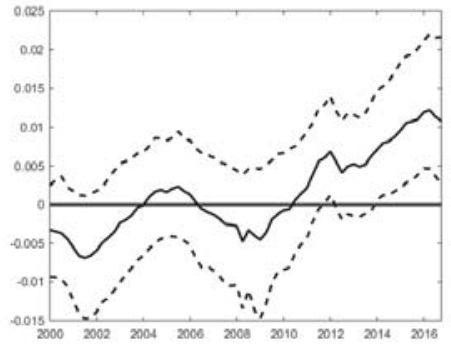

(b) Vermont

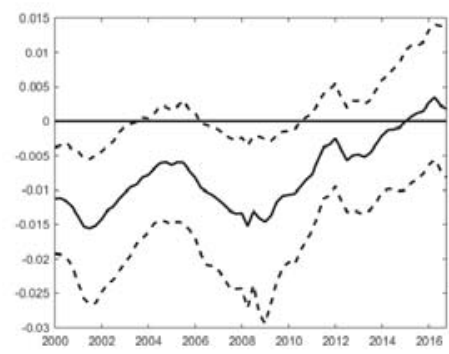

(e) Missouri

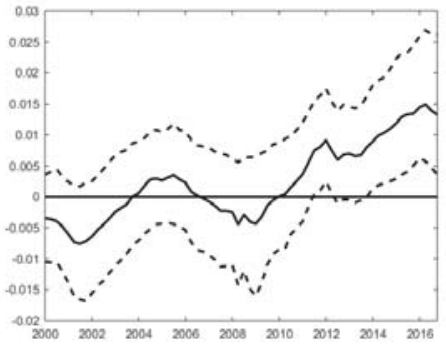

(c) Connecticut

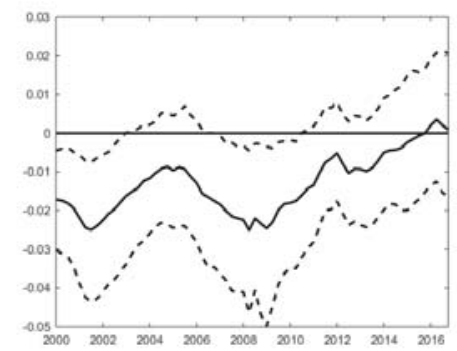

(f) Florida

Figure 9. The effect of an oil price shock: Posterior median of impulse responses for employment in some (non-oil) U.S. states. Upper row: states with a high Manufacturing share in employment, Lower row: states with a low manufacturing share in employment

positively to an oil price shock, while the non-oil states that respond significantly positive to an oil price shocks are colored blue. Light gray refer to states where the response is negative or not-significant. We have three main findings. First, Figure 10 shows that the positive and significant effects on non-oil employment are found in the large oil producing states (colored dark grey), mainly located in the middle of the U.S. All of these are part of the shale oil boom. Second, the non-oil states that now observe a significant positive effect on employment (colored blue) are either located close to the oil producing states: South Dakota (SD), Nebraska (NE), Iowa (IA) and Illinois (IL) or to the North east: Virginia (VA), West Virginia (WV), Pennsylvania (PA), New York (NY), Connecticut (CT), Maine (MA), Vermont (VT) and Massachusetts (ME). These have industries that include some of machinery, fabricated metal products, aerospace equipment, computer and electronic products, and primary metals as one the three most important industries, c.f. NAM (2015). As it was discussed in Section 4.3 these industries are typically closely connected to the energy boom and in addition, primarily located close to the oil producing states or in the north east. ${ }^{16}$ Finally, light grey are the states where the effect on employment from the oil boom is negative or insignificant. We note that none of the car manufacturing

${ }_{16}$ One exception is Hawaii (HI), which, despite having a small manufacturing sector (employing $2.1 \%$ of the workforce in the state), still finds employment responding significantly positive to an oil price increase. This could relate to the importance of the service sector: an increase in personal income is good news for tourism. 


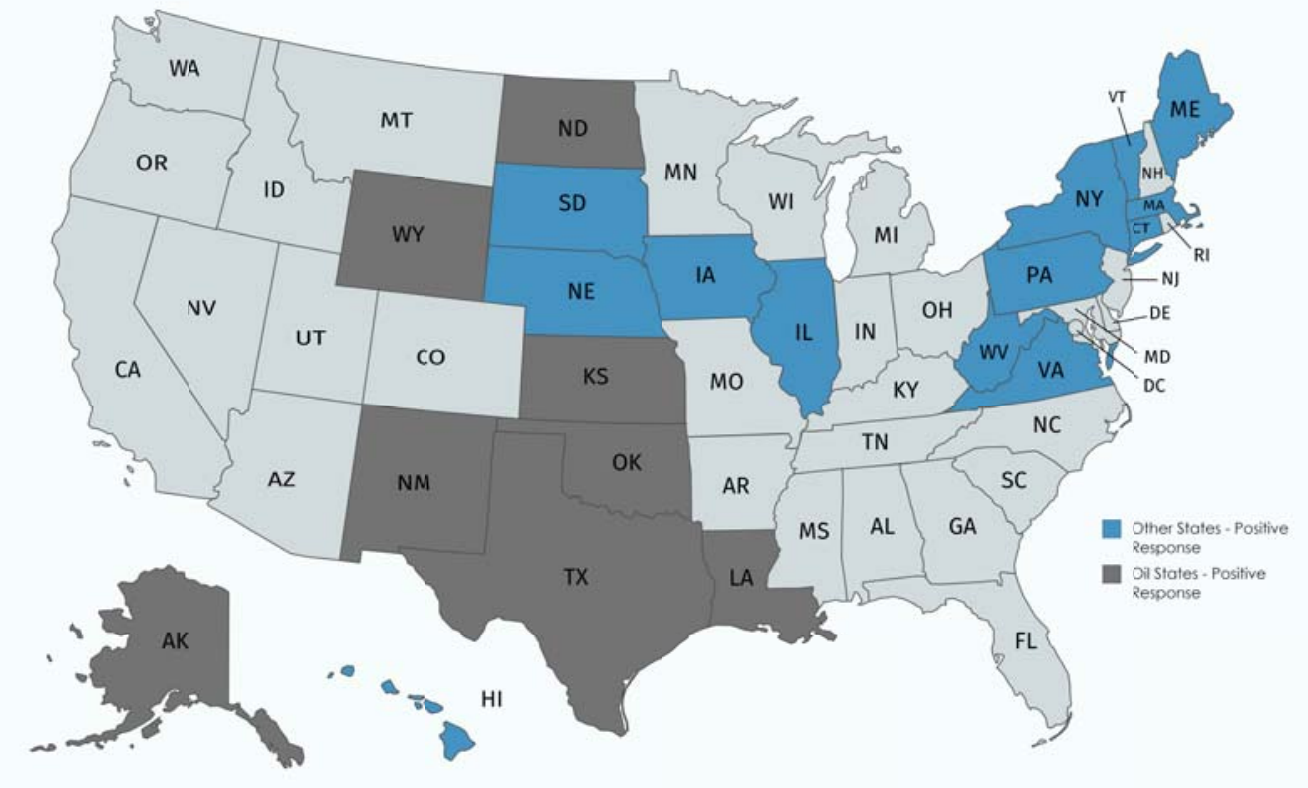

Figure 10. U.S. States and geographical dispersion of oil price shocks. Dark gray refers to oil-rich states blue refers to (non-oil) states where employment responds significantly positively to an oil price shock, while light blue refers to states where the effect on employment from an oil price shock is negative or insignificant. See the main text for additional explanations.

states, such as Michigan (MI), Ohio (OH), Indiana (IN), Kentucky (KY) and Tennessee (TN), have positive spillovers to employment from the oil boom. This is as expected, as these are states that are energy rich in production.

Finally, Table 1 displays variance decomposition for (non-oil) non-farm employment after 4 quarters for some selected states. Starting with the oil producing states (upper half of the table), the table confirms that the effects of oil price shocks have increased over time for non-oil employment in most oil rich states, in particular in Wyoming and North Dakota, where 40 percent of the variation in employment is due to oil price boom. On the other scale is California, where the oil price shocks explain a relative small part of the variation of employment; 15 percent. For the non-oil states, the effect varies, being substantial and explaining around 30 percent of the variance in employment in Vermont and Connecticut, whereas in DC, the oil boom explains a modest share of 10 percent. We also find (although not displayed here) that for the most oil rich states the variance explained by oil price shocks is highest after a quarter, while for non oil states, like Iowa and Vermont, the variance explained by oil shocks increases gradually over time and is highest after 4 quarters. This may indicate that it takes a longer time to realize the spillovers of oil to the other states, than within an oil producing state. 
Table 1. Employment variance decomposition

\begin{tabular}{|c|c|c|c|c|}
\hline & State & 2004Q1 & 2014Q1 & 2016Q1 \\
\hline \multirow{6}{*}{ 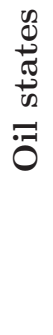 } & Wyoming & 0.20 & 0.36 & 0.47 \\
\hline & North Dakota & 0.24 & 0.35 & 0.42 \\
\hline & Alaska & 0.15 & 0.26 & 0.34 \\
\hline & Oklahoma & 0.10 & 0.20 & 0.32 \\
\hline & Texas & 0.10 & 0.15 & 0.26 \\
\hline & California & 0.18 & 0.11 & 0.17 \\
\hline \multirow{6}{*}{ 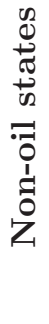 } & Vermont & 0.15 & 0.21 & 0.38 \\
\hline & Connecticut & 0.14 & 0.18 & 0.32 \\
\hline & Iowa & 0.14 & 0.16 & 0.27 \\
\hline & Florida & 0.25 & 0.14 & 0.16 \\
\hline & Missouri & 0.19 & 0.11 & 0.14 \\
\hline & District of Columbia & 0.05 & 0.06 & 0.09 \\
\hline
\end{tabular}

Note: Variance decomposition of (non-oil) non-farm employment after 4 quarters explained by oil price shocks (in percentage points)

Our results may seem surprising. As alluded to above, the manufacturing sector is a traded goods sector, and, according to the standard Dutch disease literature (e.g. Corden (1984)), we would expect to see a contraction of the traded goods sector and an expansion of the non-traded sectors (due to a spending effect). Instead, we find opposite results: The higher oil price generates a resource boom, which again leads to increased demand for output from the manufacturing sector and increased demand for labour. There is also learning by doing spillovers during the shale oil boom, affecting all sectors of the U.S. economy indirectly. For instance, as the development of new technology for drilling shale and hydraulic fracturing demands complicated technical solutions, this could in itself generate positive knowledge externalities that benefit many sectors. This is consistent with recent theoretical contributions such as Allcott and Keniston (2018) and Bjørnland et al. (2019).

We conclude that while there are heterogeneous effects to an oil price shock across the U.S. states, many of the U.S. states are now behaving more procyclically with the U.S. oil boom. Going forward, economic policy needs to take into account that the transmission of an oil price shock has changed with the shale oil boom. An oil price increase may now actually be good news for economic activity in the U.S. 


\section{Robustness}

To account for changes in the transmission of oil price shocks to the U.S. economy, we have used a time-varying FAVAR model with stochastic volatility. Here we analyze robustness along several dimensions. First, to what extent are the results driven by the use of the time-varying parameters framework? To illustrate this we re-estimate the model presented in Section 3.2, but now with constant coefficients and constant variance-covariance matrix $\left(B_{t}=B\right.$ and $\Omega_{t}=\Omega$ ), but for two different subsamples: 1990:Q2-2006:Q4 and 2000:Q12016:Q4. We then plot the differences between the responses for these two sub-periods for some selected key series in Figure 14 in Appendix E. Doing so, we find significant evidence of changing coefficients, confirming our results. Note, however, due to our short sample, there are a few years of overlap. We therefore also extend the sample backwards to start in 1974, so that we can split the sample in 2001. However, with this extended sample, we no longer have data for employment disaggregated into oil and non-oil at the state level. Still, Figure 15 in Appendix E shows that there are large differences in responses pre and post the shale boom, plotted here for manufacturing and S\&P500. Hence, the results of changing responses are not driven by the choice of model. Having said that, using a simple split sample framework is sensitive to the subjectively chosen break date, and may under or overestimate the true coefficients if there is variation within each sub-sample, as the analysis in Section 4 clearly suggests. To capture such behavior, one needs a flexible model allowing for time-variation, as the one we have applied here.

Second, as is well known in the literature, the choice of data included in the model is crucial for the results. In our benchmark model we are using a relative large dataset, and here we investigate robustness with respect to the global indicator. That is, we replace the global activity variable with an alternative measure that captures global demand, proposed by Chiaie et al. (2017). The global factor is strongly related to the measure of economic activity and has homogeneous effects on all commodity markets. Hence, we believe it is well suited alternative as a proxy for global demand. Figure 16 in Appendix F.1 shows that the results are robust to the choice of global variable.

Third, in the benchmark model, we have included industrial production and many subindices, which could be correlated. As shown by Boivin and $\mathrm{Ng}$ (2006), while additional data my be useful for extracting the factors, the resulting factors may be less useful for forecasting. Such a problem tends to arise when the idiosyncratic errors are crosscorrelated. We therefore test for robustness by excluding the Manufacturing sub-industries series, keeping only aggregate manufacturing in the model. Figure 17 in Appendix F.2 shows that the results are robust to excluding the manufacturing sub-industries.

Fourth, since the global financial crisis, interest rates have also been very low. This may have provided a stimulus to the economy, over and above the transmission of the oil 
price shocks. In particular, as pointed out by Datta et al. (2018), as the central bank does not respond to inflationary pressures by changing interest rates at the zero lower band (ZLB), changes in inflation can affect the real rate of interest differently. Thus, the impact on variables such as output, consumption and equity prices from an oil price shock, may also be different at the ZLB. To account for this, we add a shadow rate defined by Wu and Xia (2016) to our dataset. Figure 18 in Appendix F.3 show that results are robust to the inclusion of the shadow rate.

Fifth, and related to the above, many industries could have been affected by the decline in global real economic activity, while the transmission of oil price shocks could be of less importance. Hence, what we are capturing is the increased role of global demand, also as a driver of oil prices. ${ }^{17}$ In addition, the low interest rates could be a contributing factor, as discussed above. While we have controlled for global demand in the FAVAR model, through the identified factors, here we do a different exercise by running a simple rolling window linear regression model controlling for both global demand and the shadow rate:

$$
\Delta y_{t, i}=\beta_{1} \Delta g a_{t-1}+\beta_{2} \Delta o i l_{t-1}+\beta_{3} \bar{\Delta} s h a d_{t-1}+\beta_{4} \Delta y_{t-1, i}+u_{t}
$$

where $\Delta y_{t, i}$ denotes the percentage change in the variable of interest $i$, and $\Delta g a_{t}, \Delta o i l_{t}$ and $\bar{\Delta}$ shad $_{t}$ denote, respectively, changes in global industrial production, the real price of oil and the shadow rate. ${ }^{18}$ Figure 19 in Appendix F.4 displays the estimate of the $\beta_{2}$ coefficient for (a) investments and production in three (non-oil) industry groups: (b) Fabricated Metal Products, (c) Chemical industries and (d) Food and Beverage. The graph confirms our results: for both (non-oil) investments and fabricated metal products, the responses to a change in an oil price increase have changed from being negative in the 1980s, to more positive by the early 2000s, the start of the shale boom. On the other hand, industries not related to the oil boom, such as chemicals and food and beverage, display no time variation, responding negatively during whole sample period. These results are consistent with what we found in the base line analysis, suggesting that the effect of an oil price increase has changed for industries related to the oil boom, and can not be explained by global demand or the low interest rates.

Finally, an alternative explanation for why we find positive spillovers from an increase in the oil price to employment in many non-oil producing states, is the fact that there are other commodity prices, say corn and coal prices, correlated with oil prices, that also have increased. Hence, we may have found significant effects on employment in states

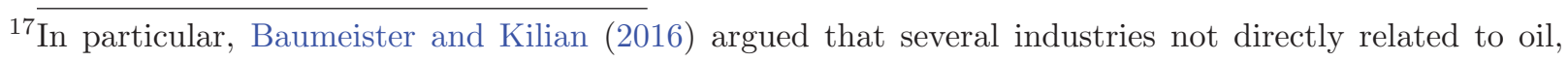
for example chemical and fabricated metal products, have performed poorly during the recent oil price decline. The main reason could be that they are negatively affected by the decline in global real economic activity.

${ }^{18} \bar{\Delta}$ denotes the first difference 
with high coal and corn production. In order to address this issue, we include prices of coal and corn in our dataset and reestimate our model. Results are robust. Furthermore, as can be seen from Figure 20 in Appendix F.5 the effect of an oil price increase on both coal and corn prices is stable during the whole sample period and do not show much time variation.

\section{Conclusion}

It is widely accepted that the unprecedented expansion of the U.S. shale oil sector has been a major contributor to oil investment since 2010. In this paper, we demonstrate that the shale oil boom has not only impacted oil investment, but has also changed the way oil price shocks are transmitted to aggregate investment, employment and various industries across the U.S. To capture these effects, we have estimated a factor-augmented vector autoregression (FAVAR) model with time-varying coefficients and stochastic volatility. Our framework allows us to study the effects of oil price shocks on a large number of U.S. macroeconomic variables and analyze the time variation in these effects. To the best of our knowledge this is the first paper that jointly models the interaction between the oil market and the U.S. economy in a large data environment, allowing also for time-varying changes during the fracking revolution.

In contrast to previous studies, we find substantial changes in the way an oil price shock is transmitted to the U.S. economy. In particular, we find both oil and the nonoil nonresidential business investments, as well as production and employment in oilproducing and manufacturing-intensive states to pick up following an oil price increase. What's more, there are positive spillovers to real personal income. Hence, this explains why the U.S. did not experience a boom following the steep decline in oil prices between 2014 and 2016. The answer is simply that the country has increased its reliance of oil, not as a consumer, but by becoming the world's largest oil producer. Going forward, economic policy needs to take into account that the transmission of an oil price shock has changed with the shale oil boom. An oil price increase may now actually be good news for economic activity in the U.S. 


\section{References}

Aastveit, K. A. (2014). Oil Price Shocks in a Data-Rich Environment. Energy Economics 45, 268-279.

Aastveit, K. A., H. C. Bjørnland, and L. A. Thorsrud (2015). What Drives Oil Prices? Emerging Versus Developed Economies. Journal of Applied Econometrics 30 (7), 10131028.

Acemoglu, D., V. M. Carvalho, A. Ozdaglar, and A. Tahbaz-Salehi (2012). The network origins of aggregate fluctuations. Econometrica 80(5), 1977-2016.

Allcott, H. and D. Keniston (2018). Dutch Disease or Agglomeration? The Local Economic Effects of Natural Resource Booms in Modern America. Review of Economic Studies 85(2), 596-731.

Baumeister, C. and J. D. Hamilton (2019). Structural interpretation of vector autoregressions with incomplete identification: Revisiting the role of oil supply and demand shocks. American Economic Review 109(5), 1873-1910.

Baumeister, C. and L. Kilian (2016). Lower Oil Prices and the U.S. Economy: Is This Time Different? Brookings Papers on Economic Activity, 287-357.

Baumeister, C. and G. Peersman (2013a). The Role of Time-Varying Price Elasticities in Accounting for Volatility Changes in the Crude Oil Market. Journal of Applied Econometrics 28(7), 1087-1109.

Baumeister, C. and G. Peersman (2013b). Time-Varying Effects of Oil Supply Shocks on the US Economy. American Economic Journal: Macroeconomics 5(4), 1-28.

Belviso, F. and F. Milani (2006). Structural Factor-Augmented VARs (SFAVARs) and the Effects of Monetary Policy. The B.E. Journal of Macroeconomics 6(3).

Bernanke, B. S., J. Boivin, and P. Eliasz (2005). Measuring the Effects of Monetary Policy: A Factor-Augmented Vector Autoregressive (FAVAR) Approach. The Quarterly Journal of Economics 120(1), 387-422.

Bjørnland, H. C., V. H. Larsen, and J. Maih (2018). Oil and macroeconomic (in)stability. American Economic Journal: Macroeconomics 10(4), 128-51.

Bjørnland, H. C., F. M. Nordvik, and M. Rohrer (2017). Supply flexibility in the shale patch: Evidence from North Dakota. CAMP Working Paper No. 2/2017, BI Norwegian Business School. 
Bjørnland, H. C. and L. A. Thorsrud (2016). Boom or Gloom? Examining the Dutch Disease in Two-speed Economies. Economic Journal 126(598), 2219-2256.

Bjørnland, H. C., L. A. Thorsrud, and R. Torvik (2019). Dutch Disease Dynamics Reconsidered. European Economic Review (forthcoming).

Boivin, J. and M. P. Giannoni (2007). Global Forces and Monetary Policy Effectiveness. International Dimensions of Monetary Policy, 429-478.

Boivin, J. and S. Ng (2006). Are More Data Always Better for Factor Analysis? Journal of Econometrics 132(1), 169-194.

Bornstein, G., P. Krusell, and S. Rebelo (2018). Lags, Costs, and Shocks: An Equilibrium Model of the Oil Industry. Working Paper 23423, National Bureau of Economic Research.

Bresnahan, T. F. and V. A. Ramey (1993). Segment Shifts and Capacity Utilization in the US Automobile Industry. The American Economic Review 83(2), 213-218.

Brown, S. P. and M. K. Yücel (2013). The Shale Gas and Tight Oil Boom: U.S. States' Economic Gains and Vulnerabilities. New York: Council on Foreign Relations.

Cashin, P., K. Mohaddes, M. Raissi, and M. Raissi (2014). The Differential Effects of Oil Demand and Supply Shocks on the Global Economy. Energy Economics 44, 113-134.

Chiaie, S. D., L. Ferrara, and D. Gionnone (2017). Common Factors of Commodity Prices. ECB Working Paper No 2111.

Clark, T. E. and S. J. Terry (2010). Time Variation in the Inflation Passthrough of Energy Prices. Journal of Money, Credit and Banking 42(7), 1419-1433.

Corden, W. M. (1984). Booming Sector and Dutch Disease Economics: Survey and Consolidation. Oxford Economic Papers 36 (3), 359-380.

Corden, W. M. and J. P. Neary (1982). Booming sector and de-industrialisation in a small open economy. The Economic Journal 92(368), 825-848.

Datta, D., B. K. Johannsen, H. Kwon, and R. J. Vigfusson (2018). Oil, equities, and the zero lower bound. Finance and economics discussion series 2018-058, Board of Governors of the Federal Reserve System.

Davis, S. J. and J. Haltiwanger (2001). Sectoral Job Creation and Destruction Responses to Oil Price Changes. Journal of Monetary Economics 48(3), 465-512. 
Del Negro, M. and G. E. Primiceri (2015, 06). Time Varying Structural Vector Autoregressions and Monetary Policy: A Corrigendum. The Review of Economic Studies 82(4), $1342-1345$.

Edelstein, P. and L. Kilian (2009). How Sensitive are Consumer Expenditures to Retail Energy Prices? Journal of Monetary Economics 56(6), 766- -779.

Fetzer, T. R. (2014). Fracking Growth. CEP Discussion Paper.

Feyrer, J., E. T. Mansur, and B. Sacerdote (2017). Geographic Dispersion of Economic Shocks: Evidence from the Fracking Revolution. American Economic Review 107(4), 1313-1334.

Foronia, C., P. Guérinb, and M. Marcellino (2017). Explaining the Time-Varying Effects of Oil Market Shocks on U.S. Stock Returns. Economics Letters 155, 84-88.

Fratzscher, M., D. Schneider, and I. Van Robays (2014). Oil Prices, Exchange Rates and Asset Prices. ECB Working Paper 1689, European Central Bank.

Gabaix, X. (2011). The granular origins of aggregate fluctuations. Econometrica 79(3), $733-772$.

Geweke, J. (1992). Evaluating the Accuracy of Sampling-Based Approaches to the Calculation of Posterior Moments. Bayesian Statistics 4, 169-193.

Gilje, E., R. Ready, and N. Roussanov (2016). Fracking, Drilling, and Asset Pricing: Estimating the Economic Benefits of the Shale Revolution. NBER working paper no. 22914, National Bureau of Economic Research.

Gylfason, T., T. T. Herbertsson, and G. Zoega (1999). A Mixed Blessing. Macroeconomic Dynamics 3(2), 204-225.

Hamilton, J. D. (1983). Oil and the macroeconomy since World War II. Journal of Political Economy $91(2), 228-248$.

Hamilton, J. D. (2008). Oil and the Macroeconomy. The New Palgrave Dictionary of Economics, Second Edition, 2008.

Hamilton, J. D. (2009). Causes and Consequences of the Oil Shock of 2007-08. Brookings Papers on Economic Activity 40(1), 215-283.

Hamilton, J. D. (2018). Measuring Global Economic Activity. Mimeo, University of California at San Diego. 
Hamilton, J. D. and A. M. Herrera (2004). Comment: Oil Shocks and Aggregate Macroeconomic Behavior: The Role of Monetary Policy. Journal of Money, Credit and Banking, 265-286.

Herrera, A. M. (2018). Oil price shocks, inventories, and macroeconomic dynamics. Macroeconomic Dynamics 22(3), 620-639.

Herrera, A. M. and E. Pesavento (2009). Oil Price Shocks, Systematic Monetary Policy, and The "Great Moderation". Macroeconomic Dynamics 13(1), 107-137.

Kanga, W., R. A. Rattib, and K. H. Yoonb (2015, 12). Time-Varying Effect of Oil Market Shocks on the Stock Market. Journal of Banking $\&$ Finance 61, S150-S163. Supplement 2 .

Kilian, L. (2009). Not All Oil Price Shocks are Alike: Disentangling Demand and Supply Shocks in the Crude Oil Market. American Economic Review 99(3), 1053-1069.

Kilian, L. and C. Park (2000). The Impact of Oil Price Shocks on the U.S. Stock Market. International Economic Review 50(4), 1267-1287.

Kilian, L. and C. Vega (2011). Do energy prices respond to US macroeconomic news? a test of the hypothesis of predetermined energy prices. Review of Economics and Statistics 93(2), 660-671.

Kilian, L. and R. J. Vigfusson (2011). Are the responses of the US economy asymmetric in energy price increases and decreases? Quantitative Economics 2(3), 419-453.

Koop, G. (2003). Bayesian Econometrics. Wiley, Chichester.

Korobilis, D. (2013). Assessing the Transmission of Monetary Policy Using Time-Varying Parameter Dynamic Factor Models. Oxford Bulletin of Economics and Statistics 75(2), $157-179$.

Krugman, P. (1987). The Narrow Moving Band, the Dutch Disease, and the Competitive Consequences of Mrs. Thatcher: Notes on Trade in the Presence of Dynamic Scale Economies. Journal of Development Economics 27(1), 41-55.

Lee, K. and S. Ni (2002). On the dynamic effects of oil price shocks: a study using industry level data. Journal of Monetary Economics 49(4), 823-852.

Lippi, F. and A. Nobili (2012). Oil and the Macroeconomy: a Quantative Structural Analysis. Journal of the European Economic Association. 
Maniloff, P. and R. Mastromonaco (2015). The Local Economic Impacts of Hydraulic Fracturing and Determinants of Dutch Disease. Colorado School of Mines, Division of Economics and Business Working Paper 8.

Mohaddes, K. and M. H. Pesaran (2017). Oil prices and the global economy: Is it different this time around? Energy Economics 65, 315-325.

NAM (2015). National Association of Manufacturers - State Manufacturing Data Reports. http://www.nam.org/Data-and-Reports/State-Manufacturing-Data/.

Peersman, G. and I. V. Robays (2012). Cross-Country Differences in the Effects of Oil Shocks. Energy Economics 34(5), $1532-1547$.

Primiceri, G. E. (2005). Time -Varying Structural Vector Autoregressions and Monetary Policy. The Review of Economic Studies 72(3), 821-852.

Sachs, J. D. and A. M. Warner (1995). Natural resource abundance and economic growth. Working papers 5398, National Bureau of Economic Research.

Stock, J. H. and M. W. Watson (2005). Implications of Dynamic Factor Models for VAR Analysis. NBER Working Paper (11467).

Stock, J. H. and M. W. Watson (2016). Dynamic factor models, factor-augmented vector autoregressions, and structural vector autoregressions in macroeconomics. In Handbook of macroeconomics, Volume 2, pp. 415-525. Elsevier.

Torvik, R. (2001). Learning by doing and the Dutch disease. European Economic Review $45(2), 285-306$.

van Wijnbergen, S. (1984). The "Dutch Disease": A Disease After All? The Economic Journal $94(373), 41-55$.

Wang, Z. and A. Krupnick (2013). A Retrospective Review of Shale Gas Development in the United States: What Led to the Boom? Resources for the Future Discussion Paper 13-12.

Weber, J. G. (2012). The Effects of a Natural Gas Boom on Employment and Income in Colorado, Texas, and Wyoming. Energy Economics 34(5), 1580-1588.

Wu, J. C. and F. D. Xia (2016). Measuring the Macroeconomic Impact of Monetary Policy at the Zero Lower Bound. Journal of Money, Credit, and Banking 48(2-3), 253-291. 


\section{Appendices}

\section{Appendix A Data Description}

\begin{tabular}{|c|c|c|c|}
\hline & \multicolumn{3}{|c|}{ Global Variables } \\
\hline & fred & id & Description \\
\hline 1 & $\begin{array}{l}\text { Baumeister } \\
\text { Hamilton (2019) }\end{array}$ & and & World Industrial Production Index \\
\hline 2 & Source: EIA & Oil price & $\begin{array}{l}\text { US Refineries Acquisition Cost of domestic } \\
\text { and imported crude oil deflated by CPI }\end{array}$ \\
\hline
\end{tabular}

Macro aggregates

\begin{tabular}{|c|c|c|c|}
\hline & fred & id & Description \\
\hline 3 & $\begin{array}{l}\text { E318RC1Q027SBEA+ } \\
\text { USIEOX..B (Datastream }\end{array}$ & Oil Investment & $\begin{array}{l}\text { Private fixed investment: Nonresidential: } \\
\text { Mining exploration, shafts, and wells + Equip- } \\
\text { ment, mining, and oilfield machinery }\end{array}$ \\
\hline 4 & RPI & Personal Income & Real Personal Income \\
\hline 5 & FEDFUNDS & Interest Rate & Effective Federal Funds Rate \\
\hline 6 & INDPRO & IP Index & Industrial Production Index \\
\hline 7 & PPIACO & PPI & Producer Price Index for All Commodities \\
\hline 8 & CPIAUCSL & CPI & CPI : All Items \\
\hline 9 & SP500 & S\&P500 & S\&Ps Common Stock Price Index: Composite \\
\hline 10 & PRFI & Residential Investment & Private Residential Fixed Investment \\
\hline 11 & PNFI & Nonresidential Investment: & **Private Nonresidential Fixed Investment: \\
\hline 12 & PCEPI & Private Consumption & $\begin{array}{l}\text { Real Private Consumption Expenditure } \\
\text { (chain-type quantity index) }\end{array}$ \\
\hline 13 & DTWEXM & $\begin{array}{l}\text { Trade Weighted U.S. FX } \\
\text { Rate }\end{array}$ & $\begin{array}{l}\text { Trade Weighted U.S. Dollar Index: Major Cur- } \\
\text { rencies }\end{array}$ \\
\hline 14 & Source: EIA & Net Petroleum Imports & $\begin{array}{l}\text { U.S. Net Imports of Crude Oil and Petroleum Products } \\
\text { (Thousand Barrels per Day) }\end{array}$ \\
\hline 15 & Source: Census & Net Trade in Goods & Trade in goods: Net trade \\
\hline
\end{tabular}

\begin{tabular}{llll}
\multicolumn{5}{c}{} & $\begin{array}{l}\text { Disaggregate } \\
\text { Production }\end{array}$ & Industrial \\
& fred & id & Description \\
\hline 16 & IPMANSICS & Manufacturing & IP: Manufacturing (SIC) \\
17 & IPMINE & Mining & IP: Mining \\
18 & IPUTIL & Utilities & IP: Electric and Gas Utilities \\
19 & IPCONGD & Consumer Goods & IP: Consumer Goods \\
20 & IPBUSEQ & Business Equipment & IP: Business Equipment \\
21 & IPB52300S & Defense and space equipment & IP: Defense and space equipment \\
22 & IPB54100S & Construction supplies & IP: Construction supplies \\
23 & IPB54200S & Business supplies & IP: Business supplies \\
24 & IPZ53010S & Materials excluding energy & IP: Materials excluding energy materials \\
& & materials & \\
25 & IPB53300S & Energy materials & IP: Energy materials \\
26 & IPG321S & Wood product & IP: Durable manufacturing: Wood product \\
\hline
\end{tabular}

Continued on next page 


\begin{tabular}{|c|c|c|}
\hline 27 & IPG327S & Nonmetallic mineral product \\
\hline 28 & IPG331S & Primary metal \\
\hline 29 & IPG332S & Fabricated metal product \\
\hline 30 & IPG333S & Machinery \\
\hline 31 & IPG334S & $\begin{array}{l}\text { Computer and electronic prod- } \\
\text { uct }\end{array}$ \\
\hline 32 & IPG335S & $\begin{array}{l}\text { Electrical equipment, appli- } \\
\text { ance, and component }\end{array}$ \\
\hline 33 & IPG3361T3S & Motor vehicles and parts \\
\hline 34 & IPG3364T9S & $\begin{array}{l}\text { Aerospace and miscellaneous } \\
\text { transportation equipment }\end{array}$ \\
\hline 35 & IPG337S & Furniture and related product \\
\hline 36 & IPG339S & Miscellaneous \\
\hline 37 & IPG311A2S & Food, beverage, and tobacco \\
\hline 38 & IPG313A4S & Textiles and products \\
\hline 39 & IPG315A6S & Apparel and leather goods \\
\hline 40 & IPG322S & Paper \\
\hline 41 & IPG323S & $\begin{array}{l}\text { Printing and related support } \\
\text { activities }\end{array}$ \\
\hline 42 & IPG324S & Petroleum and coal products \\
\hline 43 & IPG325S & Chemical \\
\hline 44 & IPG326S & Plastics and rubber products \\
\hline
\end{tabular}

IP: Durable manufacturing: Nonmetallic mineral product

IP: Durable manufacturing: Primary metal

IP: Durable manufacturing: Fabricated metal product

IP: Durable manufacturing: Machinery

IP: Durable manufacturing: Computer and electronic product

IP: Durable manufacturing: Electrical equipment, appliance, and component

IP: Durable manufacturing: Motor vehicles and parts

IP: Durable manufacturing: Aerospace and miscellaneous transportation equipment

IP: Durable manufacturing: Furniture and related product

IP: Durable manufacturing: Miscellaneous

IP: Nondurable manufacturing: Food, beverage, and tobacco

IP: Nondurable manufacturing: Textiles and products

IP: Nondurable manufacturing: Apparel and leather goods

IP: Nondurable manufacturing: Paper

IP: Nondurable manufacturing: Printing and related support activities

IP: Nondurable manufacturing: Petroleum and coal products

IP: Nondurable manufacturing: Chemical

IP: Nondurable manufacturing: Plastics and rubber products

Nonfarm Employment States

\begin{tabular}{llll}
\hline & fred & id & Description \\
\hline 45 & ALNA & Alabama & All Employees: Total Nonfarm in Alabama \\
46 & AKNA & Alaska & *All Employees: Total Nonfarm in Alaska \\
47 & AZNA & Arizona & All Employees: Total Nonfarm in Arizona \\
48 & ARNA & Arkansas & All Employees: Total Nonfarm in Arkansas \\
49 & CANA & California & *All Employees: Total Nonfarm in California \\
50 & CONA & Colorado & *All Employees: Total Nonfarm in Colorado \\
51 & CTNA & Connecticut & All Employees: Total Nonfarm in Connecticut \\
52 & DENA & Delaware & All Employees: Total Nonfarm in Delaware \\
53 & FLNA & Florida & All Employees: Total Nonfarm in Florida \\
54 & GANA & Georgia & All Employees: Total Nonfarm in Georgia \\
55 & HINA & Hawaii & All Employees: Total Nonfarm in Hawaii \\
56 & IDNA & Idaho & All Employees: Total Nonfarm in Idaho \\
57 & ILNA & Illinois & All Employees: Total Nonfarm in Illinois \\
58 & INNA & Indiana & All Employees: Total Nonfarm in Indiana \\
59 & IANA & Iowa & All Employees: Total Nonfarm in Iowa \\
60 & KSNA & Kansas & $*$ All Employees: Total Nonfarm in Kansas \\
61 & KYNA & Kentucky & All Employees: Total Nonfarm in Kentucky \\
62 & LANA & Louisiana & *All Employees: Total Nonfarm in Louisiana \\
63 & MENA & Maine & All Employees: Total Nonfarm in Maine \\
\hline
\end{tabular}

Continued on next page 


\begin{tabular}{|c|c|c|}
\hline 64 & MDNA & Maryland \\
\hline 65 & MANA & Massachusetts \\
\hline 66 & MINA & Michigan \\
\hline 67 & MNNA & Minnesota \\
\hline 68 & MSNA & Mississippi \\
\hline 69 & MONA & Missouri \\
\hline 70 & MTNA & Montana \\
\hline 71 & NENA & Nebraska \\
\hline 72 & NVNA & Nevada \\
\hline 73 & NHNA & New Hampshire \\
\hline 74 & NJNA & New Jersey \\
\hline 75 & NMNA & New Mexico \\
\hline 76 & NYNA & New York \\
\hline 77 & NCNA & North Carolina \\
\hline 78 & NDNA & North Dakota \\
\hline 79 & OHNA & Ohio \\
\hline 80 & OKNA & Oklahoma \\
\hline 81 & ORNA & Oregon \\
\hline 82 & PANA & Pennsylvania \\
\hline 83 & RINA & Rhode Island \\
\hline 84 & SCNA & South Carolina \\
\hline 85 & SDNA & South Dakota \\
\hline 86 & TNNA & Tennessee \\
\hline 87 & TXNA & Texas \\
\hline 88 & DCNA & District of Columbia \\
\hline 89 & UTNA & Utah \\
\hline 90 & VTNA & Vermont \\
\hline 91 & VANA & Virginia \\
\hline 92 & WANA & Washington \\
\hline 93 & WVNA & West Virginia \\
\hline 94 & WINA & Wisconsin \\
\hline 95 & WYNA & Wyoming \\
\hline
\end{tabular}

All Employees: Total Nonfarm in Maryland

All Employees: Total Nonfarm in Massachusetts

All Employees: Total Nonfarm in Michigan

All Employees: Total Nonfarm in Minnesota

All Employees: Total Nonfarm in Mississippi

All Employees: Total Nonfarm in Missouri

*All Employees: Total Nonfarm in Montana

All Employees: Total Nonfarm in Nebraska

All Employees: Total Nonfarm in Nevada

All Employees: Total Nonfarm in New Hampshire

All Employees: Total Nonfarm in New Jersey

*All Employees: Total Nonfarm in New Mexico

All Employees: Total Nonfarm in New York

All Employees: Total Nonfarm in North Carolina

*All Employees: Total Nonfarm in North Dakota

All Employees: Total Nonfarm in Ohio

*All Employees: Total Nonfarm in Oklahoma

All Employees: Total Nonfarm in Oregon

All Employees: Total Nonfarm in Pennsylvania

All Employees: Total Nonfarm in Rhode Island

All Employees: Total Nonfarm in South Carolina

All Employees: Total Nonfarm in South Dakota

All Employees: Total Nonfarm in Tennessee

*All Employees: Total Nonfarm in Texas

All Employees: Total Nonfarm in the District of Columbia

All Employees: Total Nonfarm in Utah

All Employees: Total Nonfarm in Vermont

All Employees: Total Nonfarm in Virginia

All Employees: Total Nonfarm in Washington

All Employees: Total Nonfarm in West Virginia

All Employees: Total Nonfarm in Wisconsin

*All Employees: Total Nonfarm in Wyoming

Mining Employment -

Oil States

\begin{tabular}{|c|c|c|c|}
\hline & fred & id & Description \\
\hline 96 & CONRMN & Mining in Colorado & $\begin{array}{l}\text { All Employees: Mining and Logging in Col- } \\
\text { orado }\end{array}$ \\
\hline 97 & KSNRMN & Mining in Kansas & All Employees: Mining and Logging in Kansas \\
\hline 99 & $\begin{array}{l}\text { SMU22000001021100001SA + } \\
\text { SMU22000001021300001SA }\end{array}$ & Mining in Louisiana & $\begin{array}{l}\text { All Employees: Mining: Oil and Gas Ex- } \\
\text { traction + Support Activities for Mining in } \\
\text { Louisiana }\end{array}$ \\
\hline
\end{tabular}

Continued on next page 


\begin{tabular}{|c|c|c|}
\hline 100 & SMU30000001000000001A & Mining in Montana \\
\hline 101 & SMU35000001000000001A & Mining in New Mexico \\
\hline 102 & SMU38000001000000001A & Mining in North Dakota \\
\hline 103 & SMU40000001000000001A & Mining in Oklahoma \\
\hline 104 & SMU02000001021001301 & Mining in Alaska \\
\hline 105 & $\begin{array}{l}\text { SMU06000001021100001SA + } \\
\text { SMU06000001021300001 }\end{array}$ & Mining in California \\
\hline 106 & $\begin{array}{l}\text { SMU48000001021100001SA + } \\
\text { SMU48000001021300001 }\end{array}$ & Mining in Texas \\
\hline 107 & $\begin{array}{l}\text { SMU56000001021100001SA } \\
\text { +SMU56000001021311201SA }\end{array}$ & Mining in Wyoming \\
\hline
\end{tabular}

All Employees: Mining and Logging in Montana

All Employees: Mining and Logging in New Mexico

All Employees: Mining and Logging in North Dakota

All Employees: Mining and Logging in Oklahoma

All Employees: Mining: Oil and Gas Extraction, Well Drilling, and Support Activities in Alaska

All Employees: Mining: Oil and Gas Extraction + Support Activities for Mining in California

All Employees: Mining: Oil and Gas Extraction + Support Activities for Mining in Texas All Employees: Mining: Oil and Gas Extraction + Support Activities for Oil and Gas Operations in Wyoming

\section{Additional Variables}

\begin{tabular}{|c|c|c|c|}
\hline & fred & id & Description \\
\hline 108 & $\begin{array}{l}\text { Sources: Board of Governors } \\
\text { of the Federal Reserve System } \\
\text { and Wu and Xia (2016) }\end{array}$ & Shadow Rate & Wu-Xia Shadow Federal Funds Rate \\
\hline 109 & Source: Chiaie et al. (2017) & Global Activity & The Global Factor \\
\hline
\end{tabular}
subtracted 
Factor 1

Factor 2

\begin{tabular}{lll}
\hline North_Carolina & 0.91 & -0.05 \\
Tennessee & 0.90 & -0.12 \\
Illinois & 0.90 & 0.08 \\
Fabricated_metal_product & 0.86 & 0.17 \\
Florida & 0.86 & -0.15 \\
Manufacturing & 0.85 & -0.08 \\
Texas & 0.85 & 0.21 \\
Electrical_equipment_appliance_component & 0.85 & 0.02 \\
Iowa & 0.81 & 0.10 \\
Business_equipment & 0.80 & 0.16 \\
Nonresidential_Investment & 0.77 & 0.03 \\
Oklahoma & 0.71 & 0.27 \\
New_York & 0.71 & 0.04 \\
Machinery & 0.71 & 0.31 \\
Computer_electronic & 0.66 & 0.02 \\
Consume_goods & 0.64 & -0.25 \\
South_Dakota & 0.63 & 0.03 \\
Real_Private_Consumption & 0.61 & -0.21 \\
Interest_Rate & 0.54 & -0.07 \\
Primary_metal & 0.54 & -0.02 \\
Real_Personal_Income & 0.53 & 0.04 \\
Residential_Investment & 0.51 & -0.33
\end{tabular}

Table 3. Examples of data series with correlation above 0.5 with factor 1 .

Factor 1

Factor 2

\begin{tabular}{lll}
\hline Empl Texas: Oil & 0.21 & 0.93 \\
Empl Oklahoma: Oil & 0.25 & 0.86 \\
Empl New Mexico: Oil & 0.35 & 0.81 \\
Empl Wyoming: Oil & 0.18 & 0.80 \\
Empl North Dakota: Oil & 0.04 & 0.79 \\
Oil Investment & 0.25 & 0.75 \\
Empl California: Oil & 0.12 & 0.71 \\
Empl Louisiana: Oil & 0.17 & 0.66 \\
Mining & 0.28 & 0.64 \\
Empl Alaska: Oil & 0.03 & 0.58 \\
Empl Montana: Oil & 0.28 & 0.57 \\
Energy Materials & 0.23 & 0.52
\end{tabular}

Table 4. Data series with correlation above 0.5 with factor 2 . 


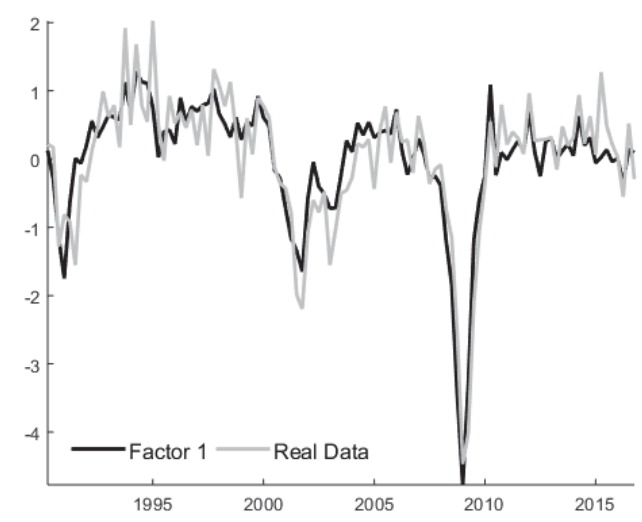

(a) Illinois

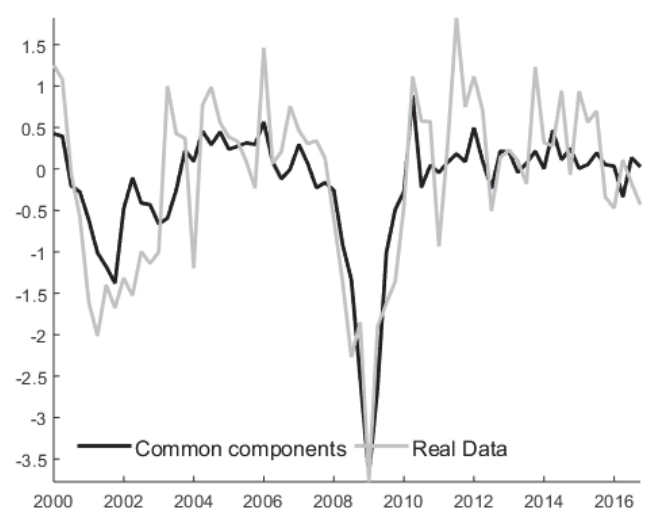

(c) Investment

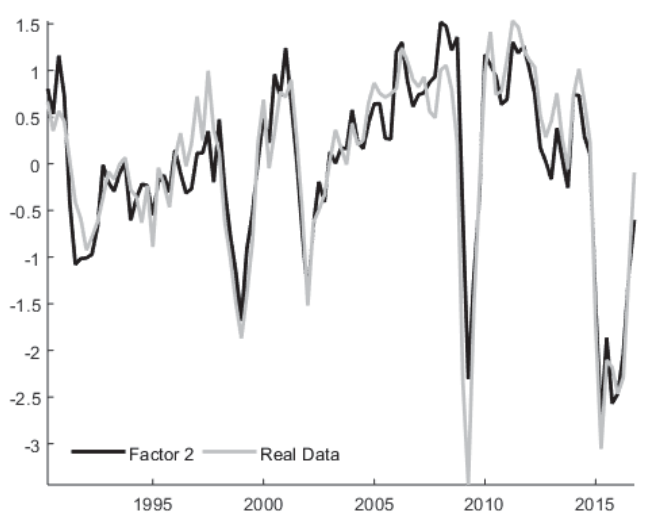

(b) Mining in Texas

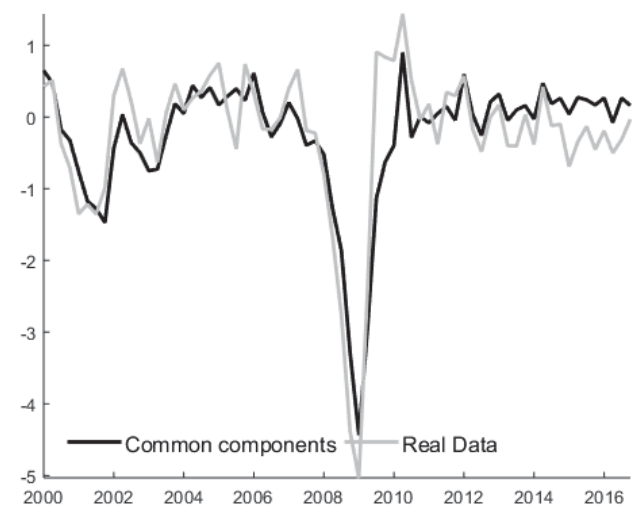

(d) Manufacturing

Figure 11. Graphs of the estimated factors compared to data series. Frame (a) and (b) plots factor 1 and factor 2 respectively compared to real data; frame (c) and (d) plot the estimated values of macroeconomic series from Equation 1 compared to real data 


\section{Appendix B Estimation of a FAVAR model}

\section{B.1 Two Step Estimator Approach}

In Section 3 of the main paper we described the benchmark model. Here we provide a more detailed overview of how the model is estimated. We start by repeating the main system equations. Recall the two main two equations in our model are the factor equation (9) and the VAR equation (10):

$$
\begin{gathered}
X_{t}=\Lambda F_{t}+e_{t} \\
F_{t}=b_{1 t} F_{t-1}+\ldots+b_{p t} F_{t-p}+A_{t}^{-1} \Sigma_{t} \varepsilon_{t} .
\end{gathered}
$$

where the common factors $F_{t}$ contain both the unobservables latent factors, $f_{t}$ and the observables factors $y_{t}: F_{t}=\left(\begin{array}{c}y_{t} \\ f_{t}\end{array}\right)$.

The time-varying parameters and covariances of the model follow random walk processes given by (11):

$$
\begin{aligned}
B_{t} & =B_{t-1}+\eta_{t}^{B} \\
\alpha_{t} & =\alpha_{t-1}+\eta_{t}^{\alpha} \\
\log \sigma_{t} & =\log \sigma_{t-1}+\eta_{t}^{\sigma}
\end{aligned}
$$

where $B_{t}$ is the vector of all R.H.S. coefficients in (10), $\alpha_{t}$ is the vector of non-zero and no-none elements of the matrix $A_{t}$, and $\sigma_{t}$ is the vector containing the diagonal elements of $\Sigma_{t}$.

The innovations in the model are assumed to be normally distributed with the following assumptions on the variance covariance matrix:

$$
\operatorname{Var}\left(\left[\begin{array}{c}
e_{t} \\
\varepsilon_{t} \\
\eta_{t}^{B} \\
\eta_{t}^{\alpha} \\
\eta_{t}^{\sigma}
\end{array}\right]\right)=\left[\begin{array}{ccccc}
R & 0 & 0 & 0 & 0 \\
0 & I_{m} & 0 & 0 & 0 \\
0 & 0 & Q & 0 & 0 \\
0 & 0 & 0 & S & 0 \\
0 & 0 & 0 & 0 & W
\end{array}\right]
$$

The system is then estimated in two steps. In the first step we estimate the unobservable factors $f_{t}$, while in the second step we estimate model parameters, conditional on the factors. Below we describe each step in greater detail.

\section{B.1.1 Step1: Latent Factor Estimation}

We start by extracting $k$ principal components from $X_{t}$ and obtain estimates of the latent factors, $f_{t}$. In doing so, we do not impose a constraint whereby the observable factors $y_{t}$ are the common component. So if the variables in $y_{t}$ are common components, they 
should be captured by the principal components. To remove $y_{t}$ from the space covered by the principal components, we follow the approach advocated by Boivin and Giannoni (2007), and impose the constraint that observable variables are two of the factors in the first-step estimation. We denote the initial estimate of $f_{t}$ by $f_{t}^{0}$, and iterate through the following steps:

1. Regress $X_{t}$ on $f_{t}^{0}$ and the observed factors $y_{t}$ and obtain $\hat{\lambda}_{y}^{0}$

2. Compute $\hat{X}_{t}^{0}=X_{t}-\hat{\lambda}_{y}^{0} y_{t}$

3. Estimate $f_{t}^{1}$ as the $k$ principal components of $\hat{X}_{t}^{0}$

4. Repeat the procedure multiple times

This procedure guarantees that the estimated latent factors will recover dimensions of the common dynamics not already captured by the observable variables, $y_{t}$. Given the factors, $F_{t}$, we can estimate parameters in (9) and (10) independently of each other.

\section{B.1.2 Step 2: The Gibbs Sampling Approach - Estimation of model param- eters}

\section{Estimation of parameters in Factor Equation}

Since the covariance matrix of the error terms in (9) is diagonal, we can estimate all the parameters equation-by-equation. The parameters are sampled using standard arguments for linear regression models (see Koop (2003)).

Block 1: $\Lambda^{\text {post }}, \operatorname{Var}(\Lambda)^{\text {post }} \mid X, F, \Lambda^{\text {prior }}, \operatorname{Var}(\Lambda)^{\text {prior }}, R$

Conditional on the priors specified in B.2, the posterior draws of factor loadings of equation $i, \lambda_{i}$, and its variance $\operatorname{Var}\left(\lambda_{i}\right)$ are:

$$
\begin{gathered}
\lambda_{i}^{\text {post }}=\left(\operatorname{Var}\left(\lambda_{i}\right)^{\text {post }}\right)^{-1}\left(\left(\operatorname{Var}\left(\lambda_{i}\right)^{\text {prior }}\right)^{-1} \lambda_{i}^{\text {prior }}+R_{i, i}^{-1} F^{\prime} X_{i}\right) \\
\operatorname{Var}\left(\lambda_{i}\right)^{\text {post }}=\left(\left(\operatorname{Var}\left(\lambda_{i}\right)^{\text {prior }}\right)^{-1}+R_{i, i}^{-1} X_{i}^{\prime} X_{i}\right)^{-1}
\end{gathered}
$$

for $i=1, \ldots, N$.

Block 2: $R \mid X, F, \Lambda^{\text {post }}, \nu_{0}, \delta_{0}$

We draw the conditional posterior for $R$ from inverse Gamma distribution:

$$
\begin{array}{r}
R_{i, i} \mid \ldots \sim \operatorname{IG}\left(\frac{\nu_{1}}{2}, \frac{\delta_{1}^{(i)}}{2}\right) \\
\nu_{1}=\nu_{0}+T \text { and } \delta_{1}^{(i)}=\delta_{0}+\left(X_{i}-\lambda_{i}^{\text {post }} F\right)^{2}
\end{array}
$$




\section{Estimation of parameters in TVP VAR}

The TVP VAR model in (10) is estimated by simulating the distribution of the parameters of interest, given the data and the priors specified in B.2. Following Primiceri (2005), Gibbs sampling is carried out in four steps, drawing in turn on time-varying coefficients $\left(B_{t}\right)$, simultaneous relations $\left(A_{t}\right)$, volatilities $\left(\Sigma_{t}\right)$, and hyper parameters $(Q, W, S)$, conditional on the observed data, estimated factors and the rest of the parameters. For further details we refer to Primiceri (2005). ${ }^{19}$

\section{B.2 Prior specification}

We use an informative prior based on the training sample (from 1990:Q2 to 1999:Q4). Following Primiceri (2005) the mean and the variance of $B_{0}$ and $\alpha_{o}$ are chosen to be OLS point estimates and four times their variance of their estimates on initial subsample. For $\log \sigma_{0}$, the mean of the distribution is chosen to be the logarithm of the OLS point estimates of the standard errors of the same time invariant VAR, while the variance covariance matrix is arbitrarily assumed to be identity matrix. Similarly, the mean and the variance of factor loadings from (9), $\Lambda$, are chosen to be OLS point estimates and four times their variance of their estimates from the training sample.

$$
\begin{gathered}
B_{0} \sim \mathcal{N}\left(\hat{B}_{O L S}, 4 \operatorname{Var}\left(\hat{B}_{O L S}\right)\right) \\
\alpha_{0} \sim \mathcal{N}\left(\hat{\alpha}_{O L S}, 4 \operatorname{Var}\left(\hat{\alpha}_{O L S}\right)\right) \\
\log \sigma_{0} \sim \mathcal{N}\left(\log \hat{\sigma}_{O L S}, I_{n}\right) \\
\Lambda \sim \mathcal{N}\left(\hat{\Lambda}_{O L S}, 4 \operatorname{Var}\left(\hat{\Lambda}_{O L S}\right)\right)
\end{gathered}
$$

We use prior from Inverted Gamma distribution for variance-covariance matrix $R$.

$$
R \sim I G\left(\frac{\nu_{1}}{2}, \frac{\delta_{1}}{2}\right)
$$

where $\nu_{1}=\nu_{0}+T$ and $\delta_{1}=\delta_{0}+\left(X-\hat{\Lambda}^{\text {post }} F\right)$. The priors for the remaining hyperparameters are all from the Inverse-Wishart distribution:

$$
\begin{gathered}
Q \sim I W\left(k_{Q}^{2}\left(1+\operatorname{dim}_{B}\right) \operatorname{Var}\left(\hat{B}_{O L S}\right), 1+\operatorname{dim}_{B}\right) \\
W \sim I W\left(k_{W}^{2}\left(1+\operatorname{dim}_{W}\right) I_{p}, 1+\operatorname{dim}_{W}\right) \\
S_{i} \sim I W\left(k_{S}^{2}\left(1+\operatorname{dim}_{S_{i}}\right) \operatorname{Var}\left(\hat{A}_{i, O L S}\right), 1+\operatorname{dim}_{S_{i}}\right)
\end{gathered}
$$

\footnotetext{
${ }^{19}$ However, we modify the algorithm of Primiceri (2005) to reflect the correction to the ordering of steps detailed in Del Negro and Primiceri (2015).
} 
Following Korobilis (2013) the degrees of freedom are set to $\operatorname{dim}_{B}=m \times m \times p$, $\operatorname{dim}_{W}=m$ and $\operatorname{dim}_{S_{i}}=1, . ., m-1$, and are larger than the dimension of the corresponding matrices, required to achieve a proper Inverse-Wishart distribution. The benchmark results in this paper are obtained with $\nu_{0}=10, \delta_{0}=10$.

As it was noted by Primiceri (2005), the values for $k_{Q}, k_{S}$, and $k_{W}$, do not parameterize time variation, but just define our prior beliefs about the amount of time variation in parameters. The setting of $k_{Q}$ defines our beliefs about the amount of time variation in time-varying coefficients in Equation 5, while setting of $k_{W}$ and $k_{S}$ defines beliefs about the amount of time variation in stochastic volatility part of the same equation. It is worth noting that there is a trade-off between setting, for example, $k_{Q}$ very high, but $k_{W}$ and $k_{S}$ very low: this will force most of the models fit to be picked up though time-varying coefficients, $B_{t}$. In the reverse case, setting $k_{S}$ and $k_{W}$ very high, but $k_{Q}$ very low, the variation in $B_{t}$ will almost be removed.

The time-varying parameters and stochastic volatilities are introduced in our FAVAR models to allow for variation due to: 1) changes in the responses of domestic factors to global shocks and 2) changes in volatility of global variables. To allow for 1) we set $k_{Q}=0.1$, which is a reasonable amount of variation in VAR coefficient in order to uncover any potential changes due to shale oil boom. However, the results obtained with lower $k_{Q}$ are very similar to the baseline model. To allow for 2 ) we set $k_{W}=0.1$, taking into account the fact that the volatility of oil price and other international business cycle shocks has changed a great deal during last decade (see e.g. Baumeister and Peersman (2013a), Baumeister and Peersman (2013b)). Similar to Primiceri (2005), we set $k_{S}=0.1$. Estimating the model with lower values of $k_{S}$ and $k_{W}$ we obtain a similar results to the benchmark case, however, if we set $k_{W}$ to 0.01 and lower, we seem to miss the high volatility of the oil price during the last downturn, as has been well documented in the literature. 


\section{Appendix C Convergence of the Markov Chain Monte Carlo Algorithm}

We perform 30,000 iterations of the Gibbs sampler. The first 15,000 draws are discarded and only every tenth of the remaining iterations is used for inference. The produced results are not sensitive to the number of discarded draws or the number of passes used for inferences. Following Primiceri (2005) and Baumeister and Peersman (2013b), we ascertain that our Markov chain has converged based on the inefficiency factors (IFs) for the posterior estimates of the parameters, that is the inverse of the relative numerical efficiency (RNE) measure proposed by Geweke (1992). Here the estimates are performed by employing a 4 percent tapered window used in computation of the RNE. As was noticed by Primiceri (2005), values of the IFs below or around 20 are regarded as satisfactory. As can be seen from the summary of the distribution of the inefficiency factors for different set of parameters, reported in Table 5, the sample seems to have converged. That is, all mean IF values are below 13 and 90 percent of the IFs are below 18., indicating modest autocorrelation for all elements.

Median Mean Min Max 10-th Percentile 90-th Percentile

\begin{tabular}{lllllll}
\hline$B$ & 3.36 & 2.96 & 0.87 & 15.00 & 1.80 & 5.47 \\
$\Lambda$ & 0.97 & 0.96 & 0.47 & 1.81 & 0.68 & 1.26 \\
$\Sigma$ & 7.22 & 7.81 & 0.82 & 14.41 & 1.97 & 11.12 \\
$A$ & 5.24 & 4.28 & 1.36 & 18.43 & 2.26 & 9.88 \\
$V$ & 9.83 & 9.54 & 2.08 & 21.80 & 5.52 & 14.64 \\
$R$ & 0.98 & 0.96 & 0.60 & 1.51 & 0.74 & 1.25
\end{tabular}

Table 5. Summery of the distribution of the IFs for different sets of parameters, where $V$ is the set of hyperparameters $\{Q, S, W\}$ 


\section{Appendix D Impulse Responses: Effect of oil price shocks on employment in the U.S. states}

\section{D.1 Oil Related Employment}

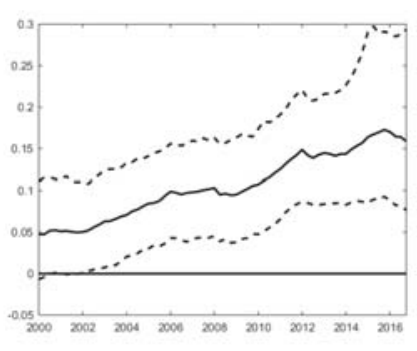

(1) Oil and Gas Extraction in Alaska

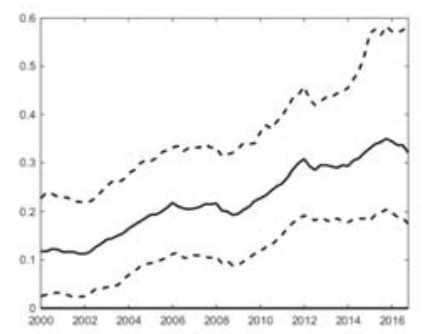

(4) Mining and Logging in Oklahoma

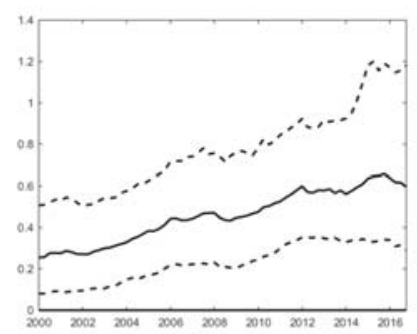

(7) Mining and Logging in North Dakota

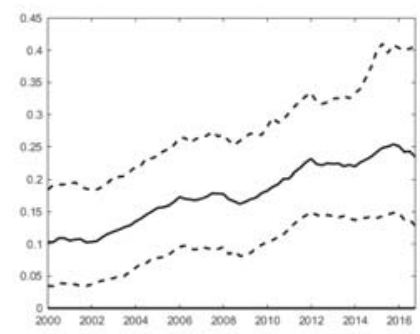

(2) Oil and Gas Extraction in California

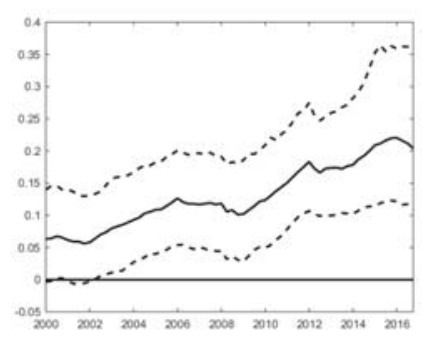

(5) Mining and Logging in Montana

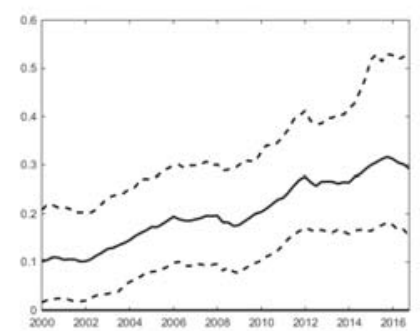

(8) Oil and Gas Extraction in Texas

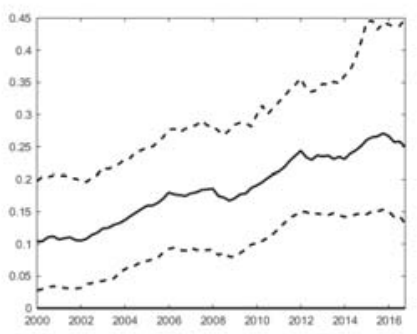

(3) Oil and Gas Extraction in Louisiana

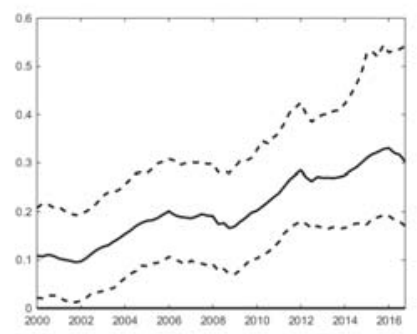

(6) Mining and Logging in New Mexico

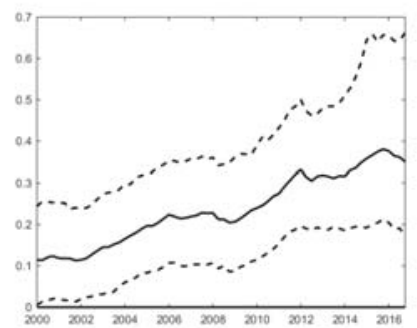

(9) Oil and Gas Extraction in Wyoming

Figure 12. Impulse responses for Oil Related Employment after 4 quarters with 16-th and 84-th percentiles 


\section{D.2 Nonfarm (non-oil) Employment}

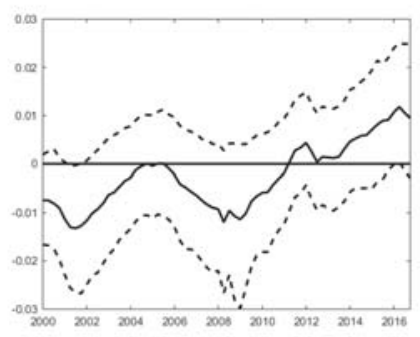

(1) Alabama

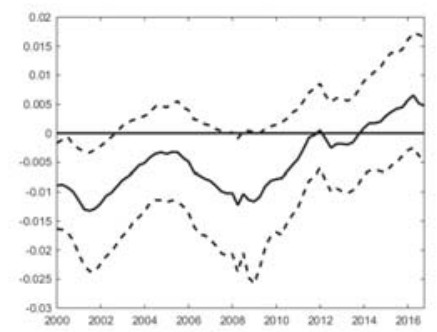

(4) Arkansas

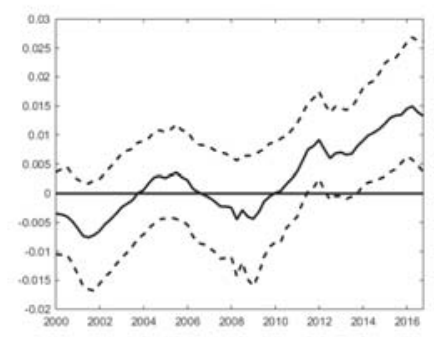

(7) Connecticut

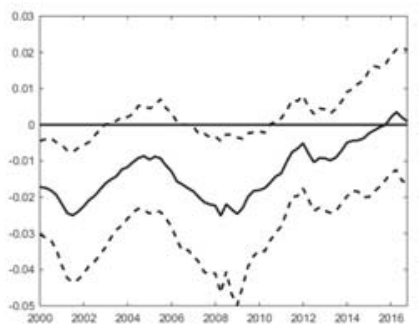

(10) Florida

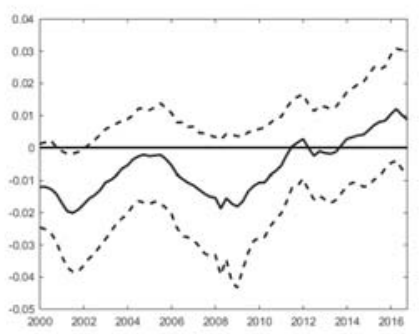

(13) Idaho

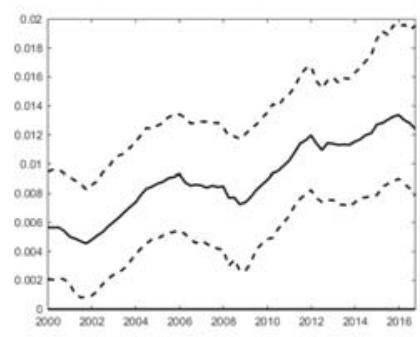

(2) Alaska

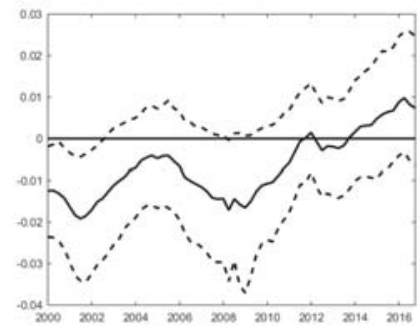

(5) California

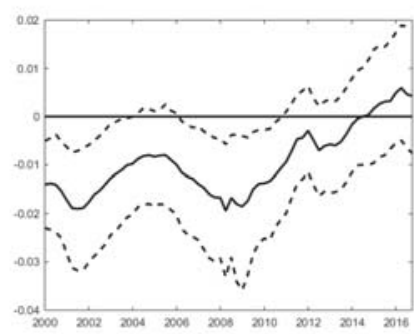

(8) Delaware

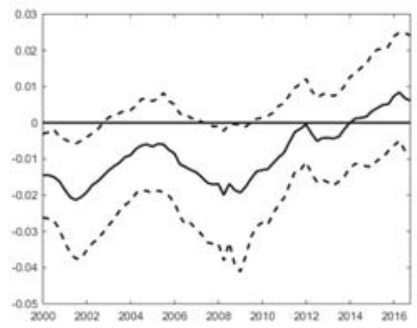

(11) Georgia

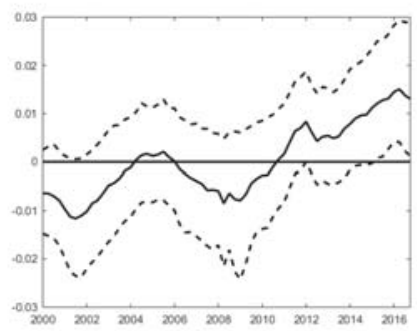

(14) Illinois

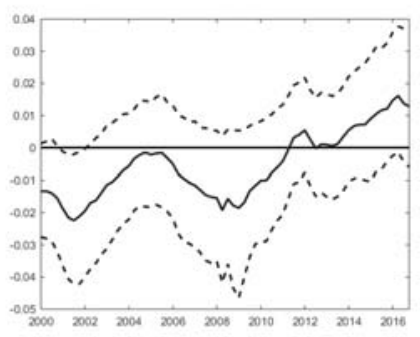

(3) Arizona

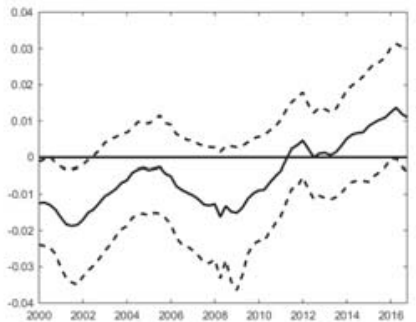

(6) Colorado

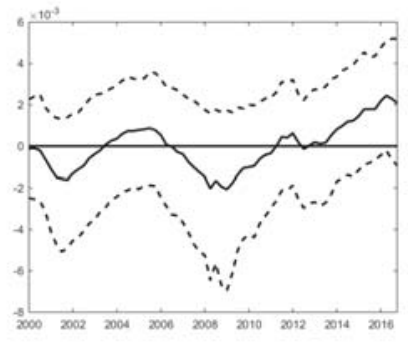

(9) District Columbia

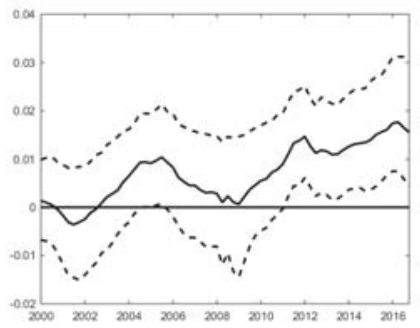

(12) Hawaii

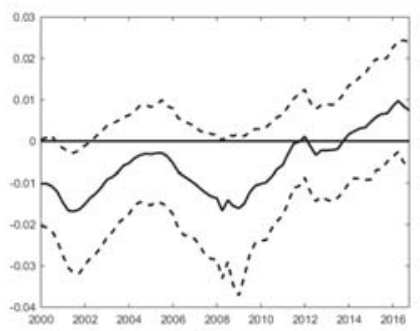

(15) Indiana 


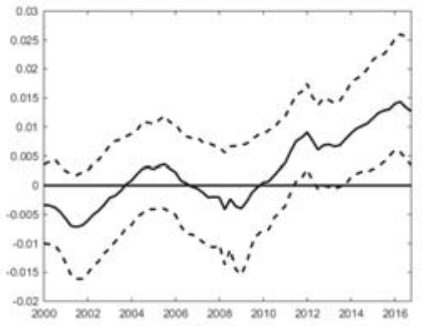

(16) Iowa

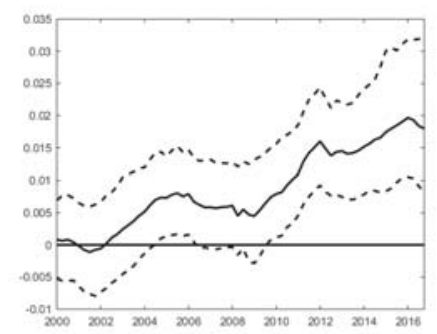

(19) Louisiana

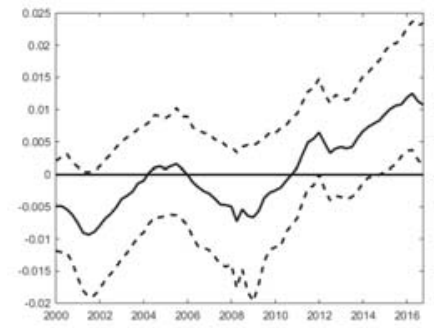

(22) Massachusetts

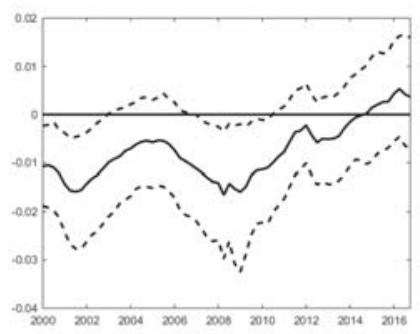

(25) Mississippi

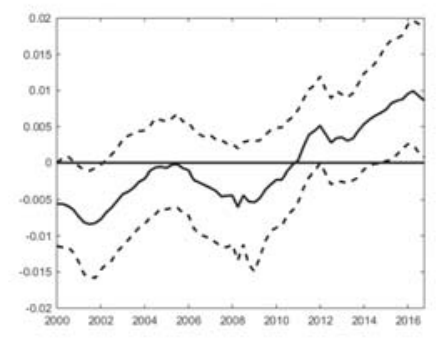

(28) Nebraska

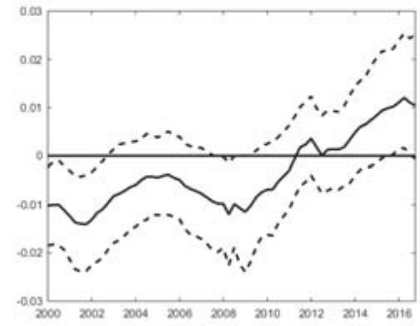

(17) Kansas

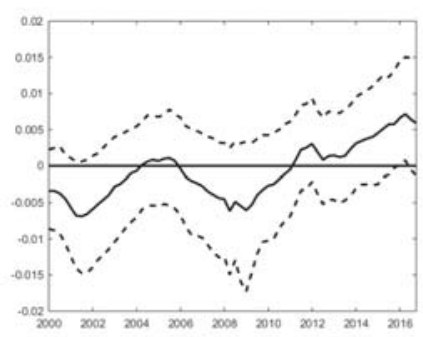

(20) Maine

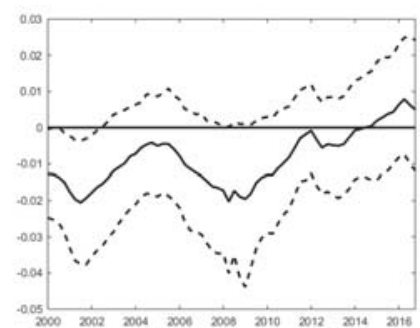

(23) Michigan

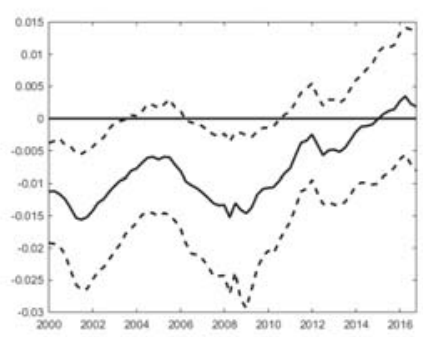

(26) Missouri

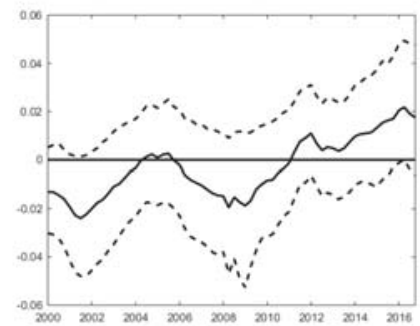

(29) Nevada

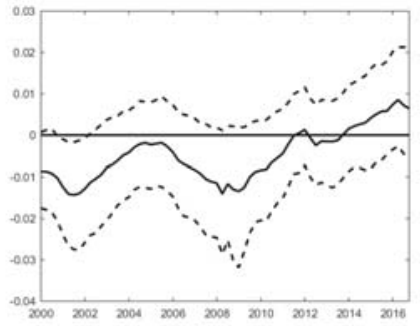

(18) Kentucky

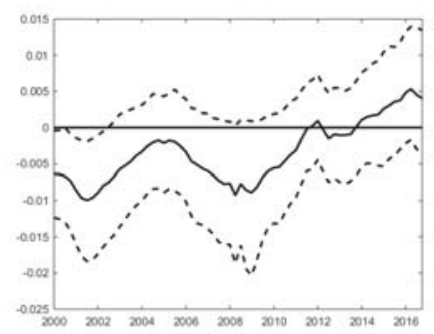

(21) Maryland

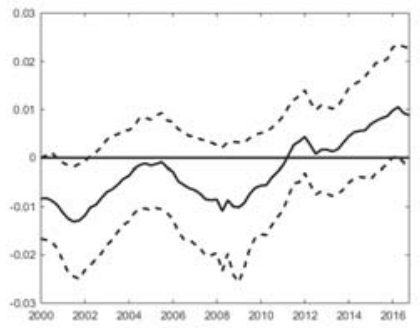

(24) Minnesota

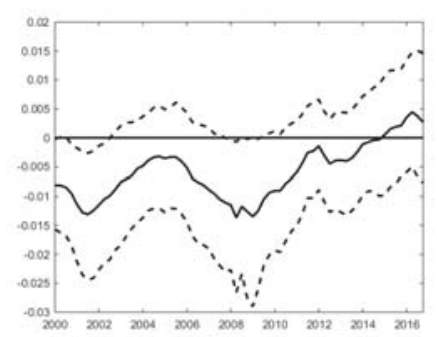

(27) Montana

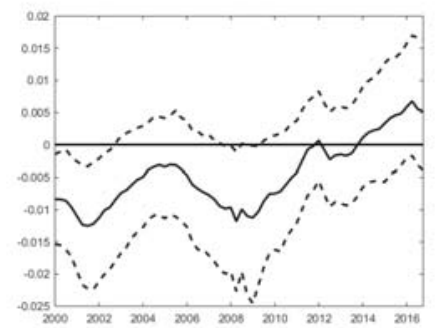

(30) New Hampshire 


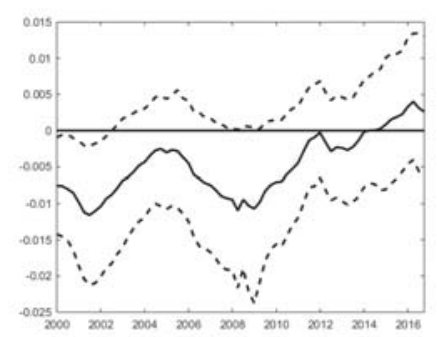

(31) New Jersey

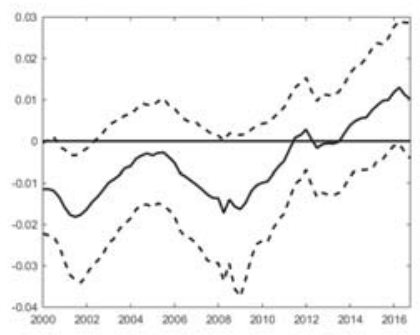

(34) North Carolina

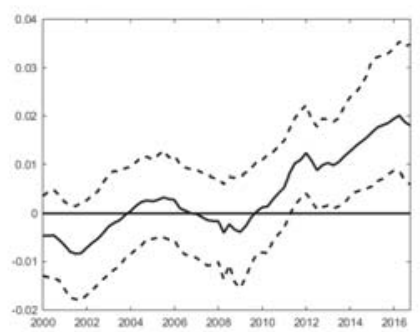

(37) Oklahoma

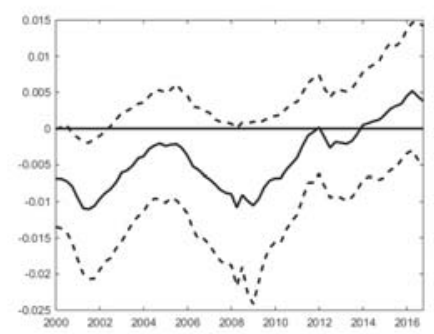

(40) Rhode Island

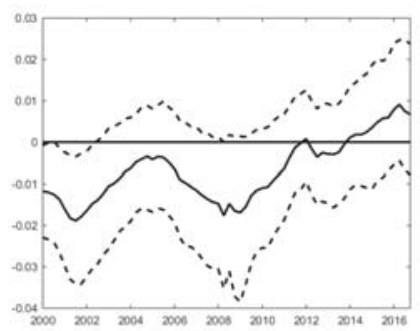

(43) Tennessee

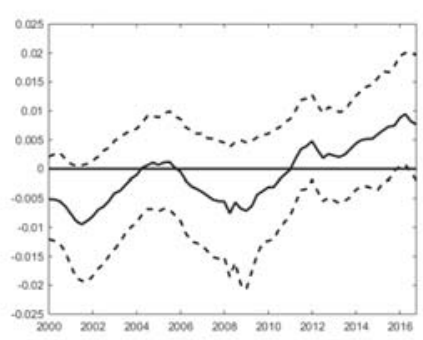

(32) New Mexico

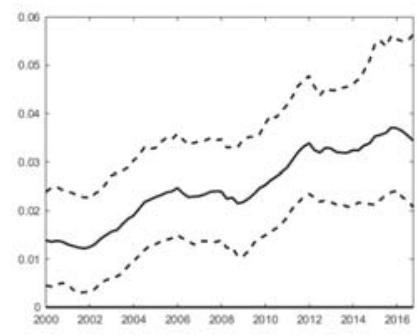

(35) North Dakota

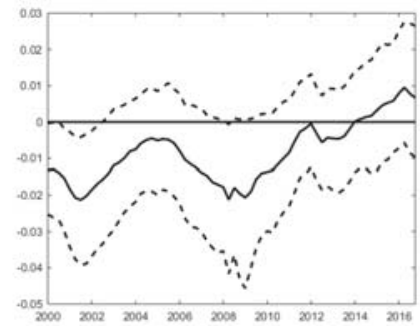

(38) Oregon

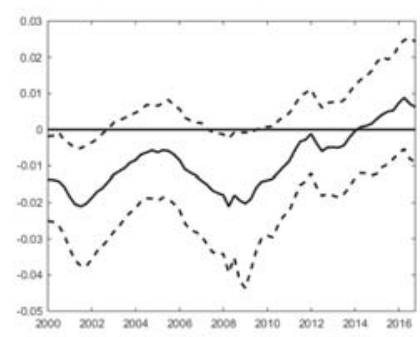

(41) South Carolina

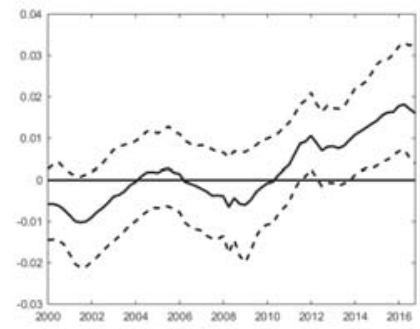

(44) Texas

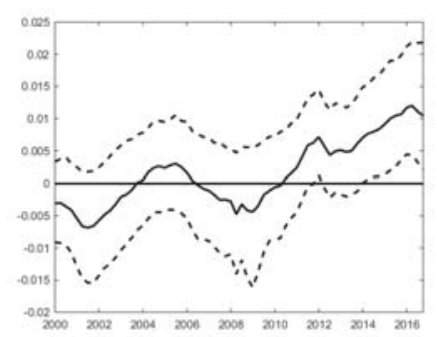

(33) New York

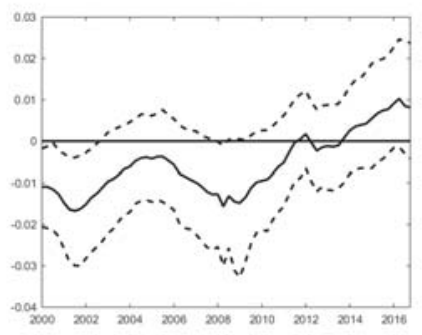

(36) Ohio

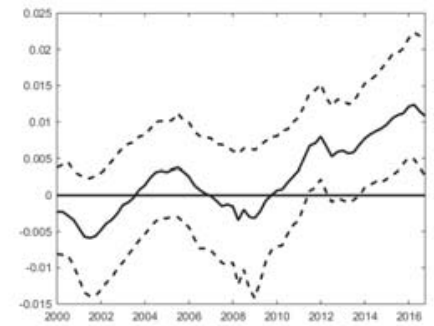

(39) Pennsylvania

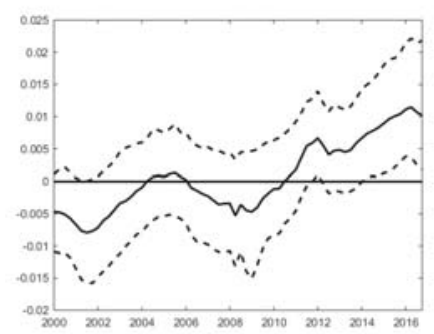

(42) South Dakota

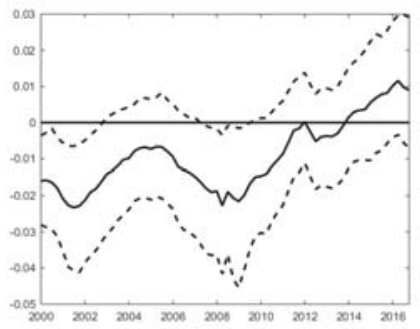

(45) Utah

Continued on next page 


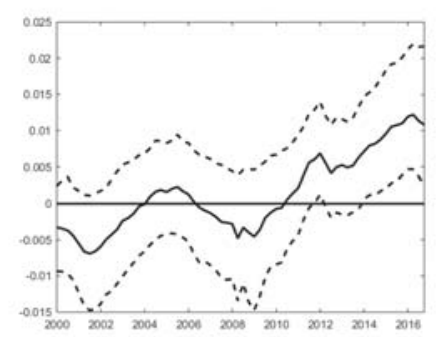

(46) Vermont

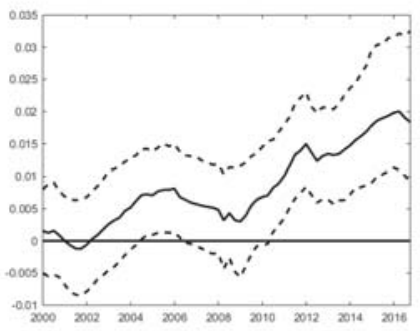

(49) West Virginia

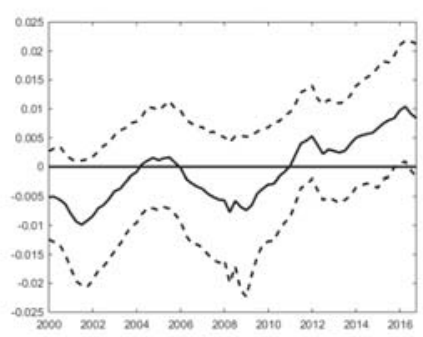

(47) Virginia

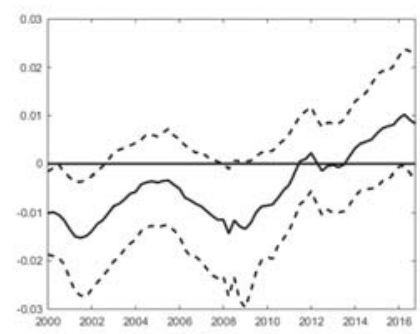

(50) Wisconsin

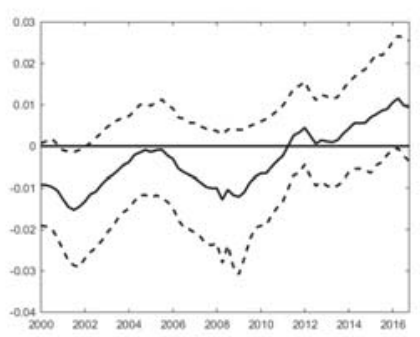

(48) Washington

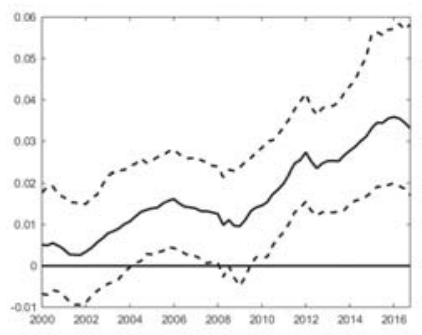

(51) Wyoming

Figure 13. Impulse responses for Nonfarm Employment after 4 quarters with 16-th and 84-th percentiles 


\section{Appendix E Split Sample}

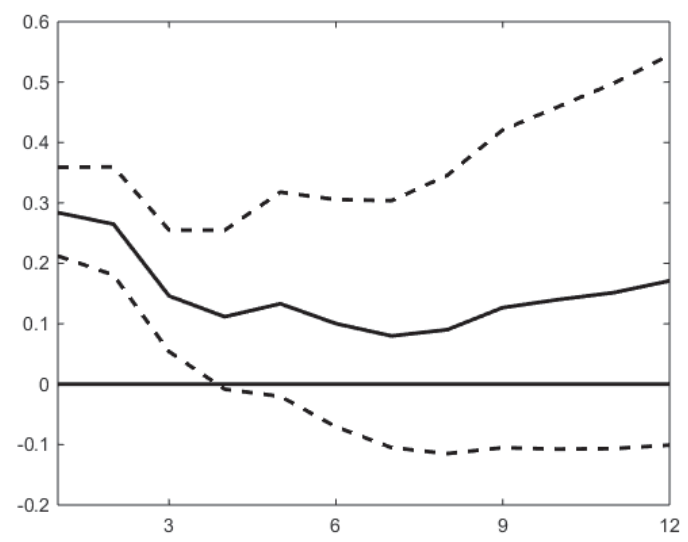

(a) S\&P500

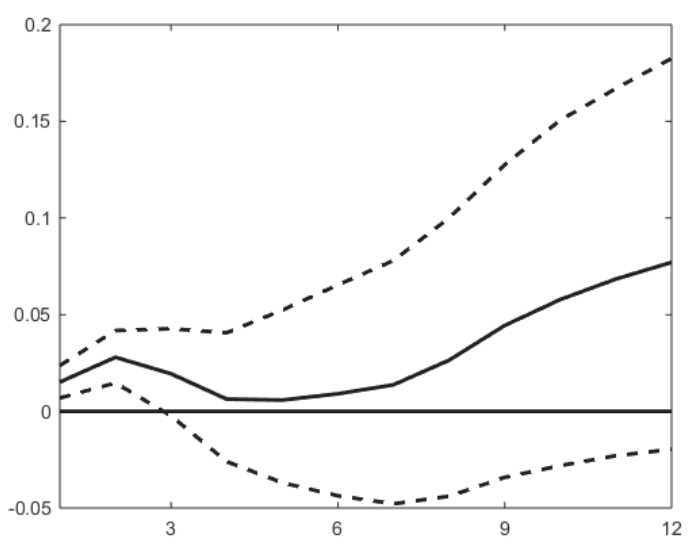

(c) Manufacturing

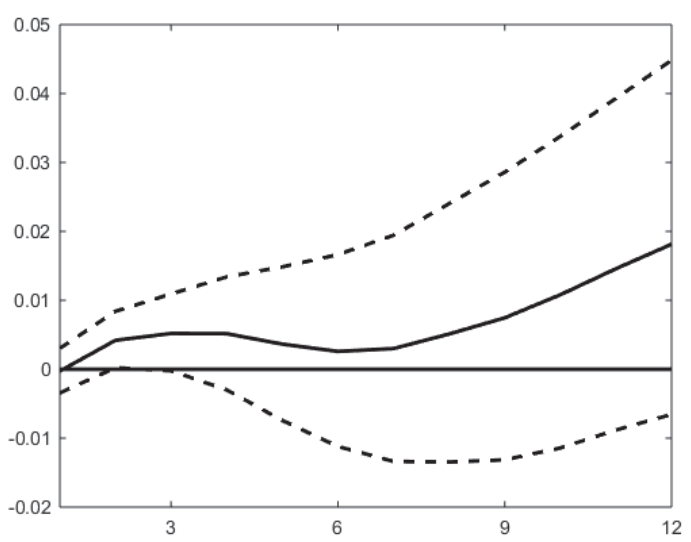

(e) Nebraska

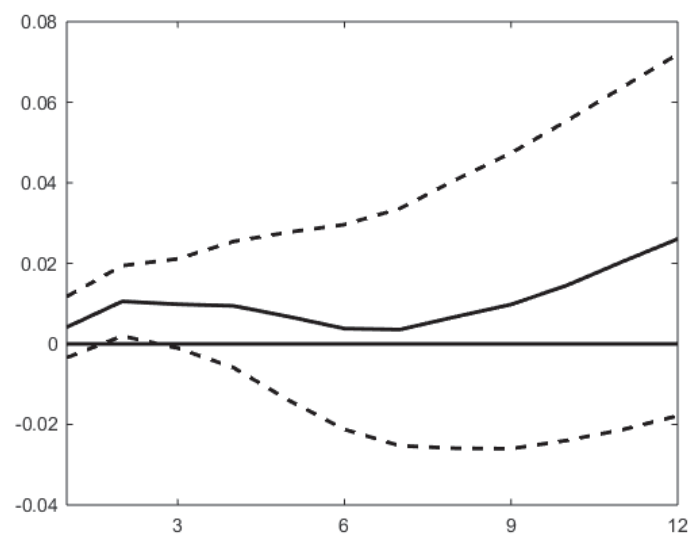

(b) Income

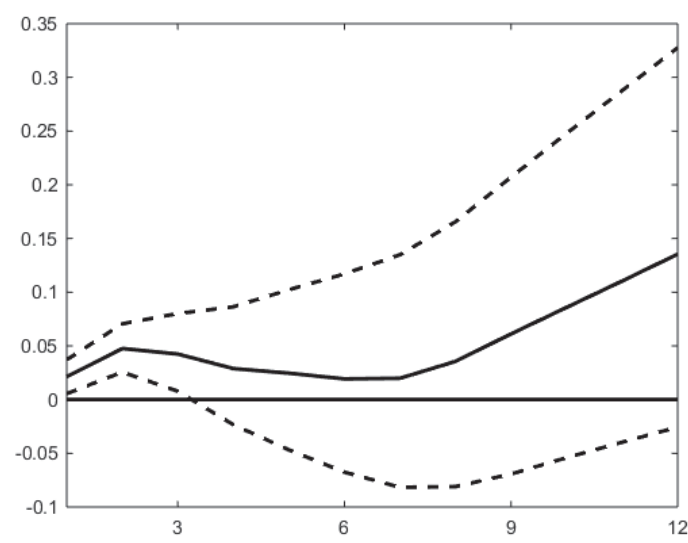

(d) Business equipment

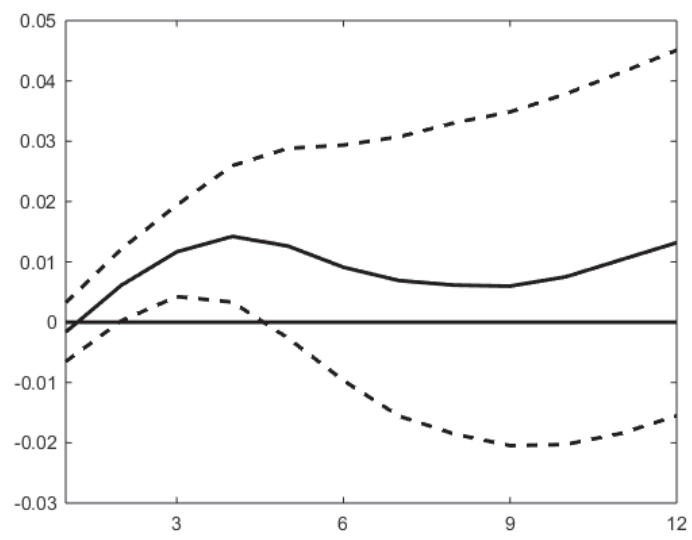

(f) Wyoming: Non-oil employment

Figure 14. Estimation of benchmark model with constant coefficients. Differences between responses in sub-periods 1990Q1:2006:Q4 and 2000Q1:2016Q4 with 16-th and 84-th percentiles. 


\section{S\&P500}

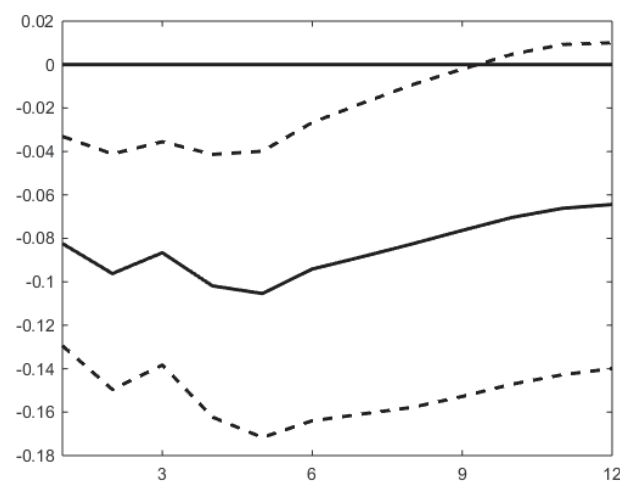

(a) Pre Shale Period

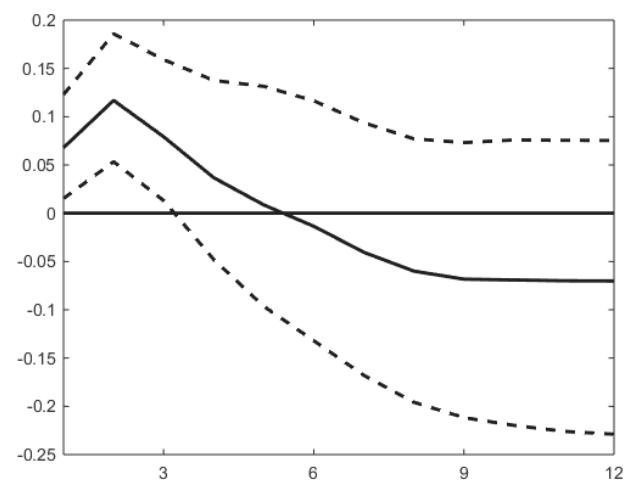

(b) Shale Boom Period

Manufacturing

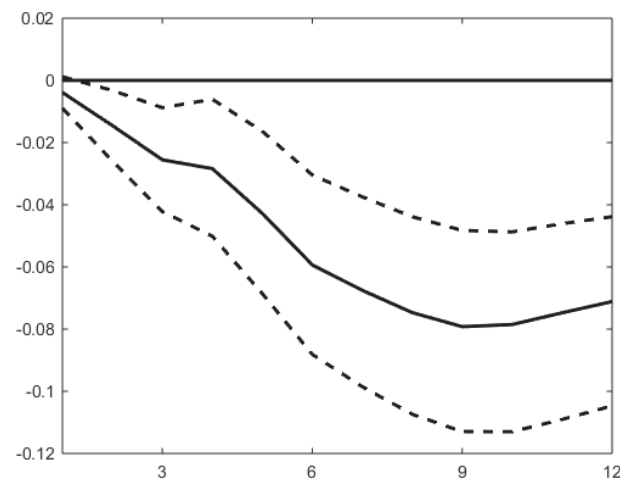

(c) Pre Shale Period

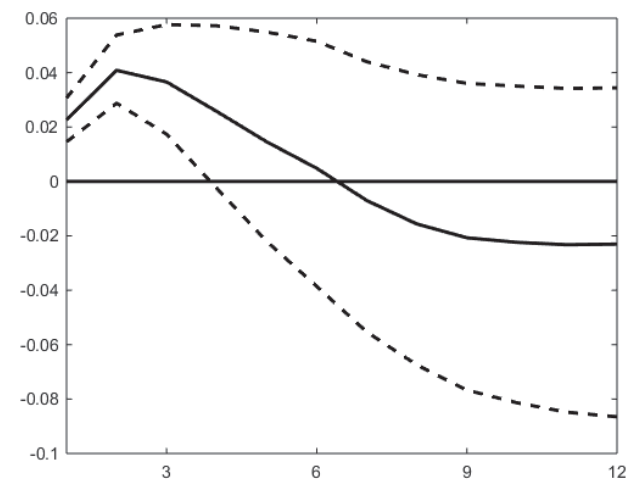

(d) Shale Boom Period

Figure 15. The effect of an oil price shock on Manufacturing: Posterior median of impulse responses with 16-th and 84-th percentiles; Left column: estimated over subsample before the Shale Boom (1974:Q12001:Q4). Right column: estimated over subsample during the Shale Boom (2002:Q1-2018:Q2) 


\section{Appendix F Robustness to choice of variables}

\section{F.1 Robustness to the choice of global activity variable}

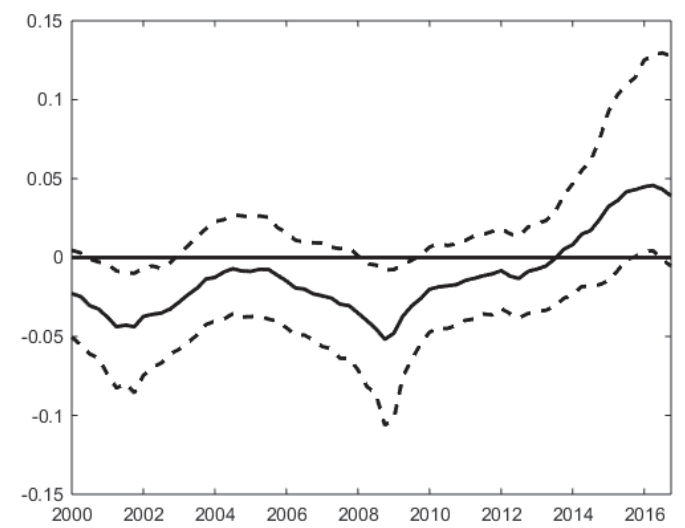

(a) Investment

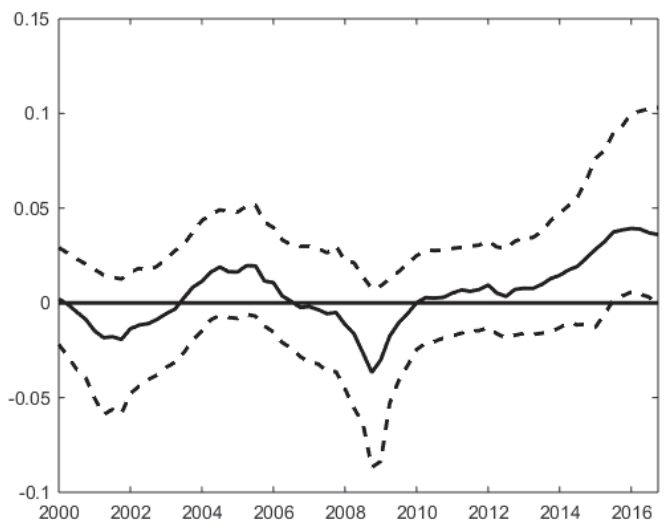

(c) Manufacturing

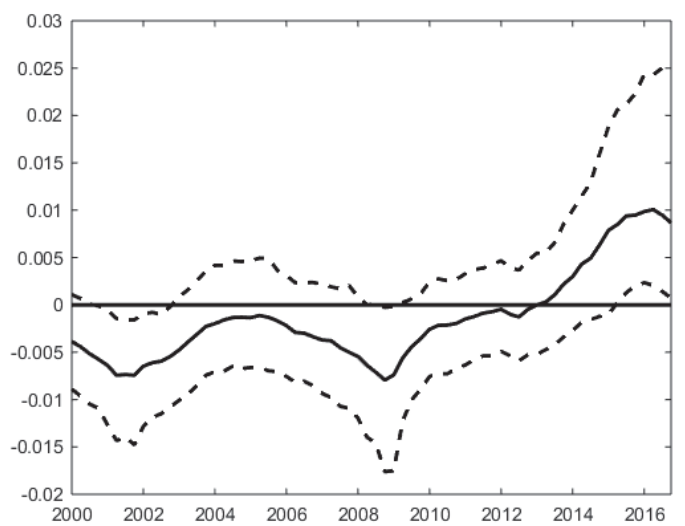

(e) Nebraska

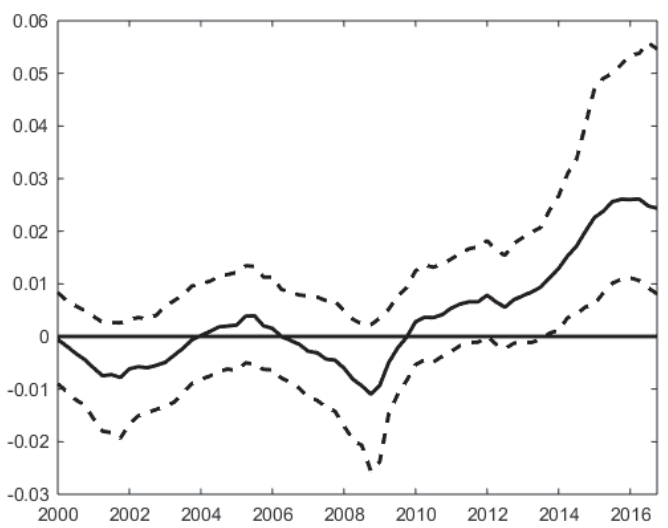

(b) Income

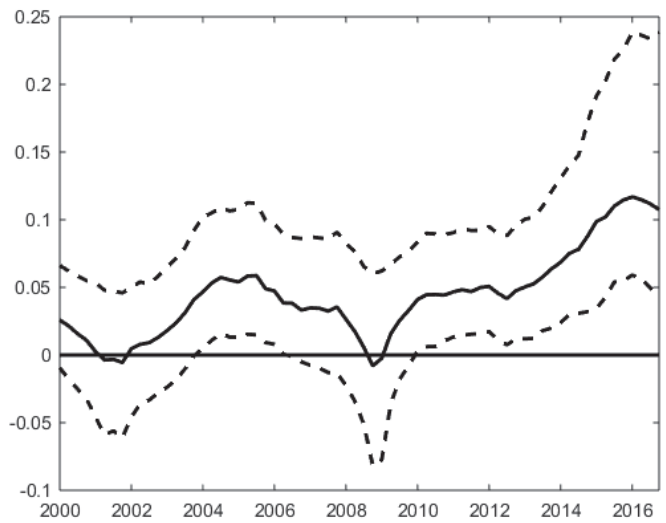

(d) Business equipment

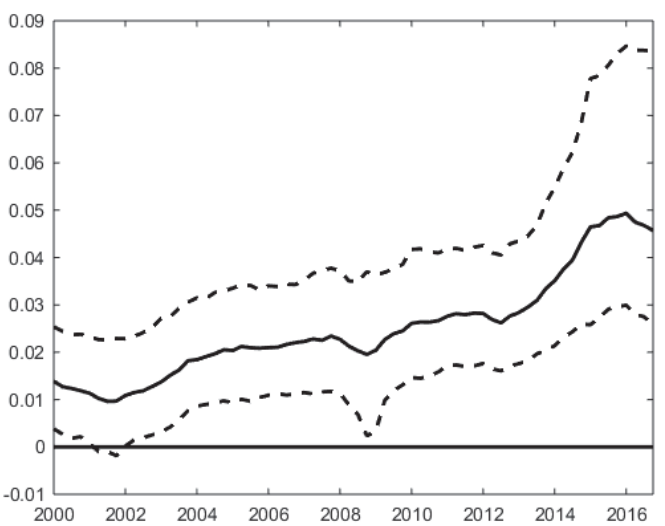

(f) Wyoming: Non-oil employment

Figure 16. The effect of an oil price shock: Impulse responses for selected indicators of the U.S. economy after 4 quarters with 16-th and 84-th percentiles from a model with alternative dataset, using a different global variable (see the main text for details). 


\section{F.2 Robustness to Manufacturing series}

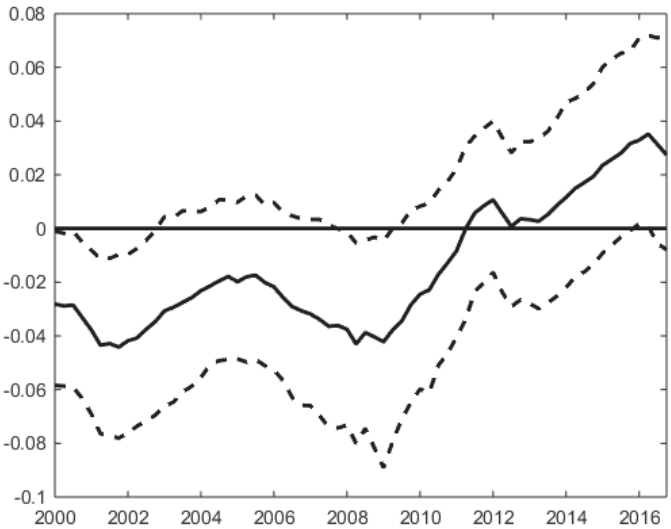

(a) Investment

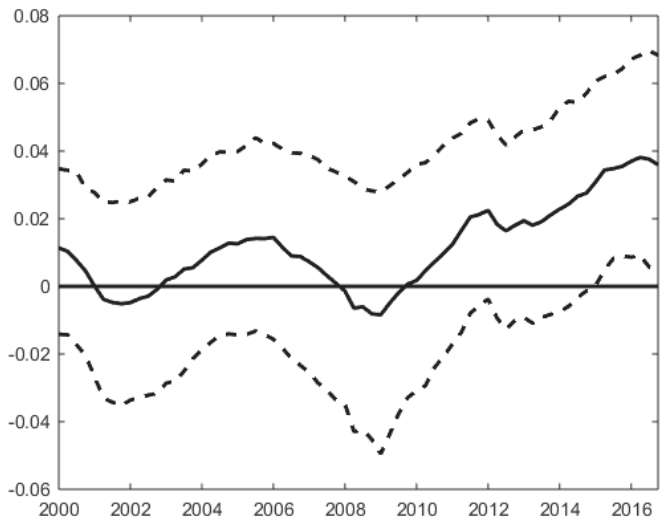

(c) Manufacturing

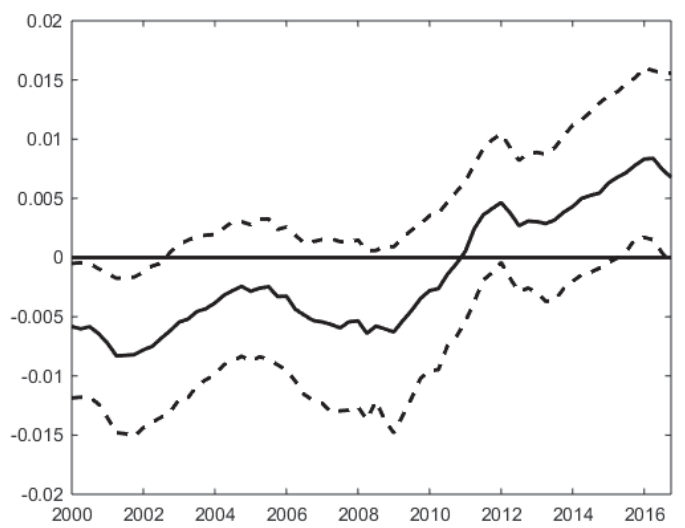

(e) Nebraska

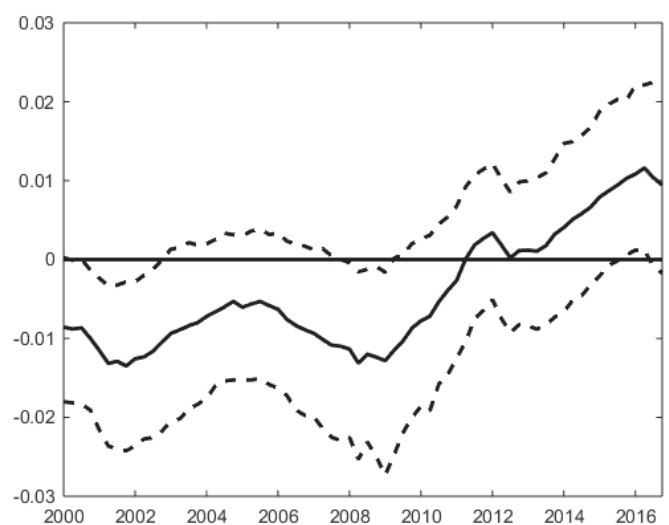

(b) Income

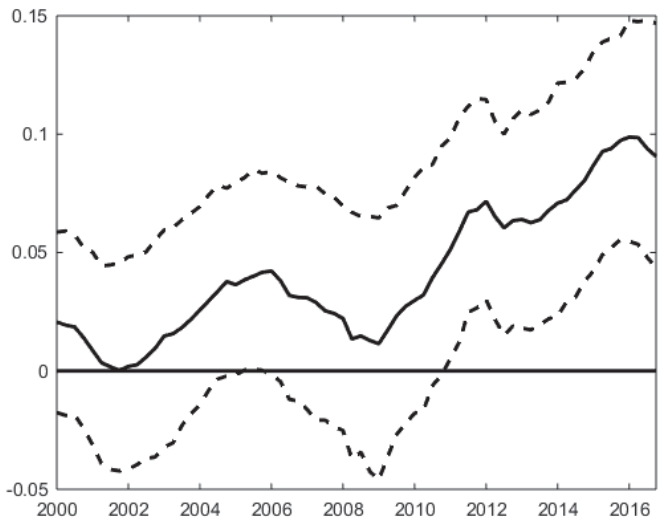

(d) Business equipment

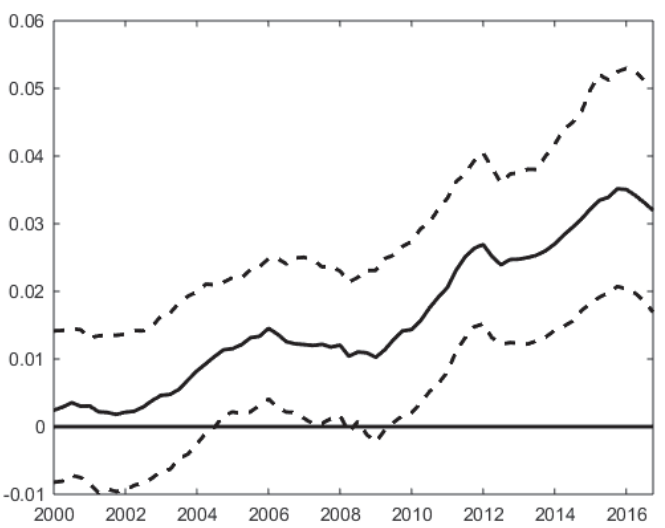

(f) Wyoming: Non-oil employment

Figure 17. The effect of an oil price shock: Impulse responses for selected indicators of the U.S. economy after 4 quarters with 16-th and 84-th percentiles from a model with an alternative dataset that excludes manufacturing sub-indexes (see the main text for details). 


\section{F.3 Robustness to the shadow rate}

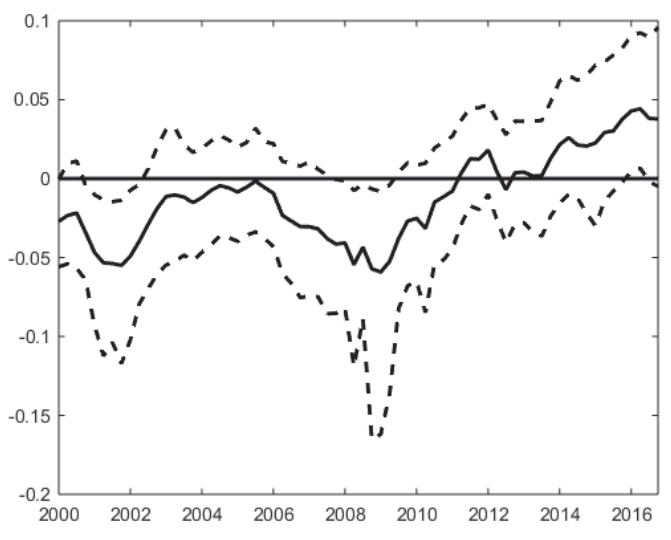

(a) Investment

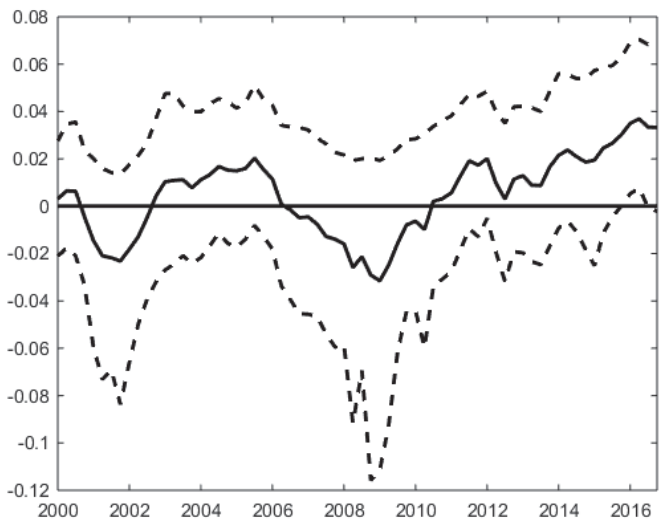

(c) Manufacturing

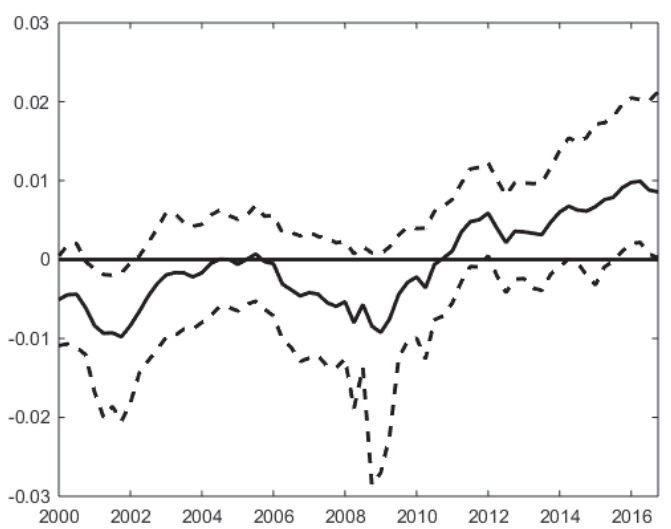

(e) Nebraska

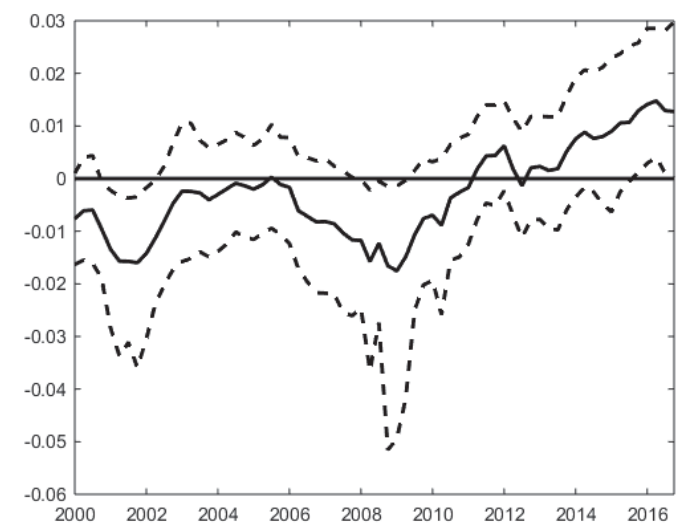

(b) Income

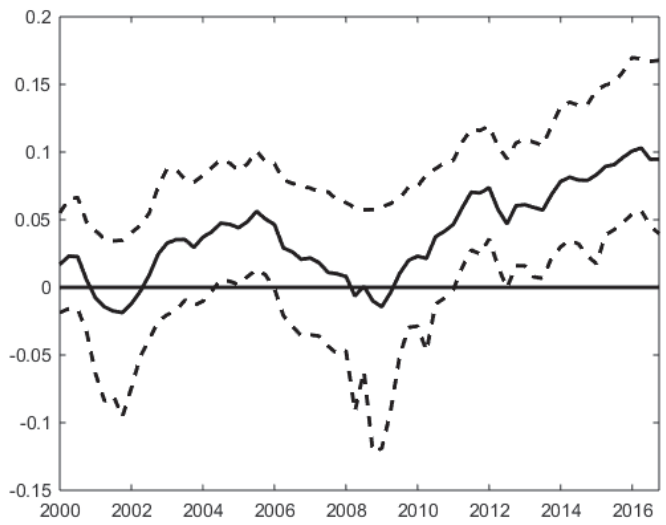

(d) Business equipment

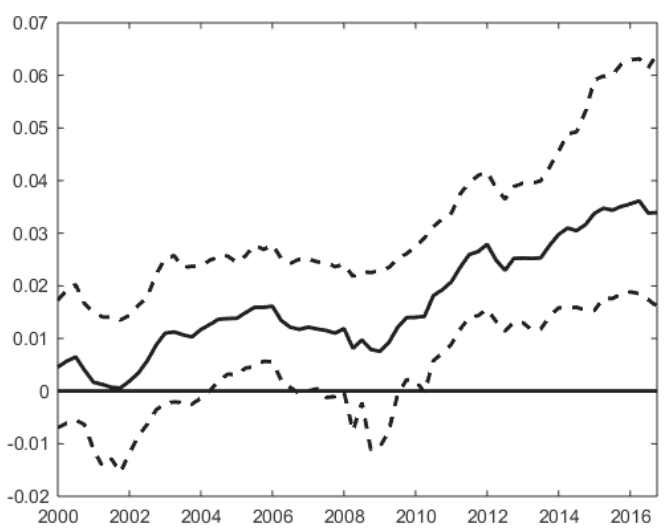

(f) Wyoming: Non-oil employment

Figure 18. The effect of an oil price shock: Impulse responses for selected indicators of the U.S. economy after 4 quarters with 16-th and 84-th percentiles from a model with an alternative dataset that uses a shadow interest rate (see the main text for details). 


\section{F.4 Rolling regressions}

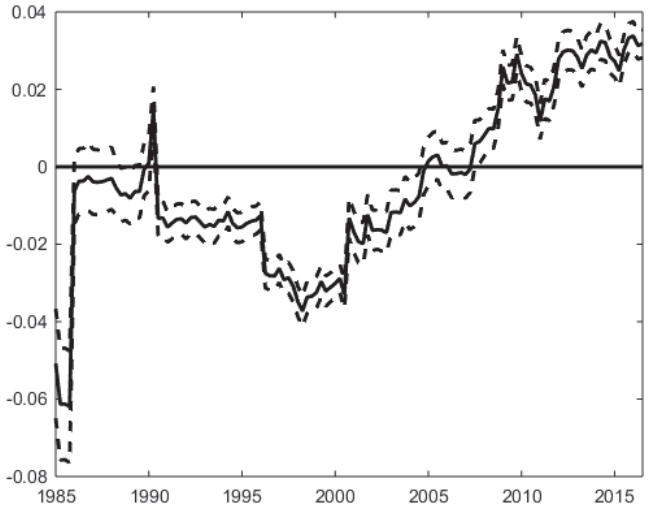

(a) Investment

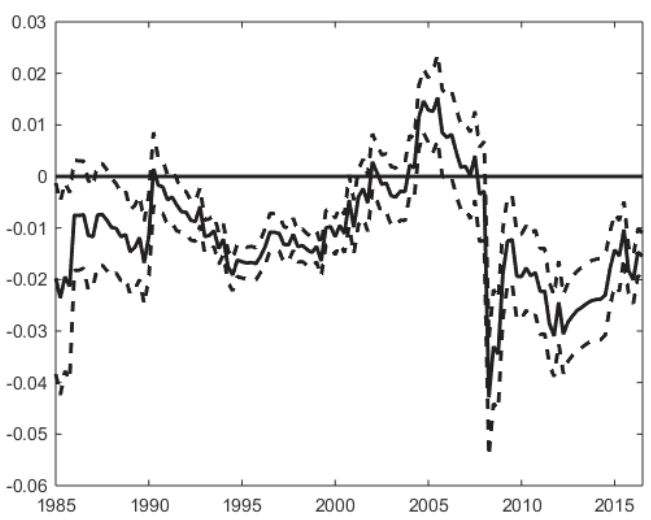

(c) Chemical production

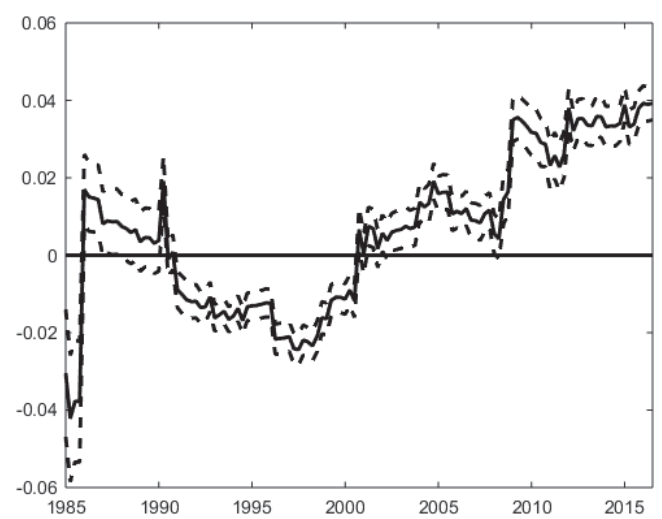

(b) Fabricated Metal production

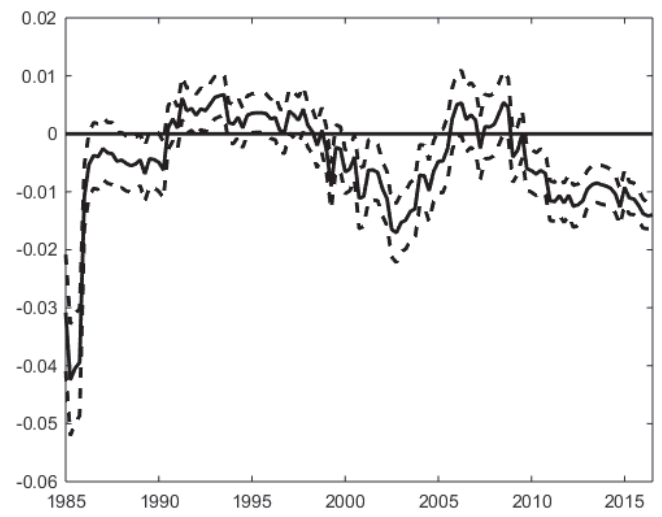

(d) Food and beverages

Figure 19. The effect of an oil price shock. Plots of the $\beta_{2}$ coefficients in the following regression: $\Delta y_{t, i}=\beta_{1} \Delta g a_{t-1}+\beta_{2} \Delta o i l_{t-1}+\beta_{3} \bar{\Delta} s h a d_{t-1}+\beta_{4} \Delta y_{t-1, i}+u_{t}$, where $\Delta y_{t, i}$ denotes the percentage change in the variable of interest $i$, and $\Delta g a_{t}, \Delta o i l_{t}$ and $\bar{\Delta} s h a d_{t}$ denote, respectively, changes in global industrial production, changes in the real price of oil and the first difference of the shadow rate. Sample period 1974:Q2-2016:Q4, Moving window 40 quarters. 


\section{F.5 Robustness to other commodities: Corn and coal prices}

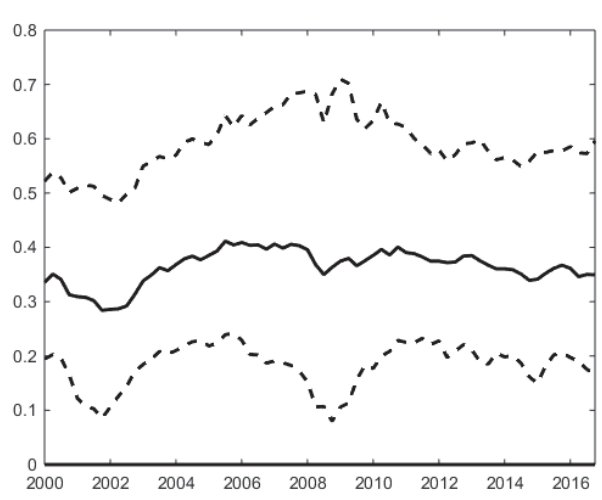

(a) Corn prices

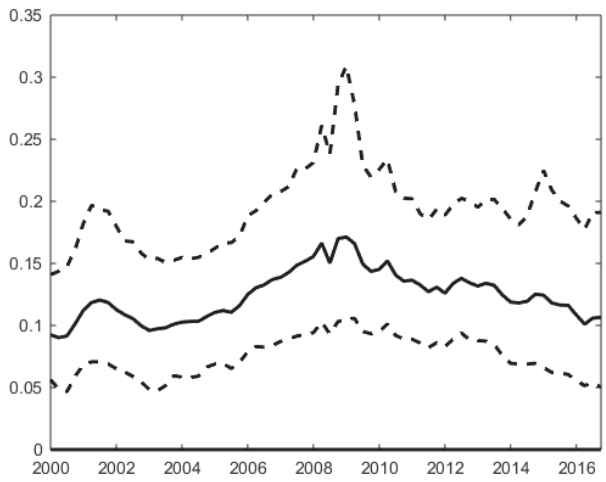

(b) Coal prices

Figure 20. The effect of an oil price shock: Impulse responses for corn and coal prices. Responses are reported after 4 quarters with 16-th and 84-th percentiles 